\title{
Eine Werksiedlung aus der Bronze- und Eisenzeit bei Kundl (Nordtirol). Vorbericht über die Ausgrabungen 2018-2019 in der Schottergrube Wimpissinger
}

\author{
Markus Staudt \\ Maria Bader \\ Lisa Maria Eß \\ Daniel Lueger \\ Lena Sigrid Oettel \\ Peter Tropper \\ Peter Trebsche
}

\section{Zusammenfassung}

In den Jahren 2018 und 2019 führte die Grabungsfirma TALPA die bislang größte urgeschichtliche Flächengrabung Nordtirols in Kundl (Bezirk Kufstein) durch. Die rund $11.000 \mathrm{~m}^{2}$ große Grabungsfläche im Areal der Schottergrube Wimpissinger schließt an das in den 1970er Jahren entdeckte eisenzeitliche Gräberfeld der FritzensSanzeno-Kultur an. Bei den neuen Grabungen wurden bronze- und eisenzeitliche Nutzungshorizonte entdeckt, die durch meterdicke Murschotter voneinander getrennt und dadurch hervorragend konserviert waren. Sie liefern bedeutende Erkenntnisse zum Produktionsprozess des Nordtiroler Fahlerzkupfers sowie zur Organisation der Metallverarbeitung während der Bronze- und Eisenzeit.

In der älteren bronzezeitlichen Phase wurden zwei Batterien von Verhüttungsöfen angelegt. Die gefundenen Schlackenreste und Tondüsenfragmente weisen auf ein Schmelzen von Kupfererz bzw. eine Raffination von Rohkupfer hin. Aus der jüngeren spätbronzezeitlichen Phase blieben Reste von Holzgebäuden sowie drei in den Schotter eingegrabene Vorratsgefäße erhalten.

Die eisenzeitliche Kulturschicht mit einer dichten Bebauung konnte auf einer zusammenhängenden Fläche von rund $10.100 \mathrm{~m}^{2}$ untersucht werden. Sie erbrachte Hinweise auf Nahrungsmittelproduktion, Textilherstellung und landwirtschaftliche Tätigkeiten (Pflugspuren, Viehzäune). Das eisenzeitliche Siedlungsareal war darüber hinaus durch eine intensive metallurgische Produktion (Bronzeund Eisenverarbeitung, möglicherweise auch Verhüttung) geprägt. Die Siedlung wurde kontinuierlich von der Stufe Ha D bis Lt D, also gleichzeitig mit dem bekannten Gräberfeld genutzt.

\section{Schlüsselbegriffe}

Bronzezeit, Eisenzeit, Tirol, Werksiedlung, Kupferverhüttung, Bronzemetallurgie, Eisenverarbeitung.

\begin{abstract}
A Bronze and Iron Age Working Camp near Kundl (North Tyrol). Preliminary Report on the Excavations 2018-2019 in the Wimpissinger Gravel Pit

In 2018 and 2019 the excavation company TALPA carried out the largest prehistoric excavation in North Tyrol to date in Kundl (Kufstein district). The approximately $11,000 \mathrm{~m}^{2}$ large excavation in the area of the Wimpissinger gravel pit adjoins the Iron Age cemetery of the Fritzens-Sanzeno culture discovered in the 1970s. During the recent excavations, Bronze Age and Iron Age horizons were discovered, which were separated from each other by metre-thick gravel strata and thus excellently preserved. They provide important insights into the production process of North Tyrolean fahlore copper and the organisation of metal processing during the Bronze and Iron Ages.

In the older Bronze Age phase, two batteries of smelting furnaces were installed. The slag remains and tuyere fragments found indicate the refining of raw copper. From the younger Late Bronze Age phase remains of wooden buildings and three storage vessels dug into the gravel were preserved.

The Iron Age cultural layer with a high density of buildings could be investigated over a continuous area of about $10,100 \mathrm{~m}^{2}$. It provided evidence of food production, textile manufacturing and agricultural activities (plough marks, cattle fences). In addition, the Iron Age settlement area was characterised by intensive metallurgical production (bronze and iron processing, possibly also smelting). The settlement was continuously used from the phase $\mathrm{Ha} \mathrm{D}$ to $\mathrm{Lt} \mathrm{D}$, i.e. simultaneously with the known cemetery.
\end{abstract}

\section{Keywords}

Bronze Age, Iron Age, Tyrol, working camp, copper production, bronze metallurgy, iron working. 


\section{Lage und Forschungsgeschichte}

Die seit den 70er Jahren des 20. Jhs. bekannte Fundstelle bei der Schottergrube Wimpissinger befindet sich ca. $5 \mathrm{~km}$ östlich der Fahlerzlagerstätten des Montanreviers SchwazBrixlegg, am südlichen Inntalrand zu Fuße des Kragenjochs, in der Katastralgemeinde Liesfeld, Marktgemeinde Kundl, Bezirk Kufstein in Tirol (Abb. 1). Dort lagerte sich ein bis zu $35 \mathrm{~m}$ mächtiger Murschotterkegel an, der vom Felsmassiv ausgehend ca. $300 \mathrm{~m}$ in das Inntal hineinragt und eine West-Ost-Ausdehnung von etwa $600 \mathrm{~m}$ aufweist. Innerhalb des vom Stubtalbach herausbeförderten Schotterkegels liegen bronze- und eisenzeitliche Siedlungs- und Nutzungshorizonte, die durch die immer wieder erfolgten Vermurungen überlagert und so konserviert wurden. Die massiven Schotterlagen werden von der Wimpissinger Beton Umweltschutz GmbH beim sogenannten „Lus“ abgebaut, wobei die prähistorischen Nutzungshorizonte zu Tage befördert und teilweise einer Untersuchung zugeführt werden konnten.

Aufgrund des Zufallsfundes eines eisernen Latèneschwertes im Jahre 1970 und den ab 1973 immer wieder bei den Schotterabbauarbeiten zutage getretenen Fundobjekten, die allesamt aus Grabkontexten stammten, konnte in der Schottergrube Wimpissinger eine eisenzeitliche Nekropole lokalisiert werden. Die anschließenden archäologischen Untersuchungen wurden von Osmund Menghin, Wilfried Allinger-Csollich und Johannes Prammer durchgeführt und dauerten bis $1977 .{ }^{1}$ Diese Nekropole, die Amei Lang 1998 ausführlich publizierte, war von der eisenzeitlichen Stufe Ha C2 bis in die Spätlatènezeit (Lt D) belegt und zählt mit mehr als 166 Bestattungen zu den größten der Fritzens-Sanzeno-Kultur.

Östlich des Gräberfeldes wurde im Jahr 1984 ein hallstatt- sowie latènezeitliches Werkstättenareal zur Eisenverarbeitung erkannt. Nachdem 1984 von Lang nur ein kleiner Abschnitt untersucht wurde, erfolgten vom Bundesdenkmalamt unter der Leitung von Wilhelm Sydow 1987-1990 weitere kleinflächige archäologische Ausgrabungen. ${ }^{2}$

Im Jahr 1977 gelang es, neben den bereits bekannten eisenzeitlichen Siedlungshorizonten auch die Nutzung des Areals in der Spätbronzezeit nachzuweisen. Auf einer kleinen Testfläche von $2 \times 7 \mathrm{~m}$ im Bereich des Ostabbruches des Lus konnten von Allinger-Csollich zum einen Siedlungsreste in Form von linearen Steinsetzungen und Pfostenlöchern dokumentiert werden. Zum anderen deuten

\footnotetext{
1 LANG 1998, 11-12.

2 LANG 1986, 276. - Sydow 1988, 227. - Sydow 1990, 202. - Sydow 1991, 219-220. - LANG 1998, 5-6, 11-29.
}

geborgene Funde, ${ }^{3}$ wie Reste von Kupfererz, unterschiedliche Kupferschlacken, Fragmente von Blasrohrdüsen und das Bruchstück eines mutmaßlichen Gebläsetopfes auf die Primärgewinnung von Kupfer aus Fahlerz hin. ${ }^{4}$ Erstmals konnten in diesem Zusammenhang Belege für die Kupfergewinnung in einer spätbronzezeitlichen Werksiedlung erbracht werden. Mineralogische Analysen an schlackengemagerten Keramikfragmenten wiesen aufgrund der hohen Antimon- und Arsenwerte auf die Verhüttung von Fahlerzen aus dem Montanrevier Schwaz-Brixlegg hin. ${ }^{5}$

Eine vom Geografen Gernot Patzelt unternommene Profiluntersuchung zur nacheiszeitlichen Entwicklung des Schwemmfächers, welche in etwa $240 \mathrm{~m}$ westlich der eben genannten Grabungstestfläche erfolgte, untermauerte diese Ergebnisse. Die zwischen 2001 und 2003 im Rahmen eines Forschungsprojektes vorgenommenen Arbeiten bestätigen eine langfristige Nutzung des Bereichs der heutigen Schottergrube Wimpissinger von der Spätbronze- bis zur Spätlatènezeit ${ }^{6}$ und unterstreichen zudem die Größe der urgeschichtlichen Siedlungsareale, deren West-Ost-Ausdehnung ca. $600 \mathrm{~m}$ beträgt (Abb. 2).

Bei der Besichtigung eines neu angelegten Schotterabbaubereiches im Oktober 2017 erkannten Markus Staudt (Universität Innsbruck) und Johannes Pöll (Bundesdenkmalamt) Holzkohle führende und mit verziegeltem Hüttenlehm durchsetzte Schichten im Südprofil des Abbaues „West“. Daher wurde auf der geplanten ca. $11.000 \mathrm{~m}^{2}$ großen Abbaustelle (Abb. 2) eine Notgrabung anberaumt, die von April 2018 bis Ende August 2019 durch die Firma TALPA GnbR unter der Leitung von Maria Bader durchgeführt wurde. ${ }^{7}$

\section{Bronzezeitliche Befunde}

Wie zu erwarten, zeigten sich bei der Notgrabung im tiefsten Bereich die bronzezeitlichen Schichten, welche bereits Allinger-Csollich und Patzelt dokumentiert hatten. Westlich eines alten Bachbettes, das sich auf dem Schwemmkegel gebildet hatte, konnten unter mehrphasigen eisenzeitlichen Siedlungsresten zwei bronzezeitliche Nutzungshorizonte erkannt werden.

3 Alle noch vorhandenen Funde der Altgrabung zum bronzezeitlichen Verhüttungsbefund, die sich im Tiroler Landesmuseum Ferdinandeum befinden, konnten von Markus Staudt für seine Dissertation dokumentiert werden.

4 Lang 1998, 29. - Tomedi, Staudt, Töchterle 2013, 62-63. Staudt, Tomedi 2015, 136-141.

5 Prader 2013. - Staudt, Tomedi 2015, 141. - Tropper et al. 2019. 6 Tomedi, Staudt, Töchterle 2013, 62-63. - Patzelt, Weber 2015, 16-20. - Staudt, Tomedi 2015, 136-141.

7 BADER 2020. - BADER 2021. 


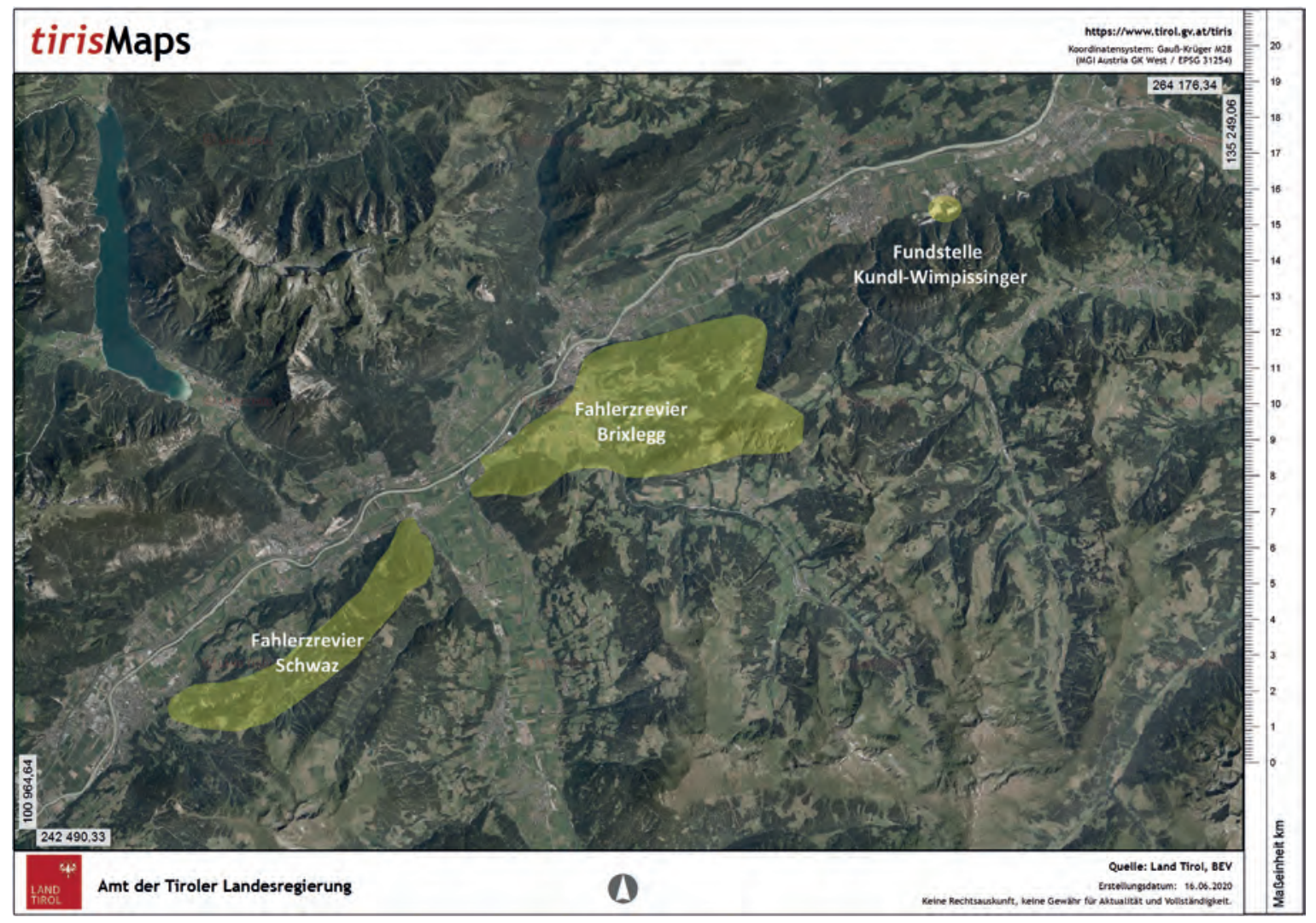

Abb. 1. Die Lage der Fundstelle Kundl-Wimpissinger und des Fahlerzreviers Schwaz-Brixlegg (Kartengrundlage: tirisMaps; Überblendung: M. Staudt).

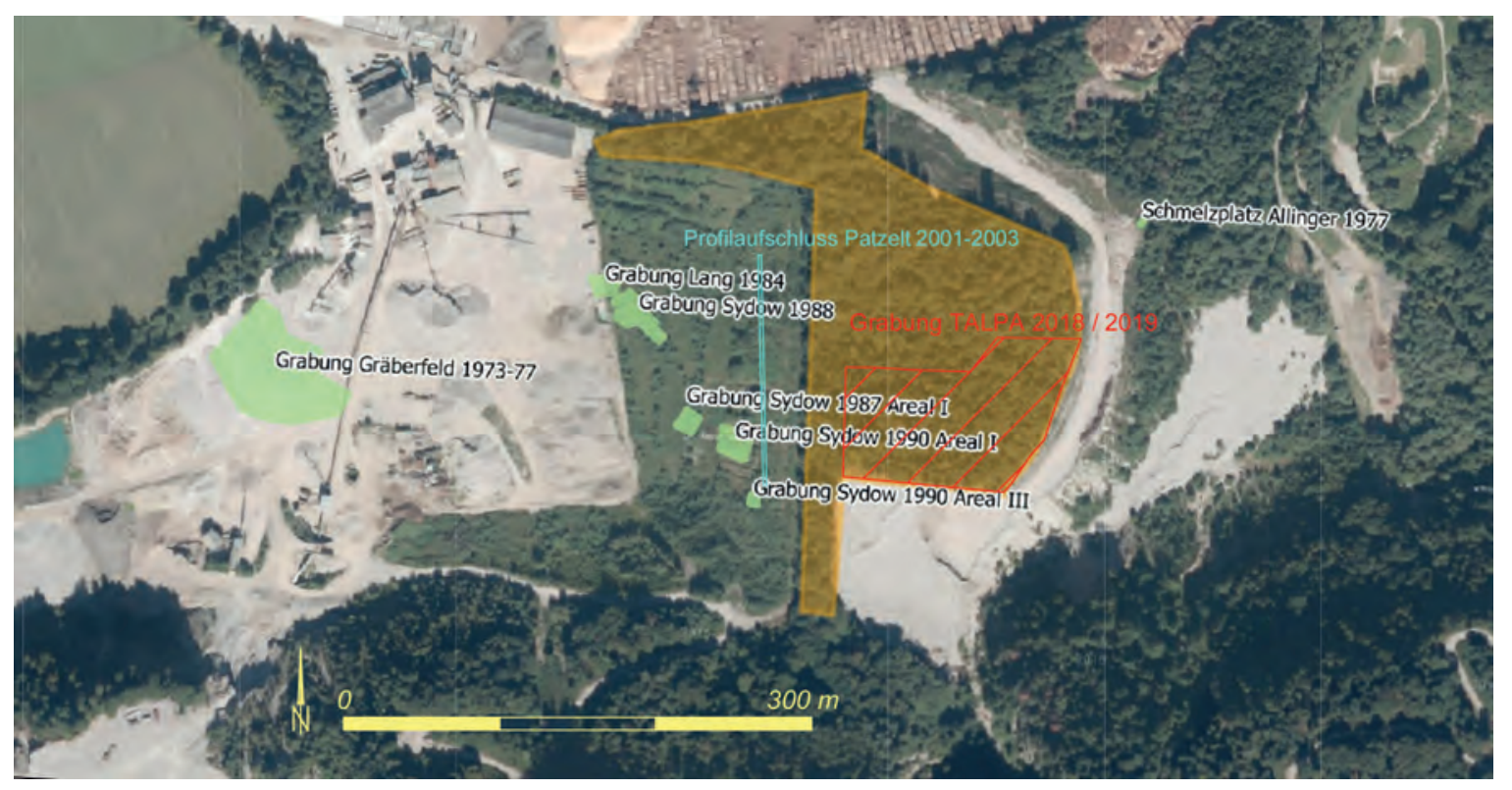

Abb. 2. Kundl. - Luftbild mit der Darstellung aller archäologischen Untersuchungsflächen von 2018 und 2019 (rot) auf dem Areal der Wimpissinger Beton Umweltschutz GmbH (Plan: BDA mit Ergänzungen von TALPA; Quelle: Land Tirol, BEV). 


\subsection{Die Verhüttungsstrukturen des älteren bronzezeitlichen Horizonts}

Die in den Jahren 2018 und 2019 freigelegten bronzezeitlichen Horizonte befanden sich ausschließlich westlich des historischen Bachlaufs. Der stratigrafisch ältere bronzezeitliche Horizont lag etwa 7,50 m unter dem rezenten Waldboden und stellt die tiefste erfasste anthropogene Schicht dar. Er war in diesem Bereich des Schwemmfächers durch massive Lagen aus Murschotter von den jüngeren spätbronzezeitlichen Befunden sowie den eisenzeitlichen Siedlungshorizonten getrennt. Zum älteren bronzezeitlichen Horizont gehören zwei Gruppen von Ofenbatterien, die im Abstand von ca. $36 \mathrm{~m}$ zueinander lagen und - nach der Schichtabfolge und Höhenlage zu urteilen - in etwa gleichzeitig bestanden haben dürften.

Die Befunde der ersten Gruppe lagen auf einer humos geprägten Bodenbildung, in welcher auf einer Fläche von 2,70 $\times 2,00 \mathrm{~m}$ ein Laufhorizont mit festgetretenem Holzkohlegrus dokumentiert werden konnte, der hauptsächlich mit Bruchstücken von heterogenen Kupferschlacken durchsetzt war (Abb. 3). Inmitten dieses Befundes lagen drei in einer Reihe angeordnete Grubenöfen (Abb. 4). Diese Ofenbatterie war aufgrund von Vermurungen und Überschwemmungen des Bachlaufs nur unvollständig erhalten;

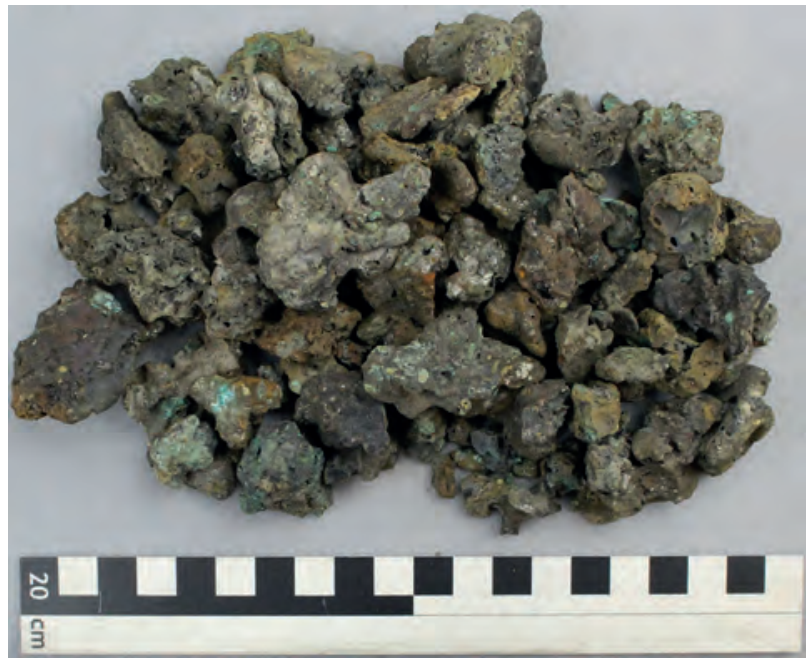

Abb. 3. Kundl, Schottergrube Wimpissinger. - Kupferschlacken aus der Ofenverfüllung von SE 647 B (Foto: TALPA).

ihre Länge betrug maximal 1,00 m. Die Breite der drei Grubenöfen belief sich auf 0,30-0,37 m (Innenmaße des Reaktionsraums). Das Steinmaterial der Konstruktionen wurde hochkant in den anstehenden Schotter gesetzt, wobei die Ofenwangen einschalig konstruiert waren. Die Steine
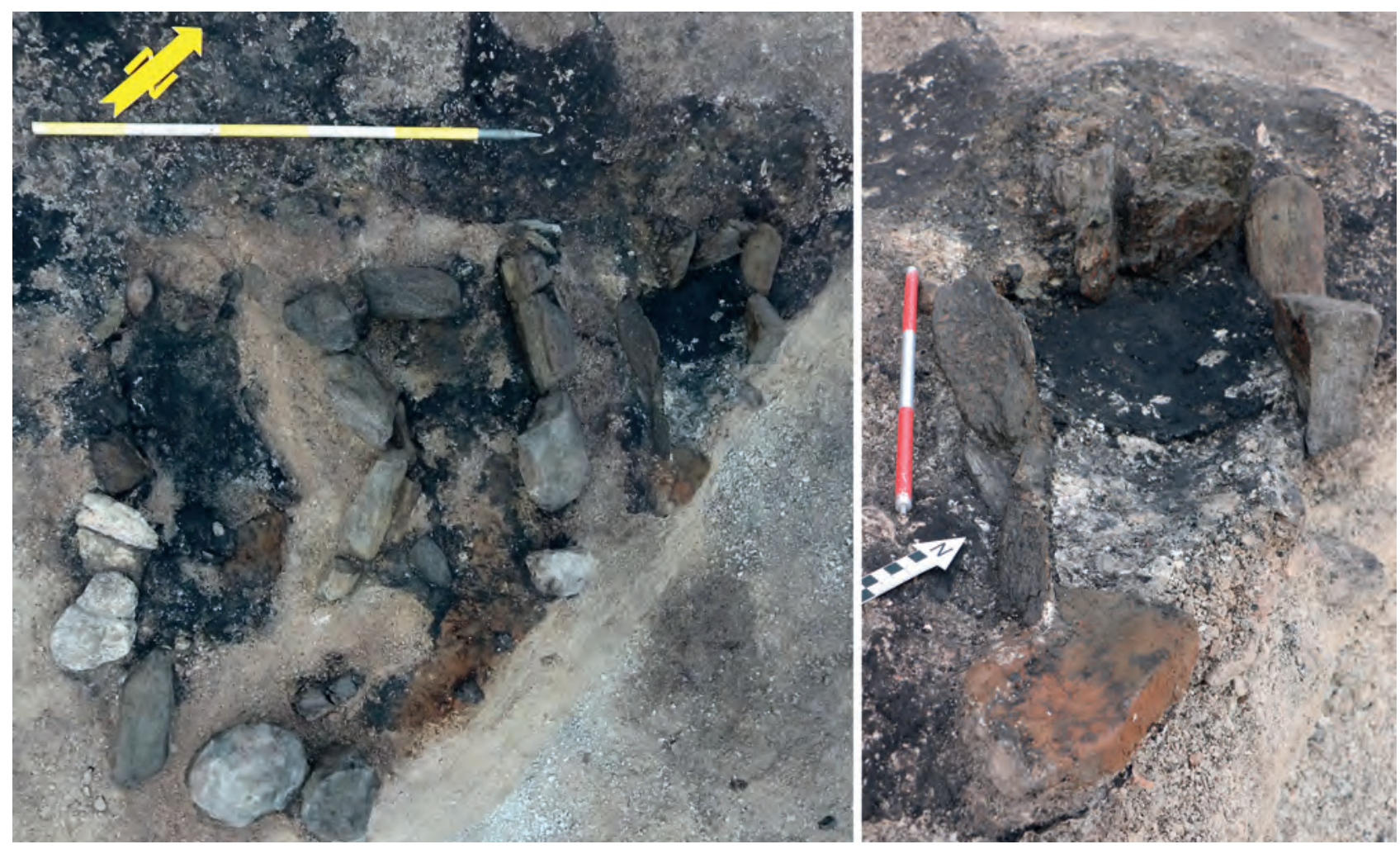

Abb. 4. Kundl, Schottergrube Wimpissinger. - Die drei Ofenreste (SE 647 A-C) mit gepresstem Holzkohlegrus/-staub an der Grubensohle (Fotos: TALPA). 
sowie der aufgebrachte Ofenlehm zeigen teilweise Verschlackungsspuren und sind an der Sohle, welche aus verziegeltem Lehm besteht, mit festgepresstem feinem Holzkohlegrus verfüllt.

Eine östlich an die Öfen angrenzende Lehmlage (Abb. 4) ist aufgrund des gut vergleichbaren Befundes der zweiten Gruppe (siehe unten) sehr wahrscheinlich als Rest eines ursprünglich dort angesetzten Röstbettes zu interpretieren. Die Strukturen und die Funde deuten auf pyrometallurgische Aktivitäten in Zusammenhang mit Kupferverhüttung hin. Eine Verhüttung von Erzen oder kupferhaltigen Zwischenprodukten ist anzunehmen, da das Schlackenaufkommen nicht mit sekundärer Metallurgie (Bronzegießen) allein erklärt werden kann. Zusätzlich sind makroskopisch sehr viele Gesteinseinschlüsse (Dolomit?) in den heterogenen Kupferschlacken zu beobachten, die einen primären Verhüttungsprozess andeuten. Diese These wird außerdem dadurch bekräftigt, dass bei der Altgrabung Allinger-Csollichs ähnliche Strukturen und Artefakte (unterschiedliche Kupferschlackenbruchstücke, Blasrohrdüsen, Gebläsetopfreste, Steingeräte etc.) mitsamt Funden von Fahlerz beschrieben wurden.

Die pyrotechnischen Befunde der zweiten Gruppe lagen wie die zuvor beschriebene Ofenkonstruktion isoliert inmitten einer Holzkohleschicht, die sich großflächig um die Steinlage angesammelt hatte. Die Struktur (ca. $2 \times 3 \mathrm{~m}$ ) zeigte sich bei der ersten Dokumentation in Form einer steinernen Einfassung mit einer massiv verziegelten Schicht aus Lehm (Abb. 5). Vor allem im westlichen Bereich traten vermehrt Steine (bis zu $60 \mathrm{~cm}$ Länge) zu Tage, die einen teilweisen Versturz der Steinkonstruktion andeuten.

Nach Entnahme dieser Steine wurde eine röstbettähnliche Konstruktion in Form einer verziegelten und rechtwinklig angeordneten Lehmtenne sichtbar, deren NordSüd-Ausdehnung ca. $3 \mathrm{~m}$ betrug und die an der Nord-, Ost- und Südseite mit aufrecht gesetzten Steinen umrahmt war. Im Westen fehlte dieser Abschluss, allerdings lagen im Abstand von ca. $1 \mathrm{~m}$ von der östlichen Einfassung vier grubenförmige Befunde, die ebenfalls mit aufrecht gestellten Steinen eingefasst waren und als kleine Grubenöfen angesprochen werden konnten. Die Außenmaße betrugen zwischen $40 \times 60$ und $50 \times 70 \mathrm{~cm}$. Das Ofeninnere $(20 \times 40$ bis $30 \times 60 \mathrm{~cm}$ ) war jeweils mit sehr klein fragmentierter verfestigter Holzkohle verfüllt. An der Sohle, die bis zu $30 \mathrm{~cm}$ tiefer als die Oberkante des Röstbettes lag, zeigte sich ebenfalls verziegelter Lehm, welcher Richtung Osten zur Lehmtenne anstieg und mit dieser direkt in Verbindung stand bzw. gleichzeitig mit dieser errichtet wurde (Abb. 5-6). Anhand des dokumentierten Steinversturzes ist anzunehmen, dass die Wangensteine der Öfen (max. drei-, aber eher zweilagig) ursprünglich etwas höher lagen als der Lehmverstrich beim Röstbett.

Innerhalb von Ofen 2 waren Reste des aufgebrachten und durch die Hitze verschlackten Ofenlehms zu erkennen. Sehr wahrscheinlich waren alle vier Öfen ursprünglich mit einer Lehmverkleidung überzogen. Beim Schneiden von Ofen 3 war im Profil eine Ausbesserung des in den Ofen abfallenden Lehms zu beobachten, was wie die massive Verziegelung (bis zu $8 \mathrm{~cm}$ ) für eine mehrfache Benützung dieser Befunde spricht. Da im angeschwemmten Bachschotter beim Lus keine natürlichen Lehmvorkommen zu finden sind, musste das Material für den Ofenbau aus größerer Entfernung herbeigebracht worden sein.

Zur Funktion dieses Befundensembles können erst nach der Auswertung von geochemischen und mineralogischen Schlackenanalysen konkrete Aussagen getroffen werden. Es scheint sich aufgrund der zahlreichen aufgelesenen Kupferschlacken (heterogene und massive Schlackenbruchstücke, auffallend wenige Plattenschlackenfragmente) sowie der selten auftretenden Erzreste ${ }^{8}$ um Einrichtungen zur Kupferproduktion (primäre Metallurgie) zu handeln. Sehr wahrscheinlich waren das Röstbett und die vier Öfen gleichzeitig in Betrieb gewesen, da alle Gruben Richtung Osten offen waren und sich eine durchgehend abfallende Lehmtenne beobachten ließ. Mit dieser mehrfachen Anordnung der Grubenöfen hatte man offenbar die nötigen Prozessschritte optimiert, um möglichst effizient arbeiten zu können. Derartig perfektionierte pyrometallurgische Anlagen sind von den bronze- und eisenzeitlichen Kupferverhüttungsplätzen im Ost- sowie Südalpenraum bekannt, auch wenn diese zumeist größer dimensioniert konstruiert wurden. ${ }^{9}$

Der als Röstbett angesprochene Befund könnte auch zur Herstellung oder zum Vorheizen von Holzkohle gedient haben, die von dort im glühenden Zustand über den Lehmverstrich direkt in die Öfen befördert wurde. ${ }^{10}$ Prinzipiell sind auch beide Nutzungen (Röstbett und Kohlebett) kombinierbar. Es wäre auch denkbar, dass man in den Öfen nicht nur Erz, sondern auch stark kupferhaltige

\footnotetext{
8 Das seltene Vorkommen von Erzen ist nicht verwundernswert, da auch bei den untersuchten Verhüttungsplätzen Rotholz und Mauk A nur in wenigen Fällen Erzfragmente dokumentiert werden konnten. Die prähistorischen Hüttenleute sind beim Erzausklauben offenbar sehr sorgfältig vorgegangen.

9 Nothdurfter, Hauser 1986. - Goldennerg 2004. - Herdits, LÖCKER 2004. - Cierny 2008. - Goldenberg et al. 2011. - Klemm 2015. - Koch Waldner, Klaunzer 2015. - Reitmaier-Naef 2019. - Silvestri, Bellintani, Hauptmann 2019. - Staudt et al. 2019b. - TuRcK 2019.

10 Bisher ist die prähistorische Herstellung von Holzkohle im Tiroler Unterinntal aber nicht nachgewiesen.
} 

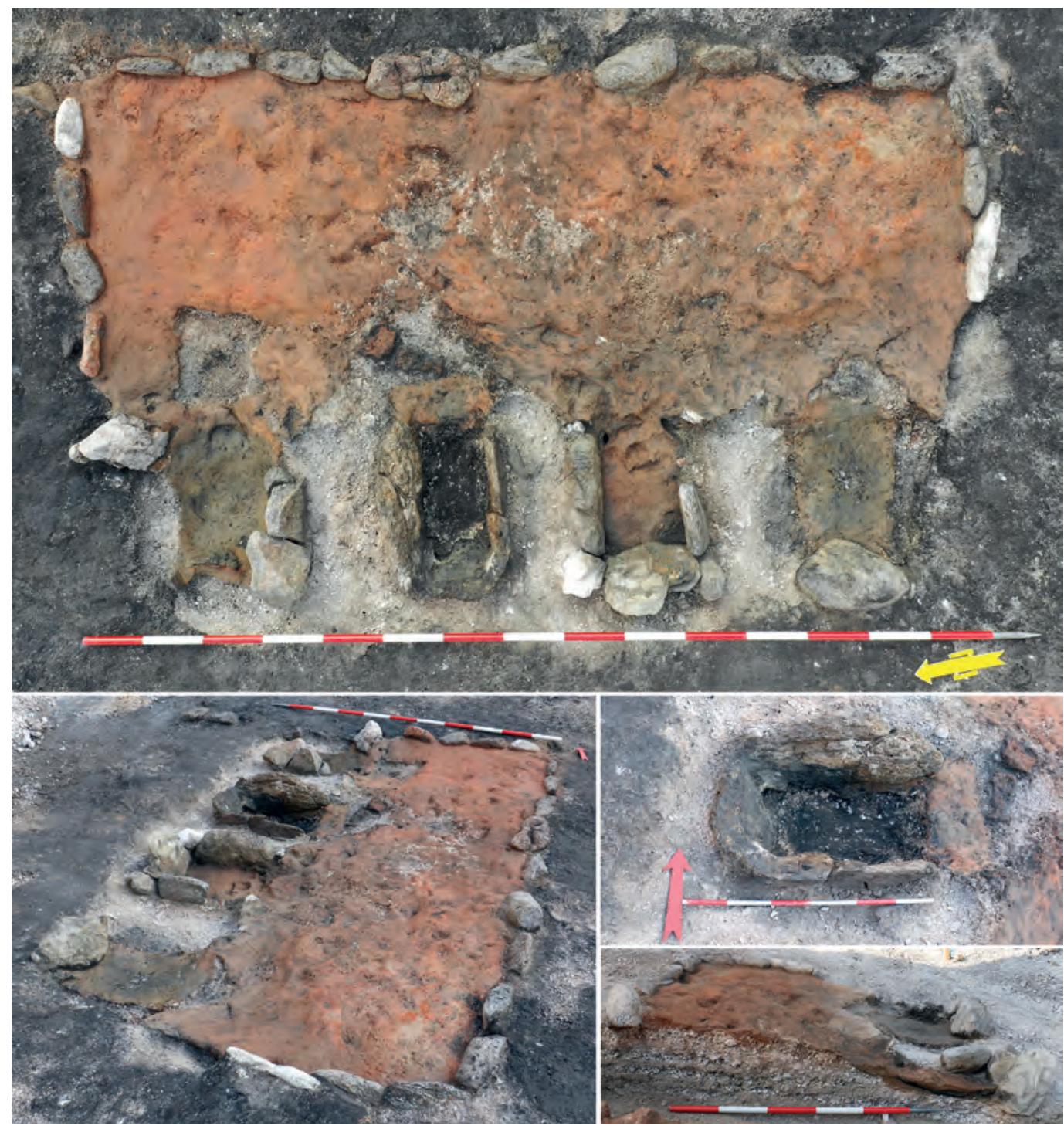

Abb. 5. Kundl, Schottergrube Wimpissinger. - Die vier bronzezeitlichen Grubenöfen mit zugehörigem Röstbett (Fotos: TALPA).

Zwischenprodukte(Kupferstein)weiterverarbeitete. Bereits seit längerem vermutet man, dass mit Kupfer angereicherte Zwischenprodukte, welche von den Verhüttungsplätzen im Umkreis der Erzlagerstätten stammen, an günstig gelegenen Plätzen wie Siedlungen in „einfachen Gruben“ (unter reduzierenden Bedingungen) zum gewünschten Endprodukt weiterverarbeitet wurden. ${ }^{11}$ Das an den nahegelegenen Verhüttungsplätzen produzierte Rohkupfer könnte in Kundl raffiniert und in diesem Zuge zu homogenen plankonvexen Gusskuchen zusammengeschmolzen worden sein.

Aus dem stark holzkohlehaltigen Gehniveau stammen jedenfalls vielekleine(höchstens wahlnussgroße) heterogene

11 Hanning, Herdits, Silvestri 2015, 227.
Schlackenbruchstücke und sehr wenige Plattenschlacken, ${ }^{12}$ welche aufgrund der teils grünlichen Verfärbung als Kupferschlacken angesprochen werden. Auffallend ist dabei ein relativ massives plattenförmiges Bruchstück, das den

12 Das geringe Vorkommen von Plattenschlacken ist auffällig und könnte damit zu erklären sein, dass diese bei weiteren Verhüttungsaktivitäten als Flussmittel eingesetzt und der Charge beigemengt wurden, um eine Schlackenbildung zu erleichtern. Oder sie wurden als Schlackenmagerung für die Keramikherstellung weiterverarbeitet. Bei den Verhüttungsplätzen Mauk A und Rotholz konnten verhältnismäßig wenige und klein fragmentierte Plattenschlacken geborgen werden. Dies hängt wahrscheinlich mit der akribischen Aufbereitung der Schlacken und deren Verwendung als Zuschlag bei der Verhüttung zusammen. 

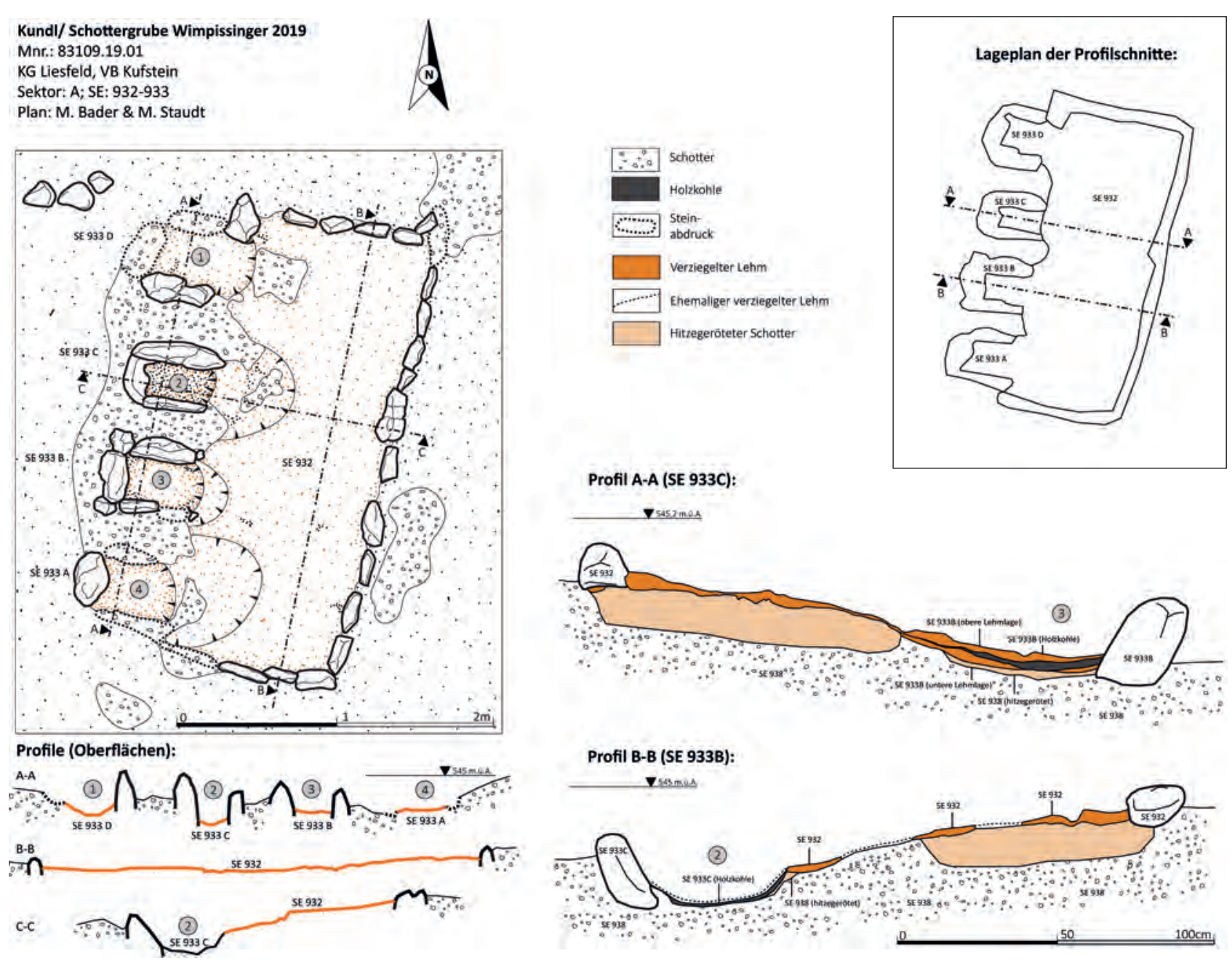

Abb. 6. Kundl, Schottergrube Wimpissinger. - Grundriss und Profile der vierfachen Ofenbatterie mit anschließendem Röstbett (Grafik: M. Staudt und M. Bader).

massiven Schlacken von den spätbronzezeitlichen Verhüttungsplätzen in Rotholz und im Maukental entspricht.

Zudem fanden sich zahlreiche Fragmente von kleinen Blasrohrdüsen, die metallurgische Aktivitäten an dieser Stelle belegen (Abb. 7). Auffälligerweise fehlen Fragmente von größeren Gebläsetöpfen, wie sie von anderen spätbronzezeitlichen Kupferverhüttungsplätzen in Tirol bekannt sind. Dies verwundert insofern nicht, als die kleinen Grubenöfen bei Kundl nur von oben betrieben werden konnten und nicht genug Platz für die Verwendung dieser massiveren geraden Düsentypen mit Blasebalg boten, welche normalerweise an der Vorderfront der Ofenwand angebracht waren. ${ }^{13}$ Aufgrund des Platzmangels mussten die kleinen

13 Bei der Dokumentation der Altfunde vom Kundler Lus waren allerdings wenige mutmaßliche größere Düsenfragmente aufgefallen, die wahrscheinlich Reste von Gebläsetopfdüsen darstellen (siehe Abb. 7, rechts unten).
Öfen von Kundl nur mit Blasrohrdüsen oder eventuell mit gebogenen Gebläsetopfdüsen betrieben werden. Sicherlich waren einige Personen notwendig, um mit diesen Düsen die erwünschte Temperatur von $1300^{\circ}$ Celsius erreichen zu können.

Kleine Blasrohrdüsen, wie sie im älteren spätbronzezeitlichen Horizont von Kundl auftreten, wurden bisher eher mit der kupfer- bzw. frühbronzezeitlichen Verhüttung von kupferhaltigen Sekundärmineralien in Zusammenhang gebracht. ${ }^{14}$ Vom spätbronzezeitlichen Verhüttungsplatz Rotholz liegt allerdings auch ein verschlacktes Keramikfragment vor, das möglicherweise als Blasrohrdüse angesprochen werden kann. Gebogene Gebläsetopfdü$\operatorname{sen}^{15}$ fanden vornehmlich in der sekundären Metallurgie

14 TÖchterle et al. 2013, 4-7.

15 Töchterle et al. 2013, Abb. 5. 


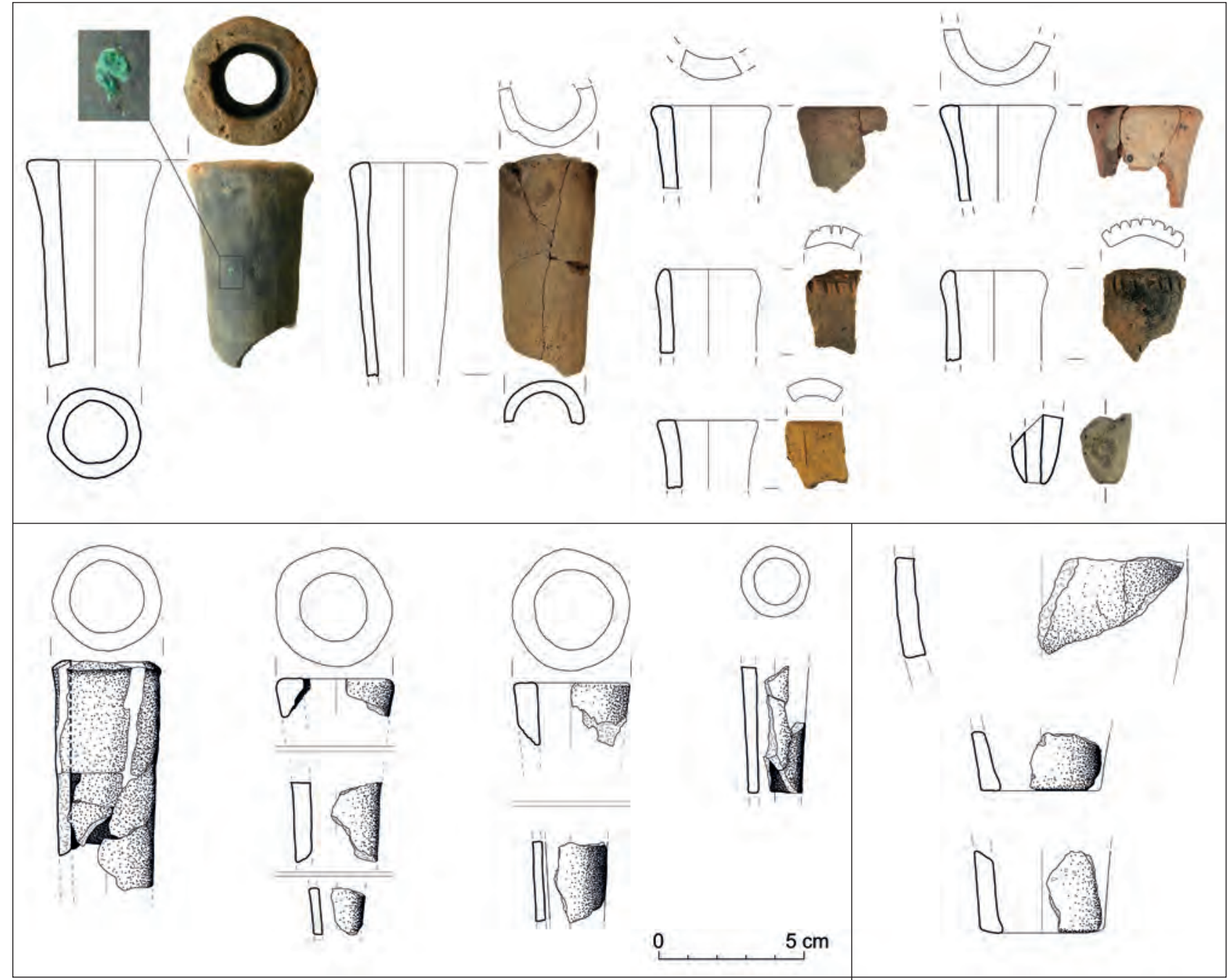

Abb. 7. Kundl, Schottergrube Wimpissinger. - Oben: Bronzezeitliche Blasrohrdüsen von den Grabungen der Firma TALPA. - Unten: Blasrohrdüsen sowie mutmaßliche Fragmente von Gebläsetopfdüsen der Untersuchung von Allinger-Csollich (Grafik: TALPA und M. Staudt).

(Aufschmelzen von Kupfer oder Bronze) der späten Bronze- bzw. Eisenzeit Verwendung, wohingegen die geraden Gebläsetopfdüsen ${ }^{16}$ bei den mittel-, spätbronze- bzw. eisenzeitlichen Verhüttungsplätzen zum Einsatz kamen.

Wie bereits kurz erwähnt, könnte das bei den Verhüttungsplätzen hergestellte Rohkupfer (vermutlich flache und eher heterogene Gusskuchen $)^{17}$ in solchen kleinen Grubenöfen wie in Kundl, das heißt im gesicherten Bereich einer Siedlung, zu sekundären, besser verhandelbaren Produkten (homogenere plankonvexe Gusskuchen) weiterverarbeitet worden sein. Aufgrund der Funde von größeren, flachen sowie heterogenen Gusskuchen im Bergbaurevier Schwaz-

16 Töchterle et al. 2013, Abb. 7.

17 STAUDT in Vorb.
Brixlegg und im direkten Umkreis des Verhüttungsplatzes Rotholz kann zumindest im Fahlerzrevier des Tiroler Unterinntals angenommen werden, dass man Rohkupfer in größeren Mengen bereits bei den Verhüttungsplätzen produziert hatte. Bei den Schmelzplätzen in den östlich und südlich gelegenen Kupferkiesrevieren (Salzburg, Kitzbühel/Jochberg, Trentino) ist es derzeit fraglich, ob überhaupt Rohkupfer oder nur Kupferstein hergestellt werden konnte. ${ }^{18}$ Der kleine Reaktionsraum der Öfen von KundlWimpissinger würde von der Größe den kleineren und homogenen plankonvexen Gusskuchen entsprechen, auch wenn die Größe des Gusskuchens prinzipiell von der Form (Gussform, Grube, Holzkohlebett) und nicht unbedingt

18 Modl 2010, 129. - Hanning, Herdits, Silvestri 2015, 227. 
von der Dimension des Reaktionsraumes der Öfen abhängt. Plankonvexe Gusskuchen ${ }^{19}$ stellen eine Art von Barren dar, die in erster Linie für den Vertrieb bestimmt waren. ${ }^{20}$ Sie kommen bereits ab der Frühbronzezeit vor. ${ }^{21}$

Zusammengefasst wurde im älteren bronzezeitlichen Horizont am Kundler Lus also Kupfer aus Fahlerzen gewonnen und möglicherweise wurden auch angereicherte Zwischenprodukte wie Kupferstein hergestellt. Daran schloss ein weiterer Arbeitsschritt an: Wahrscheinlich wurde in den kleinen Grubenöfen auch heterogenes primäres Rohkupfer zu homogenen sekundären und einheitlichen Produkten (Gusskuchen) zusammengeschmolzen. Jedenfalls finden sich zumindest in der Frühbronzezeit häufig Spuren primärer (Verhüttung von Erzen) und sekundärer Metallurgie (Schmelzen und Verarbeitung von Kupfer/Bronze) eng benachbart innerhalb der Siedlungen (z. B. Wiesing-Buchberg, Brixlegg-Mariahilfbergl, EbbsTischoferhöhle). ${ }^{22}$ Vom spätbronzezeitlichen Verhüttungsplatz Mauk A ist sogar eine Gussform aus Sandstein bekannt. ${ }^{23}$ Die neu entdeckten Verhüttungsbefunde am Kundler Lus sind aufgrund der fehlenden Begleitfunde relativchronologisch nicht datierbar. Stratigrafisch gesehen sind die Strukturen spätbronzezeitlich oder auch älter einzuordnen. Eine frühbronzezeitliche Verhüttung von oxidischen und eventuell sulfidischen Fahlerzen kann daher nicht ausgeschlossen werden. Auf diese frühe Zeitstellung könnten die vielen Blasrohrdüsen und das sehr geringe Vorkommen von Plattenschlacken hinweisen.

Da im direkten Umkreis der Öfen auch einige „Gusstropfen“ lagen, wurden zwei Exemplare chemischen Analysen (Rasterelektronenmikroskopie gekoppelt mit energiedispersiver Spektroskopie = EDS) unterzogen, um Aussagen zu einer möglichen Produktion von Fertigobjekten (Bronzeguss) treffen zu können. Für diese vorläufige Untersuchung wurde die oberflächliche Malachitschicht abgekratzt, um den metallischen Kern zu untersuchen. Die semi-quantitative EDS-Untersuchung ergab, dass sämtliche analysierte Messpunkte ein Spektrum aus Kupfer $(\mathrm{Cu})$, Antimon ( $\mathrm{Sb}$ ) und Kohlenstoff (C) aufweisen. Während das Antimon dem metallischen Kupfer zugeordnet werden kann, weist der gemessene Kohlenstoff auf die Anwesenheit eines $\mathrm{CO}_{3}$-hältigen Hydroxids (z. B. Malachit, Azurit) hin. Die beobachteten Sb-Gehalte (ca. 2 Gew.-\%) weisen deutlich auf ein Kupfermetall aus einer Fahlerzverhüttung

\footnotetext{
19 Modl 2019.

20 Modl 2010, 128. - Lutz 2016, 339.

21 Lutz, Krutter, Pernicka 2019, 323.

22 Hanning, Herdits, Silvestri 2015, 226.

23 Goldenberg 2013, Abb. 36.
}

hin. Dies steht in Einklang mit Ergebnissen aus dem Unterinntaler Raum, wo Fahlerzverhüttung in der Spätbronzezeit betrieben wurde. ${ }^{24} \mathrm{Im}$ Gegensatz zu Sb kann bezüglich des Arsen(As)- bzw. Silber(Ag)-Gehalts keine endgültige Antwort gegeben werden. Die Messpunkte bzw. die EDSSpektren weisen zwar schwache Peaks bei den Energielinien von Arsen und Silber auf, allerdings heben sich diese kaum vom Untergrund ab. Da bei der Probe kein Zinn detektiert wurde, kann eine sekundäre Metallurgie (Bronzeproduktion) in diesem Befundzusammenhang vorerst ausgeschlossen werden. Zur Klärung sind weitere Untersuchungen mit präziseren Messgeräten und einer größeren Anzahl von Artefakten vorgesehen.

Die bisher gesichteten Kupferschlacken von den Untersuchungen Patzelts und Allinger-Csollichs belegen ebenfalls eine lokale Verhüttung von Kupfererzen beim Kundler Lus. Damals waren unterschiedliche Schlackentypen (Plattenschlacken und heterogene Schlacken) dokumentiert worden. In den heterogenen Schlackenfragmenten befinden sich teilweise winzige Dolomiteinschlüsse, ${ }^{25}$ die beim Schmelzen von Kupferstein nicht mehr in makroskopischer Größe vorhanden sein dürften und daher auf eine primäre Verhüttung von Kupfererzen hinweisen.

Sehr viele der geborgenen Keramikfragmente aus der Schottergrube Wimpissinger weisen zerkleinerte Schlacke als Magerungsmaterial auf. Einige schlackengemagerte Keramikfragmente aus der von Patzelt untersuchten spätbronzezeitlichen Schicht vom Lus wurden chemisch analysiert. Die in der Schlackenmagerung enthaltenen Kupfereinschlüsse bestätigen, dass bei der Verhüttung Kupfererz von den nahegelegenen Fahlerzlagerstätten verwendet wurde. ${ }^{26}$

Die Schlackenfragmente in der Keramikmatrix sind zum Teil auch ohne Mikroskop gut sichtbar und die Größe der Körner beträgt bis zu $1 \mathrm{~cm}$ im Durchmesser. So sind z. B. in den Keramikproben W1 und 11, welche aus der Verfüllung von Patzelts Gefäß 1 stammen, scharfkantige homogene Schlackenfragmente mit Eisensilikatkristallen und Eisenoxid deutlich sichtbar, welche Reste von zerkleinerten Plattenschlacken darstellen (Abb. 8). Die mit dem Mikroskop untersuchten Schlackenfragmente weisen eine Größe von 300 bis $400 \mu \mathrm{m}$ auf und bestehen oftmals auch aus Glas, das eine charakteristische Schlierentextur mit Farben von dunkelgrau bis hellbraun zeigt. Untergeordnet treten Gesteinsund Kristallfragmente auf. Die Bruchstücke haben eine Größe von bis zu $500 \mu \mathrm{m}$ und bestehen größtenteils aus Orthogneis (Metagranit). Die Kristallfragmente (Quarz,

24 Krismer, Tropper 2013.

25 Von W. Allinger-Csollich „Muttergestein“ genannt.

26 Prader 2013. 

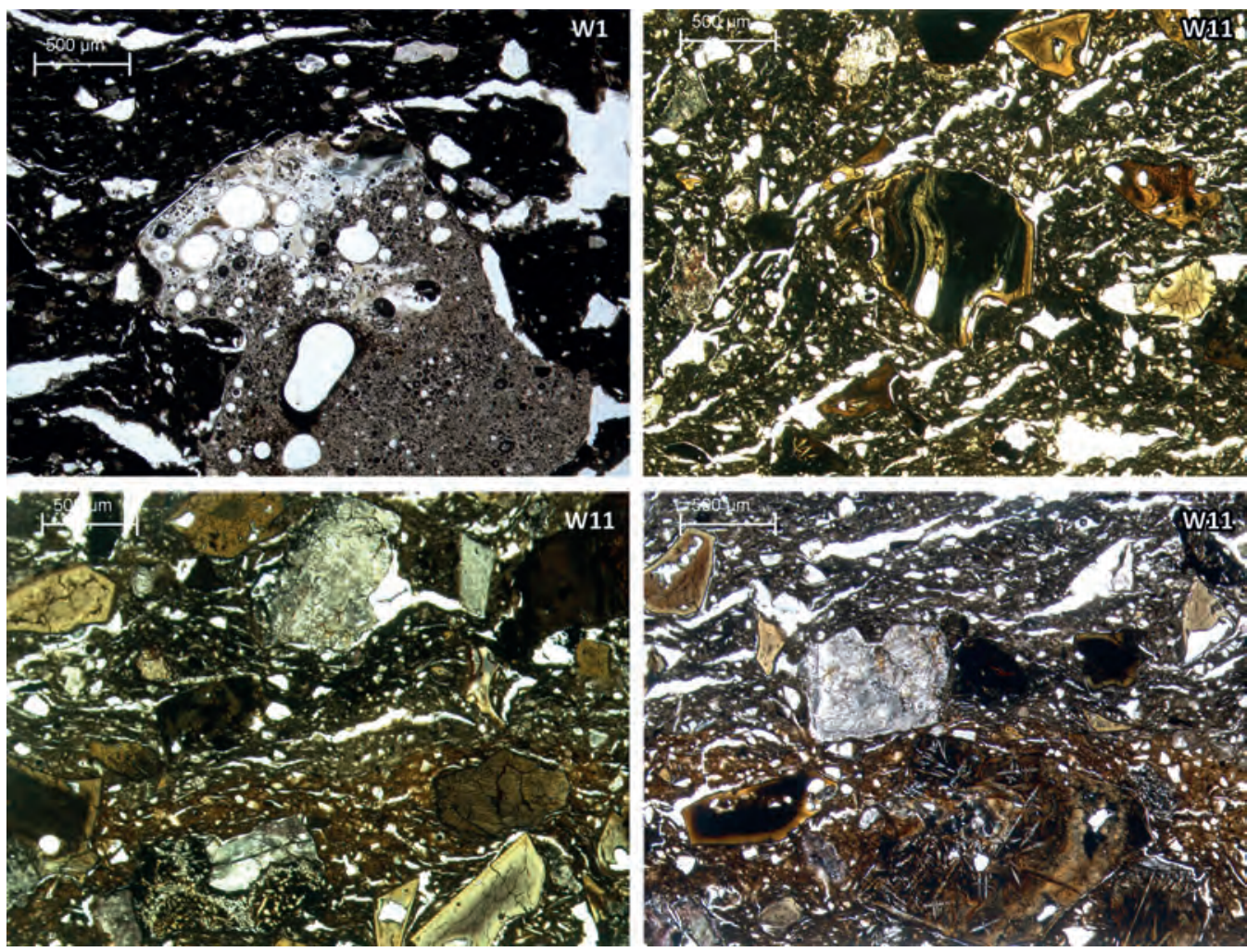

Abb. 8. Kundl, Schottergrube Wimpissinger. - Dünnschliffbilder unterschiedlicher mit granulierter Schlacke gemagerter Keramikfragmente (W1 und W11) aus Gefäß 1 von Patzelt (Grafik: P. Tropper).

Feldspat, Glimmer) sind viel kleiner und weisen eine Größe von $10-50 \mu \mathrm{m}$ auf.

\subsection{Die Siedlungsstrukturen des jüngeren spätbronzezeit- lichen Horizonts}

Der jüngere spätbronzezeitliche Horizont war vom älteren durch eine Schotterlage getrennt. Er konnte auf einer Fläche von etwa $35 \times 10 \mathrm{~m}$ untersucht werden, auf der sich eine flächige Kulturschicht (SE 896) erhalten hatte. Darin zeigten sich Gebäudereste in Form von Balkengräben, Pfostensetzungen und Gruben. Zahlreiche Hüttenlehmfragmente belegen die für die Spätbronzezeit Nordtirols typischen Konstruktionen aus Holz mit Lehmverputz. ${ }^{27}$ Außerdem wurden seichte Gruben mit einer Verfüllung aus Steinen und Holzkohle dokumentiert, die als „Röstgruben“ angesprochen wurden und mit handwerklichen Tätigkeiten in Verbindung stehen.

Vom unteren Abschnitt der Kulturschicht ausgehend waren drei große Gefäße in den darunter liegenden Schotter eingetieft worden. Die drei Gefäße lagen im Bereich von Balkengräben und Pfostengruben, könnten also in oder unmittelbar neben einem Holzgebäude eingegraben worden

27 STAudT 2016 sein. ${ }^{28}$ Sie wurden im Block geborgen und zur genaueren Untersuchung in das Mikroarchäologische Labor am Institut für Archäologien der Universität Innsbruck verbracht.

Um den Rand eines der Vorratsgefäße (SE 930) waren faustgroße Fahlerzstücke ringförmig niedergelegt worden (Abb. 9). ${ }^{29}$ Das Gefäß ist schlackengemagert und besitzt eine Zierleiste mit Fingertupfen knapp unterhalb des Randes. Die Form des eingegipsten Gefäßes wurde zunächst mittels Computertomografie ermittelt. Sie ähnelt zwei Gefäßen, die 2002 von Patzelt im Westabbruch der Schottergrube geborgen wurden. ${ }^{30}$ Das Gefäß und seine Verfüllung wurden im Anschluss an die Ausgrabung im Mikroarchäologischen Labor feinstratigrafisch abgetragen und dokumentiert. Dabei ließen sich drei unterschiedliche Verfüllschichten im

28 Innerhalb von Pfostenbauten eingegrabene Vorratsgefäße sind z. B. auch aus der urnenfelderzeitlichen Siedlung von BerchingPlankstetten (Oberpfalz) bekannt: Zuber 2011, 295 und Abb. 30. - Vgl. auch ein mittelbronzezeitliches eingegrabenes Gefäß aus Ingoldstadt-Zuchering: Bankus 1995, 68 und Abb. 12.

29 Dieses Gefäß wurde bereits im Rahmen einer Masterarbeit von Lisa Maria Eß mikroarchäologisch untersucht: Eß 2021.

30 Patzelt, Weber 2015, 17-18 und Abb. 8-11. - Staudt, Tomedi 2015, Abb. 2. 

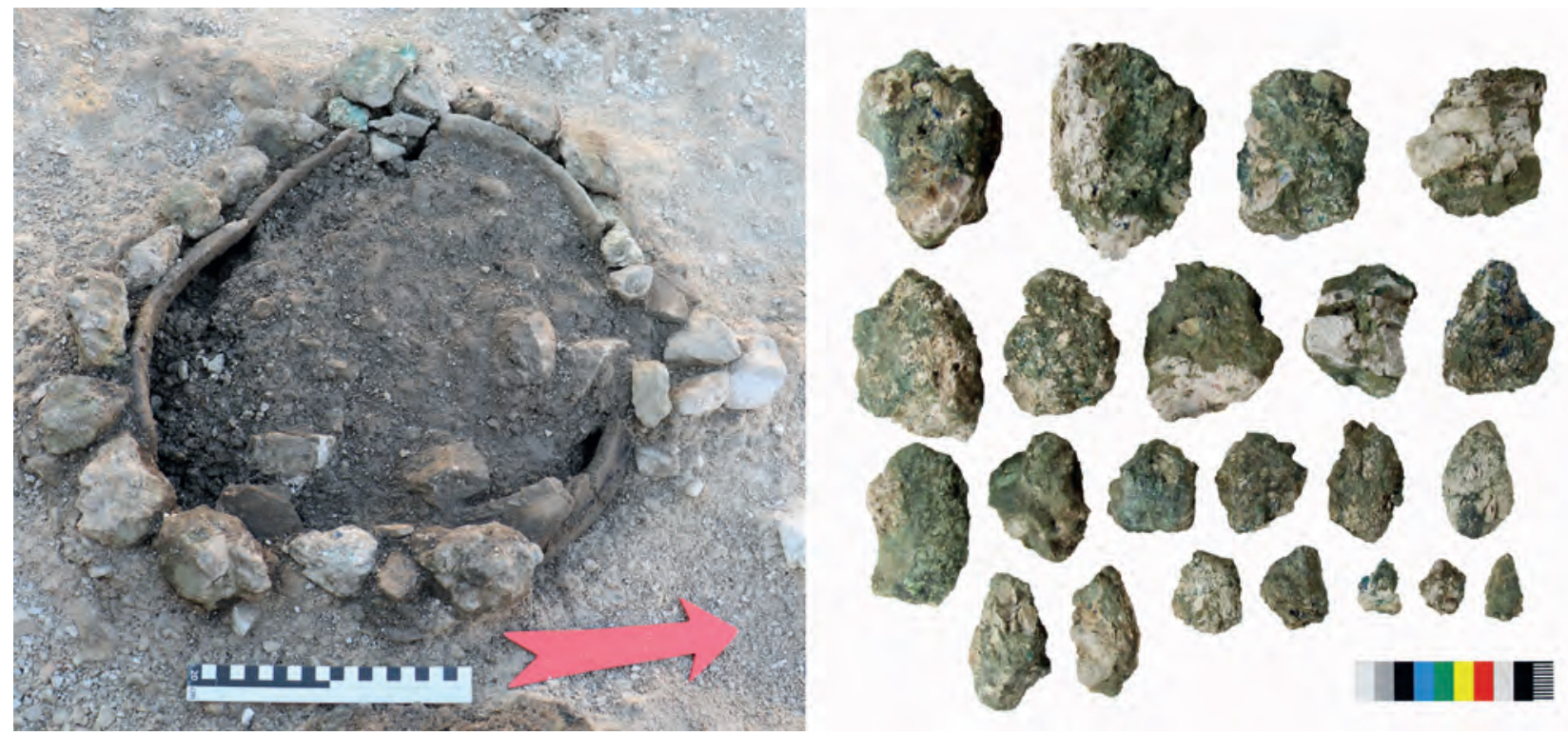

Abb. 9. Kundl, Schottergrube Wimpissinger. - Das im Schotter eingetiefte Gefäß mit einer Einfassung (links) aus stark kupferhaltigem Gestein (Fahlerz, rechts) (Foto links: TALPA, rechts: B. Zerobin).

Inneren des Vorratsgefäßes feststellen: Die zuunterst liegende SE 930-3 ist sehr schottrig und vereinzelt mit Holzkohle durchsetzt. Darüber folgte SE 930-2, eine sehr kompakte, dunkelbraune Verfüllung, welche auch die meisten Kleinfunde beinhaltet. Die oberste Füllung SE 930-1 besteht aus relativ inhomogenem und lockerem hellbraunem Sediment. Zu den Makrofunden aus SE 930-2 und SE 930-1 zählen Wand- sowie Randfragmente andersartiger Tongefäße, eine blasige bzw. heterogene Schlacke, mehrere Plattenschlackenfragmente, winzige granulierte Schlackenpartikel und ein vollständiger Bronzepfriem. Dazu kommen winzige unverbrannte, verbrannte sowie kalzinierte Tierknochenbruchstücke.

Der Inhalt dieses Vorratsgefäßes lässt sich sehr gut mit den beiden von Patzelt geborgenen Töpfen vergleichen (Abb. 10). Die beiden vollständig erhaltenen Gefäße lagen etwa $150 \mathrm{~m}$ voneinander entfernt im damaligen Westabbruch der Schottergrube, also rund $65 \mathrm{~m}$ östlich der drei im Jahr 2019 entdeckten Gefäße entfernt (vgl. Abb. 2). Die großen schlackengemagerten Behältnisse waren mit Fragmenten unterschiedlicher Keramikgefäße, verschiedenen Kupferverhüttungsschlacken, wenigen kleinen Fahlerzresten und geringen Mengen an winzigen Knochen verfüllt. ${ }^{31}$ Patzelt bemerkte zu Gefäß 1: „Am oberen Gefäßrand lagen mehrere größere, kantige Steine, wie sie im Murschutt darüber und darunter nicht enthalten sind, und somit zugetragen

31 STAudT in Vorb. wurden. Sie dürften zur Abdeckung des Gefäßes verwendet worden sein.“ 32

Die nahezu identen Gefäßverfüllungen (Abb. 10) der drei beschriebenen schlackengemagerten Gefäße von Patzelt (1 und 2) und der Grabungsfirma TALPA (SE 930) sowie die zweimal dokumentierte Einfassung mit „Fremdgestein“ - in einem Fall sogar mit wertvollem Fahlerz könnten auf kultische Handlungen hinweisen.

Um mehr Informationen über den ehemaligen Inhalt und den Verfüllprozess von Gefäß SE 930 zu erlangen, wurden die einzelnen Abträge mit verschiedenen Maschenweiten $(2 \mathrm{~mm}, 1 \mathrm{~mm}, 500 \mu \mathrm{m})$ flotiert und anschließend geschlämmt, um verkohlte organische Reste und sonstige Mikrofunde zu gewinnen. Innerhalb des Gefäßes haben sich sowohl Kulturpflanzen (Getreide) als auch Wildpflanzen in verkohlter Form erhalten, wie bei einer stichprobenartigen Untersuchung bereits festgestellt werden konnte. ${ }^{33}$ Eine genauere Interpretation des Befundes wird nach den geplanten Inhaltsanalysen, Radiokarbondatierungen der Verfüllschichten und ausführlichen archäobotanischen und archäozoologischen Untersuchungen möglich sein. Eine rituelle Interpretation des Befundes - besonders der Erzdeponierung rund um das Gefäß - soll im Moment

32 Patzelt, Weber 2015, 17.

33 Freundliche Mitteilung von Klaus Oeggl und Marlies Außerlechner, Arbeitsgruppe Palynologie und Archäobotanik, Universität Innsbruck. 


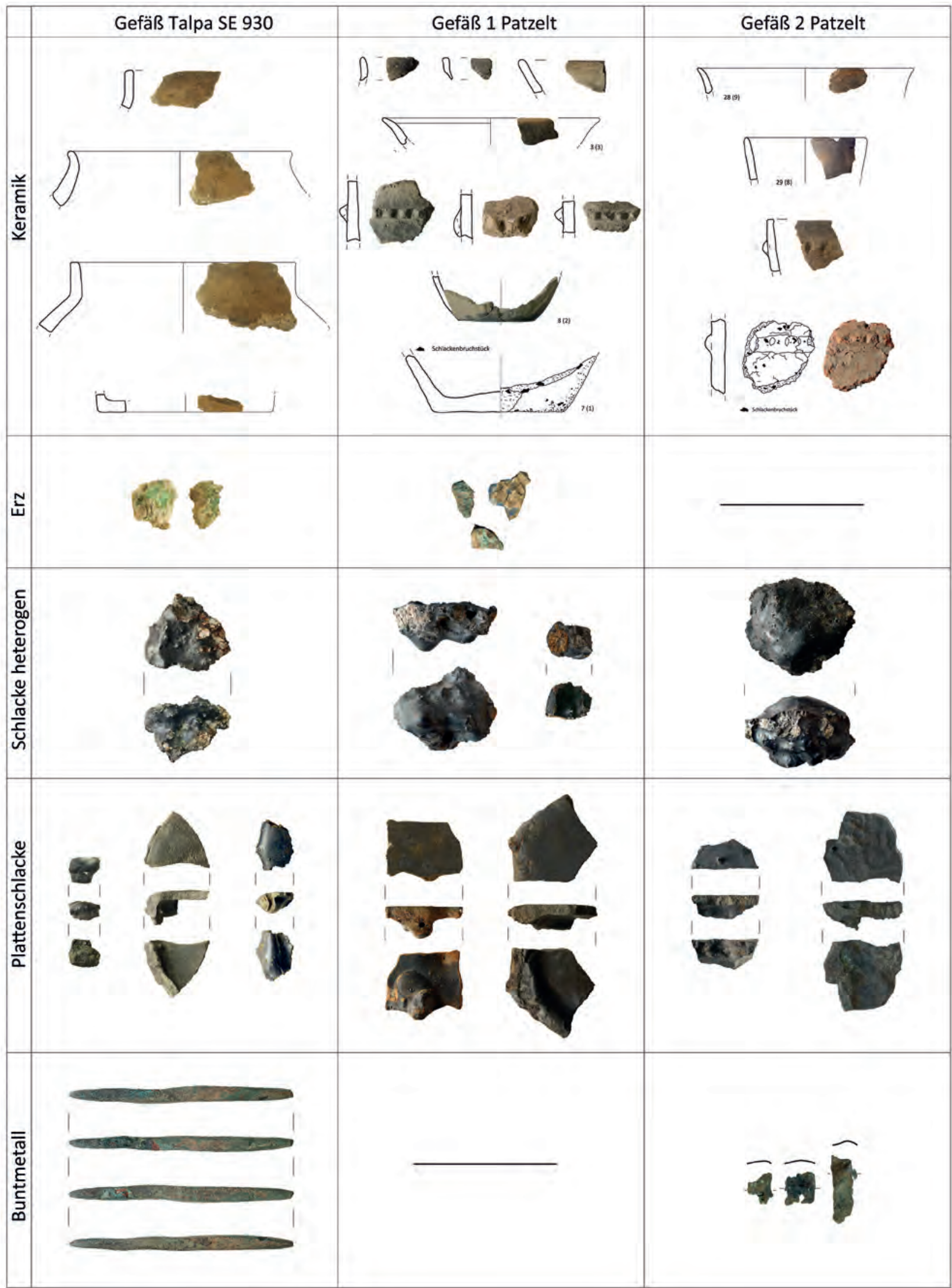

Abb. 10. Kundl, Schottergrube Wimpissinger. - Inhalte der drei eingetieften und verfüllten Gefäße (Grafik: M. Staudt und L. M. Eß). 


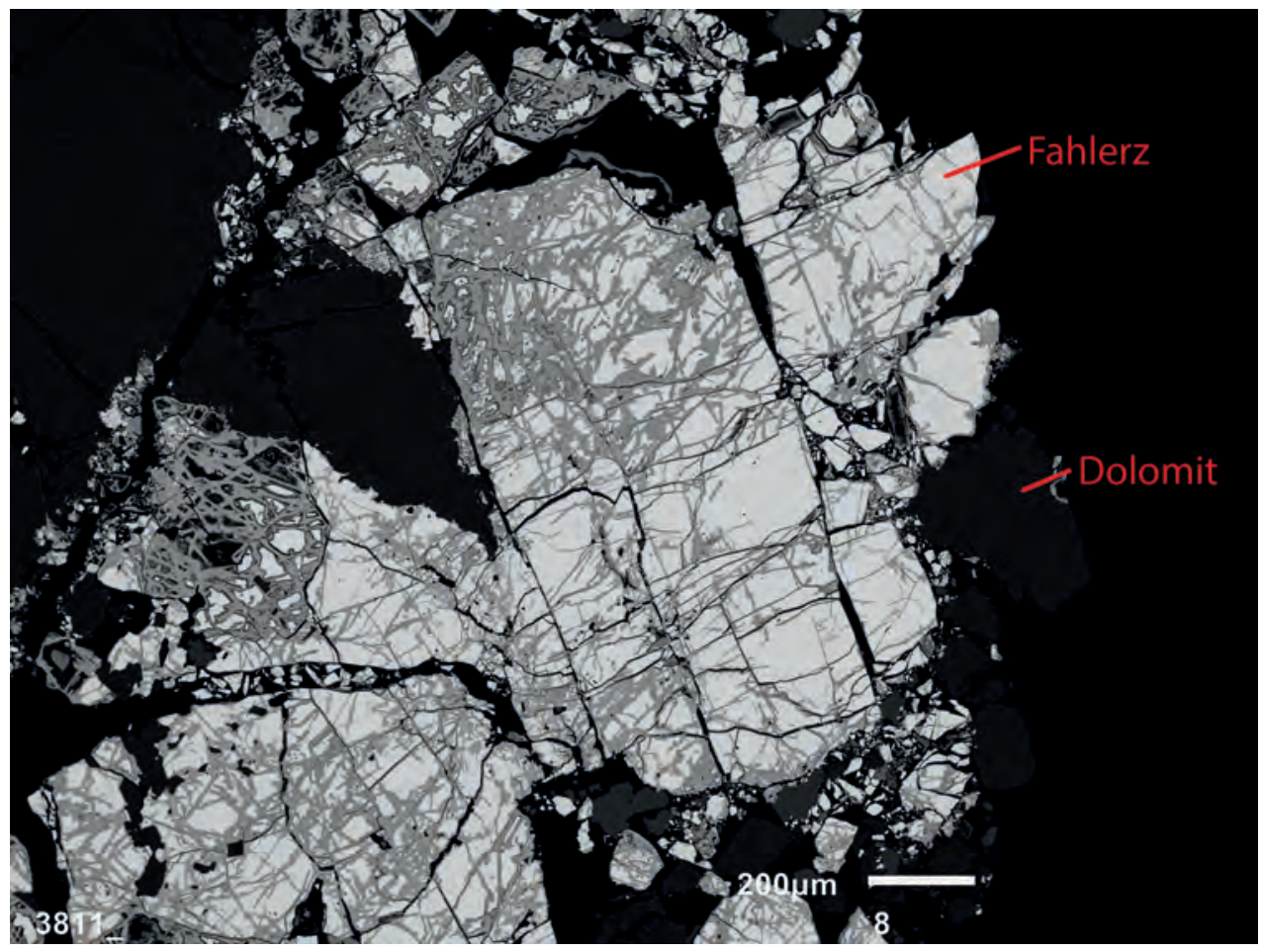

Abb. 11. Kundl, Schottergrube Wimpissinger. - Rückgestreutes Elektronenbild (BSE) der Erzprobe 3811 mit Darstellung der verschiedenen Phasen (Grafik: L. Oettel und P. Tropper).

nicht ausgeschlossen werden. Der Fokus der mikroarchäologischen Untersuchung richtet sich jedoch zuerst auf die unterschiedlichen Nutzungsphasen des Gefäßes, seine Taphonomie und die Rekonstruktion des Handlungsablaufs, der zur aufgefundenen Situation führte.

Aus den rund um das Gefäß (SE 930, Abb. 9) deponierten Erzstücken wurde eine Probe mineralogisch untersucht, um die Zusammensetzung des Fahlerzes zu analysieren und dieses möglicherweise einem Bergbaurevier zuzuordnen. Das Erzbruchstück zeigt eine verwitterte, unregelmäßige Oberfläche. Eine grün-bläuliche Verfärbung (Malachit, Azurit) der sichtbaren Erzminerale deutet auf alterierte Kupfererze hin. Im rückgestreuten Elektronenbild eines Anschliffs (Abb. 11) offenbart sich die massive Fahlerzvererzung in einer grobkörnigen Matrix, welche überwiegend aus Dolomit und Quarz besteht.

Die Untersuchung der Probe erfolgt mit einer Elektronenstrahlmikrosonde des Typs JXA 8100 SUPERPROBE der Firma JEOL. Die Messung der Elemente As, S, Ag, Cu, $\mathrm{Zn}, \mathrm{Fe}, \mathrm{Hg}, \mathrm{Sb}$ und $\mathrm{Bi}$ erfolgte wellenlängendispersiv bei $15 \mathrm{kV}$ und $10 \mathrm{nA}$ Messbedingungen. Dafür wurden insgesamt 23 Messpunkte analysiert (Tab. 1).

Die Zusammensetzung der Fahlerze ist recht homogen mit 18,52-20,41 Gew.-\% Antimon, 41,51-42,13 Gew.-\%
Kupfer und 6,62-8,04 Gew.-\% Arsen. Der Silbergehalt ist mit max. 0,81 Gew.-\% niedrig, ähnlich dem Zink-Gehalt, welcher maximal 1,55 Gew.-\% beträgt. Quecksilber wurde mit maximal 0,57 Gew.-\% gemessen. Bismut wurde nicht detektiert. Der Anteil an Tetraedritkomponenten (XSb*100) variiert zwischen 59 und $63 \%$.

Im Vergleich mit bereits publizierten Werten ${ }^{34}$ weist die Zusammensetzung auf Fahlerze aus dem Revier Schwaz hin. Dies wird sowohl durch das Fe/Zn-Verhältnis (Abb. 12) als auch durch das Fehlen der für das Brixlegger Revier typischen Reaktionsgefüge im Zuge des Fahlerzzusammenbruchs zu Enargit + Sphalerit + Stibnit untermauert.

Aufgrund derselben stratigrafischen Verhältnisse und der identischen Gefäßform der von Patzelt gefundenen Gefäße und jener aus den Ausgrabungen von 2019 kann eine Datierung des jüngeren spätbronzezeitlichen Horizonts in das 10. bis 9. Jh. v. Chr. angenommen werden. Die von Patzelt veröffentlichten Radiokarbondaten ${ }^{35}$ aus den Gefäßverfüllungen und der Kulturschicht wurden in einem neuen Kalibrationsmodell (als phasing der spätbronzezeitlichen Daten) berechnet (Abb. 13). Da alle Proben an Holzkohle

34 Tropper et al. 2019.

35 Patzelt, Weber 2015, 20. 


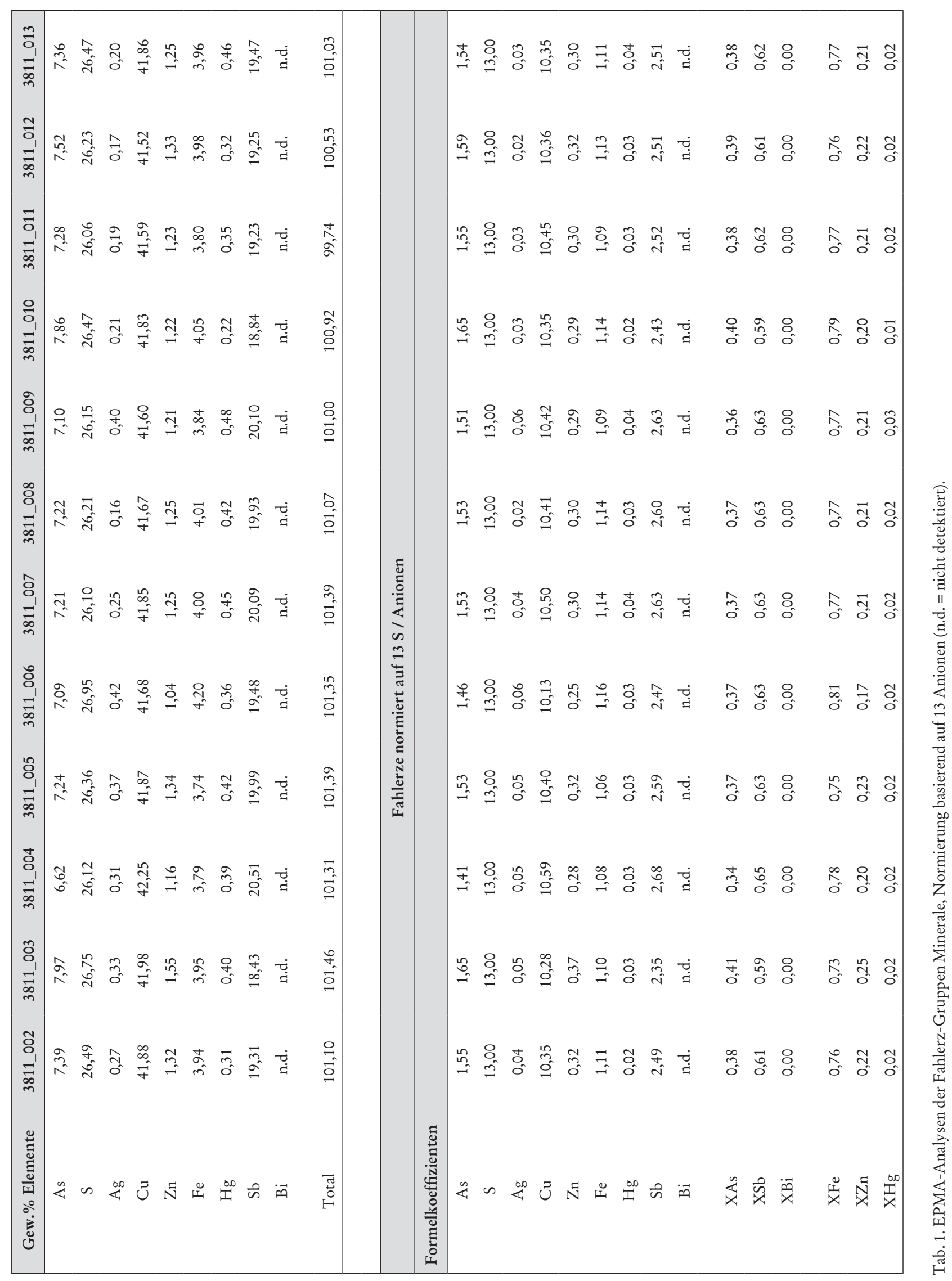




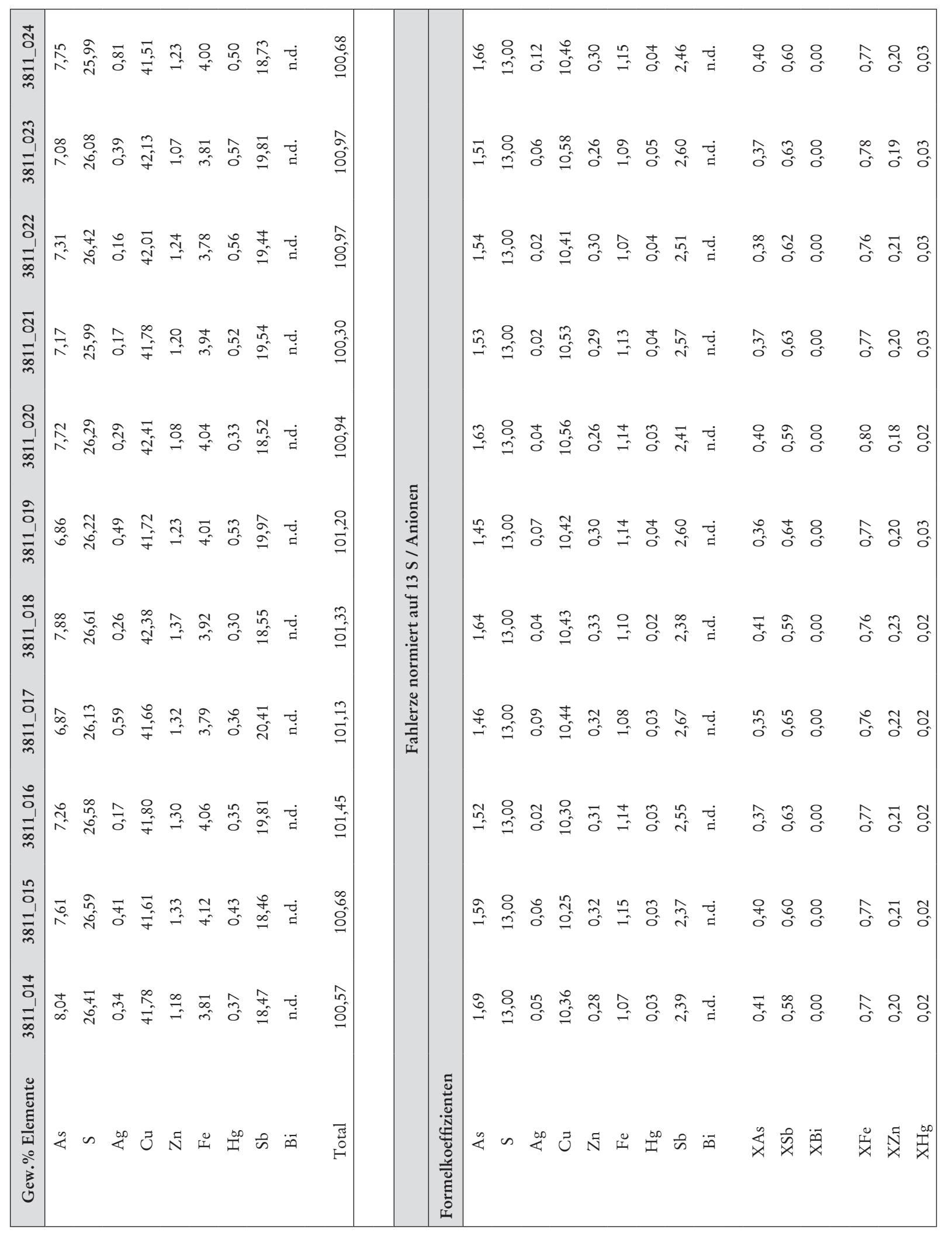




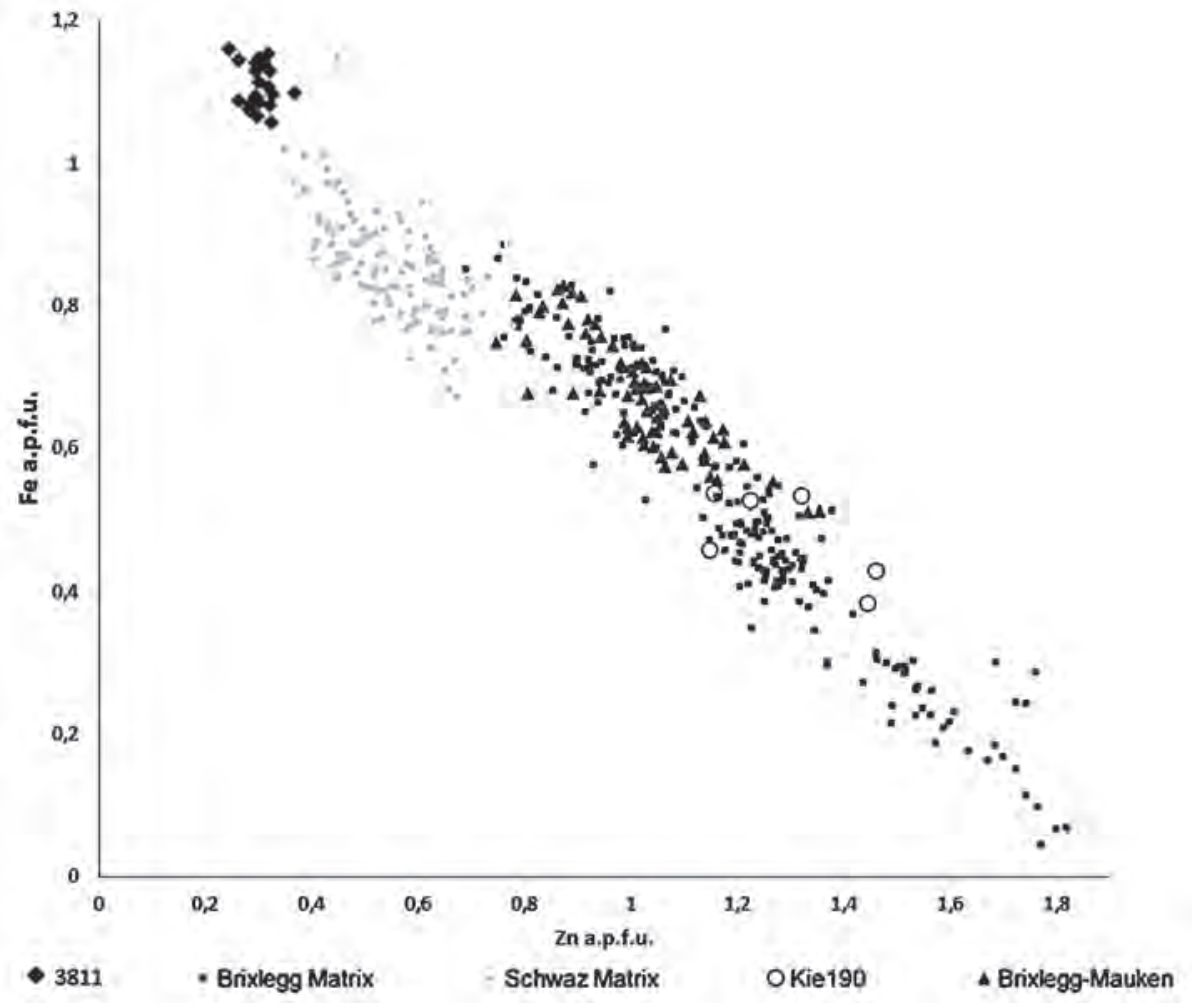

Abb. 12. Plot von Fe vs. Zn von Mineralen der Fahlerz-Gruppe aus Schwaz, Brixlegg, Brixlegg-Mauken, Kiechlberg und Kundl (Probe 3811) (Grafik: L. Oettel und P. Tropper)

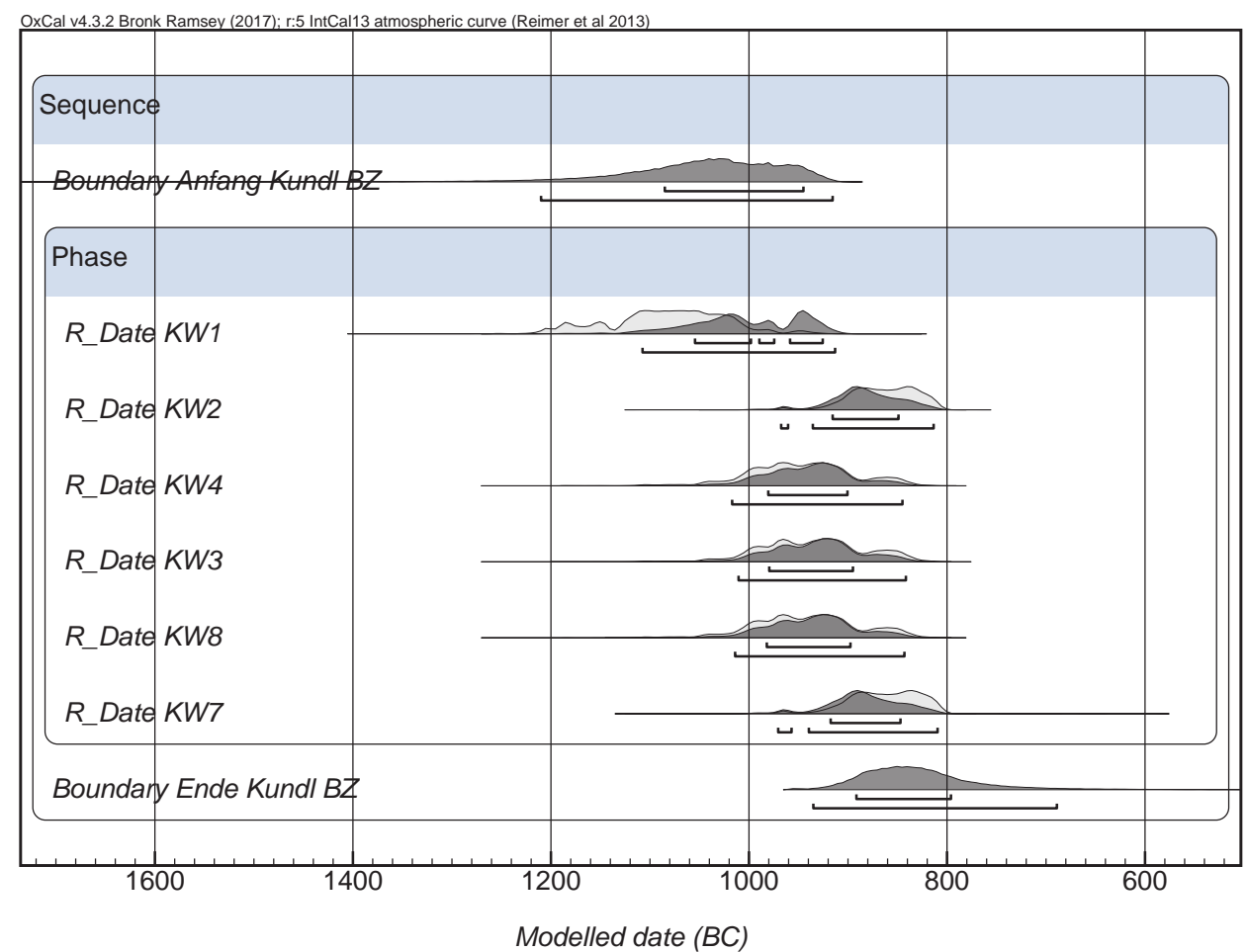

Abb. 13. Kundl, Schottergrube Wimpissinger. - Die Radiokarbondatierungen der spätbronzezeitlichen Kulturschicht und der eingetieften Gefäße (Daten nach Patzelt, Weber 2015, 20; Grafik: P. Trebsche mit OxCal 4.3.2). 


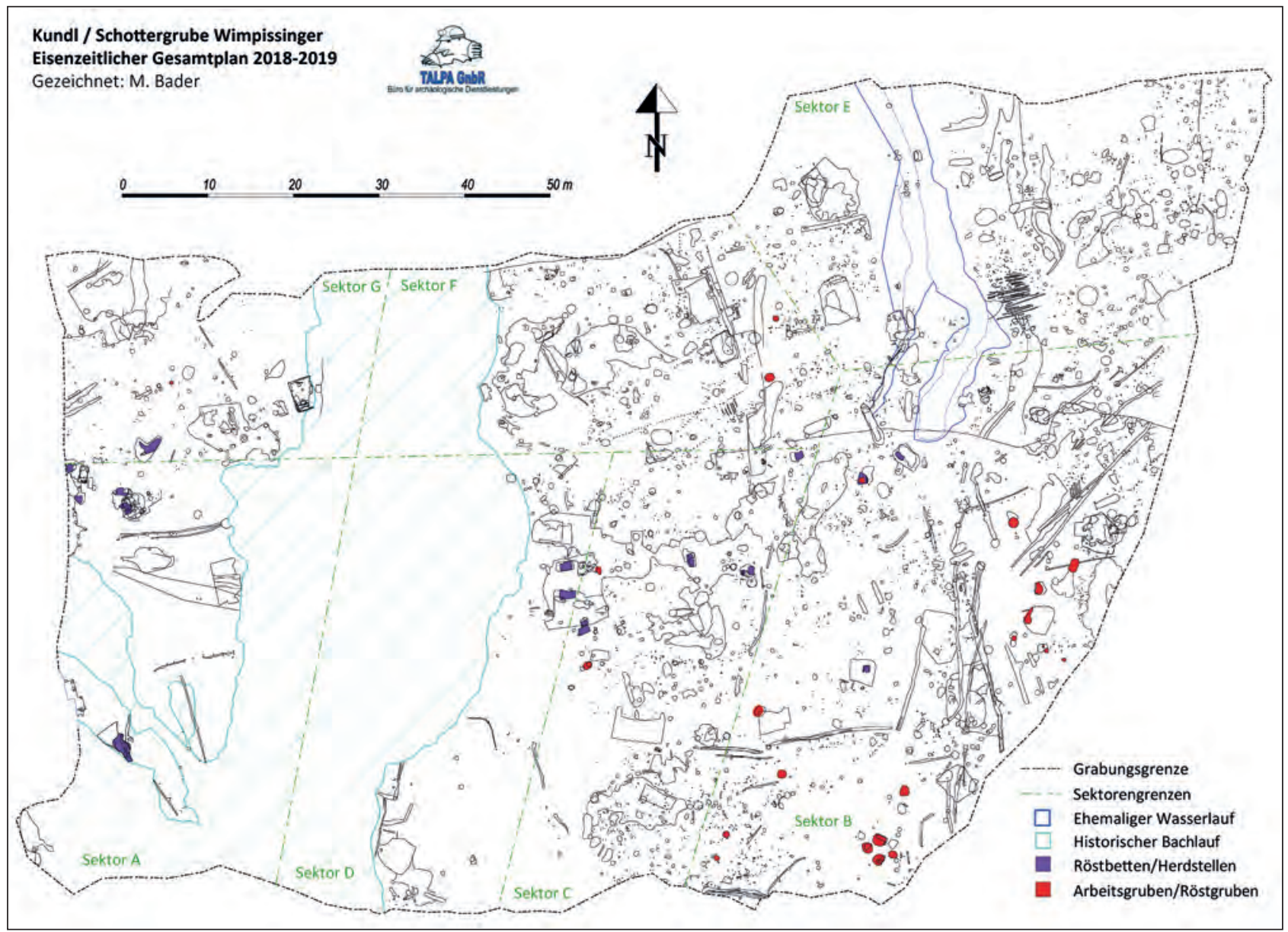

Abb. 14. Kundl, Schottergrube Wimpissinger, Grabung 2018-2019. - Plan des eisenzeitlichen Horizonts (Plan: TALPA).

gemessen wurden, ist mit Altholzeffekten zu rechnen, wie an Probe KW1 deutlich wird. Schließt man dieses Datum daher aus, so fallen sämtliche Daten in den Zeitraum zwischen 983-898 BC (ältestes Datum: KW8, 1-Sigma-Bereich) und 918-848 BC (jüngstes Datum: KW7, 1-Sigma-Bereich), also in das 10. und in die erste Hälfte des 9. Jhs. v. Chr.

\section{Das eisenzeitliche Siedlungs- und Werkstattareal}

Die späthallstatt- bis spätlatènezeitliche Kulturschicht konnte auf einer Fläche von $10.100 \mathrm{~m}^{2}$ freigelegt werden (Abb. 14). Sie fiel von Süd nach Nord um rund $8 \mathrm{~m} \mathrm{ab}$; im Süden der Grabungsfläche lag sie ca. $5 \mathrm{~m}$ unter dem rezenten Waldboden, im Norden trat die Kulturschicht bereits in 0,45 m Tiefe zum Vorschein. Von Süden nach Norden floss der alte Bachlauf durch das eisenzeitliche Areal. Aufgrund immer wiederkehrender Überschwemmungen und Vermurungen lagerten sich bis zu 0,60 m starke Schotterschichten zwischen den eisenzeitlichen Nutzungshorizonten ab, die vom alten Bachlauf ausgehend Richtung Westen und Osten ausliefen. In Bachnähe waren bis zu drei eisenzeitliche
Horizonte greifbar, während sich die eisenzeitliche Kulturschicht in den anderen Bereichen östlich und westlich des Baches als durchgehendes, mehr oder weniger homogenes, 0,10-0,25 m starkes Paket zeigte.

In den eisenzeitlichen Siedlungshorizonten wurden einerseits Baubefunde wie Balkengräben, Pfostengruben und Unterlegsteine, andererseits handwerkliche Befunde wie Röstbetten, Grubenöfen/Herdgruben und Lehmwannen dokumentiert. Die Kleinfunde zeigen eine kontinuierliche Nutzung von der Späthallstatt- bis in die Spätlatènezeit (6.-1. Jh. v. Chr.) an.

\subsection{Die Gebäudebefunde}

Die dokumentierten Baubefunde weisen auf unterschiedliche Konstruktionstechniken der eisenzeitlichen Gebäude als Pfosten-, Ständer- oder Schwellenbauten bzw. auf eine kombinierte Konstruktionsweise hin. ${ }^{36}$ Besonders hervorzuheben ist der ausgezeichnete Erhaltungszustand der

36 Zur Terminologie vgl. Volmer, Zimmermann 2012. 


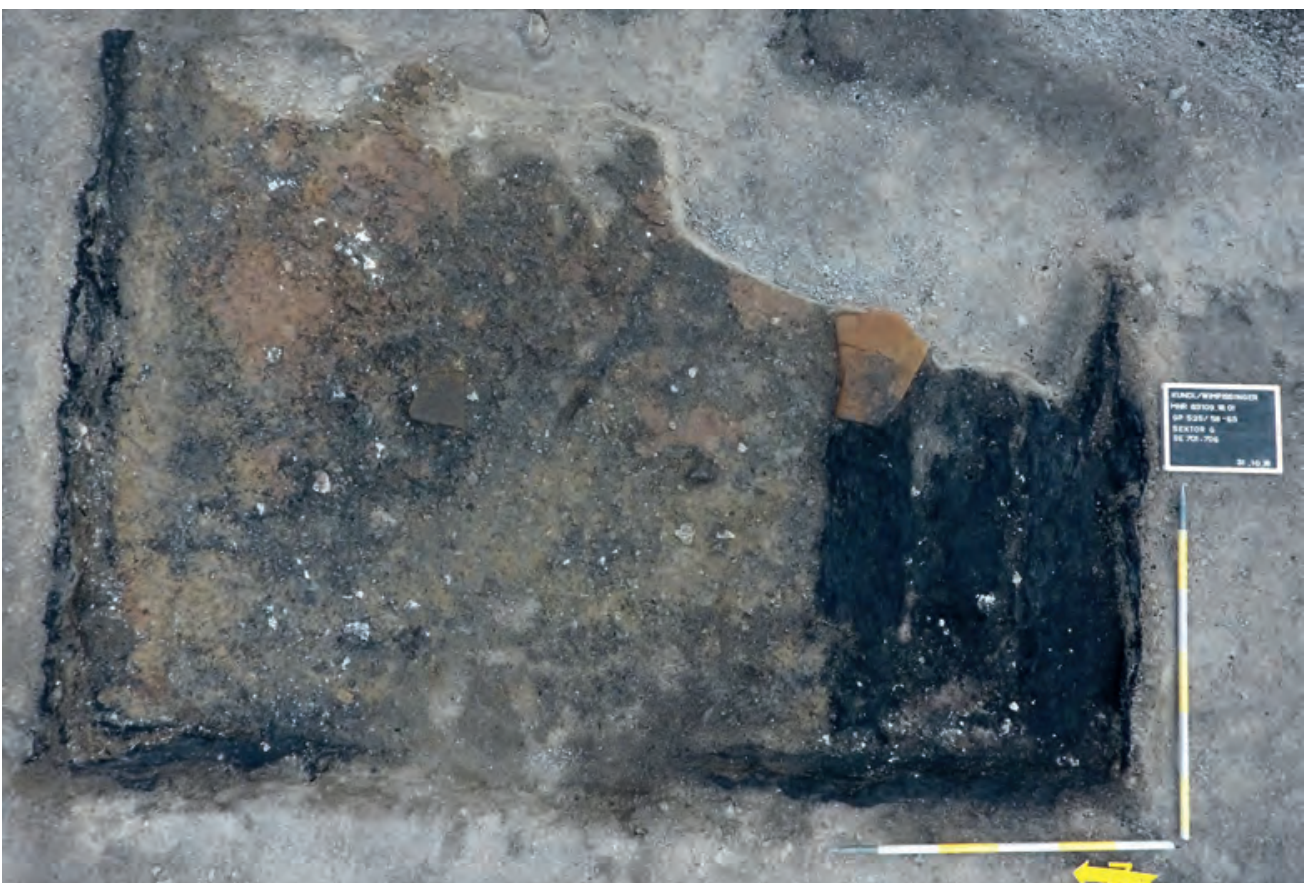

Abb. 15. Kundl, Schottergrube Wimpissinger. - Mit Holzbalken (SE 701) eingefasste Reste eines Gebäudes mit einem Stampflehmboden (SE 706) und Holzdielenboden (SE 702) (Foto: TALPA).
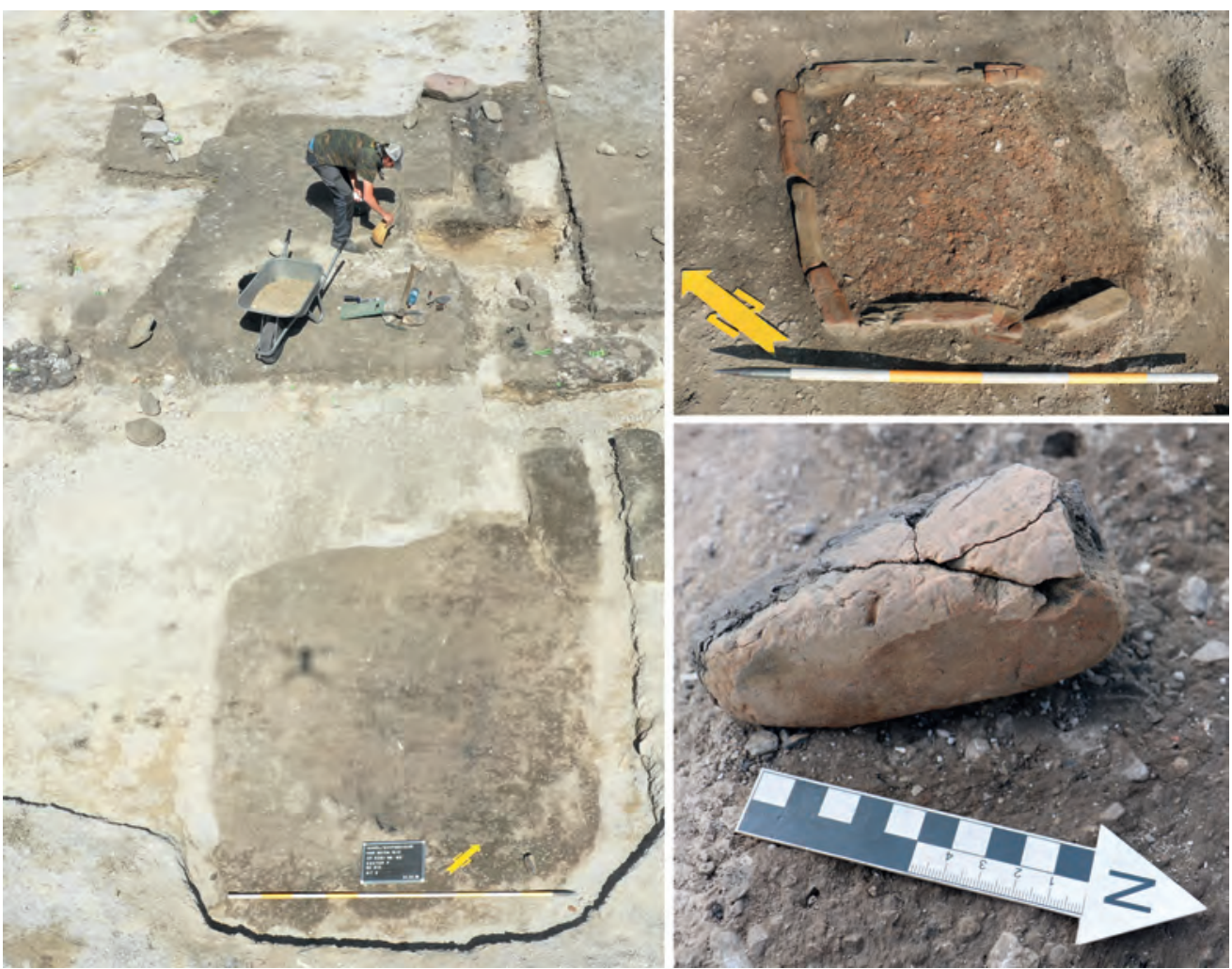

Abb. 16. Kundl, Schottergrube Wimpissinger. - Ein Webgewicht (unten rechts) aus einer Grubenverfüllung eines ehemaligen Holzgebäudes (links) sowie der Rest einer Feuerstelle (rechts oben) (Fotos: TALPA). 
Bebauungsreste (Abb. 15), der am Vorhandensein der flächigen Kulturschicht, der Unterlegsteine für Ständerbauten, der Schwellbalken und der Herdstellen sofort erkennbar ist. ${ }^{37}$ Das ehemalige Begehungsniveau wurde durch die Überdeckung mit Murschotter sozusagen versiegelt.

Die Pfosten waren in den Pfostengruben häufig mit Steinen verkeilt, um sie im anstehenden Schotter zu stabilisieren. Auch die linearen Balkengräben wiesen teilweise eine Verkeilung mit hochkant gesetzten Steinen auf und waren mit Steinen verfüllt, um die Schwellen vor der Bodenfeuchtigkeit zu schützen. Bei einigen Gebäuden waren die Schwellbalken aber auch direkt in den Schotter eingegraben und haben sich zum Teil in Holzresten, zum Teil in verkohlter Form erhalten. Pfostengruben oder flache Unterlegsteine für Ständer befanden sich häufig in den Ecken und in der Flucht der Schwellbalkengräben, sodass auf eine Schwellriegelkonstruktion geschlossen werden kann. Des Öfteren wurden die Balkengräben auch von Stangenlöchern begleitet, die ein- oder doppelreihig parallel zu den schmalen Gräben verliefen.

Durch Brandereignisse wurde der Lehmbewurf mancher Holzgebäude verziegelt und blieb so erhalten. Zahlreiche Hüttenlehmreste mit Rutenabdrücken weisen darauf hin, dass die Rahmenkonstruktion der Schwellen- oder Schwellriegelbauten mit Flechtwerk ausgefacht und mit Lehm verstrichen war. Es existieren auch keilförmige Hüttenlehmfragmente mit dem typischen dreieckigen Querschnitt, die durch das Verfugen von übereinander gesetzten Rundlingen mit Lehm entstanden. Dadurch ist auch die Blockbauweise für die aufgehenden Wände nachweisbar. ${ }^{38}$

An den eisenzeitlichen Gebäuden von Kundl fällt die große Variabilität in der Konstruktionsweise auf, die auf funktionale Unterschiede, aber auch auf diachrone Veränderungen im Laufe der Eisenzeit hinweist. Sogenannte rätische Häuser, die für die späte Eisenzeit im Gebiet der Fritzens-Sanzeno-Kultur als typisch gelten, ${ }^{39}$ fehlen in Kundl. Für Nordtirol erbrachten erst Grabungen des letzten Jahrzehnts den Nachweis, dass parallel zu dieser charakteristischen Hausform auch andere Konstruktionstypen wie Pfosten- und Schwellenbauten existierten. ${ }^{40}$ Die für Kundl dokumentierte variantenreiche Bauweise ähnelt den Befunden in der frühlatènezeitlichen Gewerbesiedlung im Ramsautal auf dem Dürrnberg, wo viele Gebäude in

37 Zur Klassifikation des Erhaltungszustandes vgl. Trebsche 2009, 507-508.

38 Fries-Knoblach 2009.

39 Migliavacca 1996. - SÖLder 1994.

40 Z. B. Fließ: Wallner 2019. - Thaurer Felder: Senffter 2011. Mieming-Locherboden: KIRCHMAYR 2015. kombinierter Schwellen-, Schwellriegel- und Pfostenbauweise konstruiert waren. ${ }^{41}$

Jedenfalls ist aufgrund der neuen Grabungsergebnisse nun gesichert nachweisbar, dass auf dem Kundler Lus eine umfangreiche Siedlung mit zahlreichen Gebäuden Bestand hatte, und es sich nicht nur um einige Werkstätten handelt, wie aufgrund der älteren Grabungen angenommen worden war. ${ }^{42}$

Der Haushaltscharakter wird an den zahlreichen Herdstellen sowie an einer Webstuhlgrube (Abb. 16) mit den dazugehörenden Webgewichten deutlich. Auch das Fundspektrum zeigt an, dass in der Siedlung nicht nur metallverarbeitende Aktivitäten stattfanden, sondern auch Nahrungsmittel erzeugt, zubereitet und konsumiert sowie Textilien hergestellt wurden. Als Belege dafür sind die großen Mengen an Fein- und Grobkeramik, Webgewichte, Spinnwirtel, Nähnadeln, Mühlsteine und Reibplatten sowie Tierknochen (Schlacht- und Speiseabfälle) zu erwähnen. Etliche Schmuck- und Trachtbestandteile, Toilettegeräte und Waffenfragmente geben auch Hinweise auf den sozialen Status der Einwohnerinnen und Einwohner und ermöglichen einen Vergleich mit den Beigaben im zeitgleichen Gräberfeld. ${ }^{43}$

Zwei bemerkenswerte Hinweise auf landwirtschaftliche Produktion im Siedlungsareal sollen noch erwähnt werden: Zum einen handelt es sich um mehrere lineare Reihen von Stangenlöchern, die keinen unmittelbaren Bezug zu Hausgrundrissen aufweisen und wahrscheinlich als Reste von Zäunen interpretiert werden können. Sie geben Hinweise auf Viehpferche und/oder Grundstücksgrenzen im Siedlungsareal. Überreste eines Viehzaunes wurden auch in einer ausgedehnten jüngereisenzeitlichen Talsiedlung im Bereich der Thaurer Felder am Kinzachbach im Inntal dokumentiert. ${ }^{44}$

Zum anderen blieben auf einer kleinen Fläche (ca. $7 \times 5 \mathrm{~m}$ ) parallele schmale Pflugfurchen (Abb. 17) erhalten, die auf kleine Ackerflächen im Siedlungsbereich (zwischen zwei Siedlungsphasen?) hinweisen. Geeignetere und größere Anbauflächen sind natürlich auf den nördlich angrenzenden Innterrassen zu vermuten. Eisenzeitliche Pflugspuren blieben in den Alpen allgemein nur sehr selten erhalten. ${ }^{45}$ Bereits Lang beobachtete bei ihrer Grabung 1984 auf dem Kundler Lus Pflugspuren, die sie als Überreste eines „Abschlussrituals“ nach der Beendigung

\footnotetext{
41 STÖLlner 1999. - Lobisser 2005.

42 LANG 1998, 19.

43 LANG 1998.

44 Senfter 2011.

45 Fries-KNoblach 2020.
} 


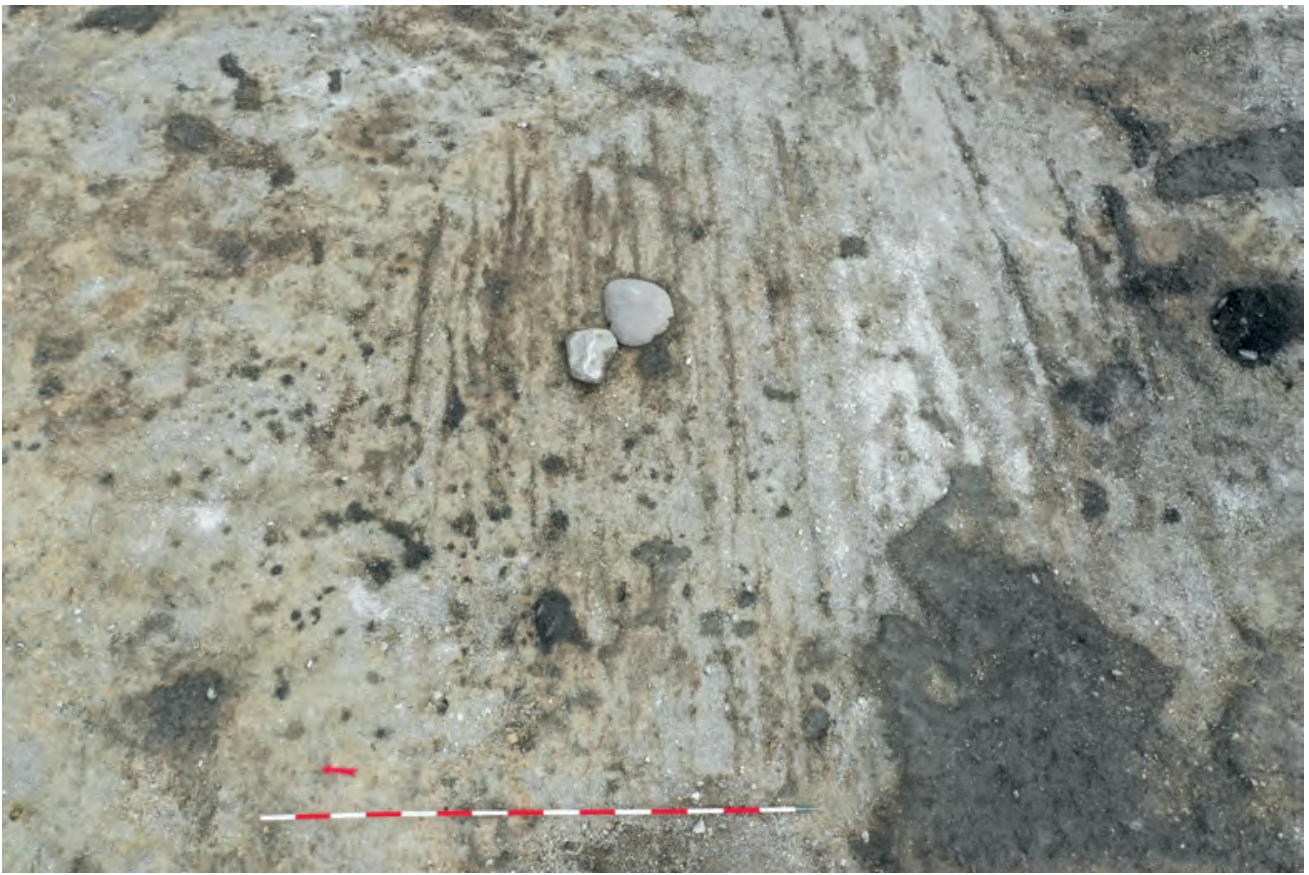

Abb. 17. Kundl, Schottergrube Wimpissinger. - Parallele Pflugfurchen im eisenzeitlichen Siedlungsareal (Foto: TALPA).
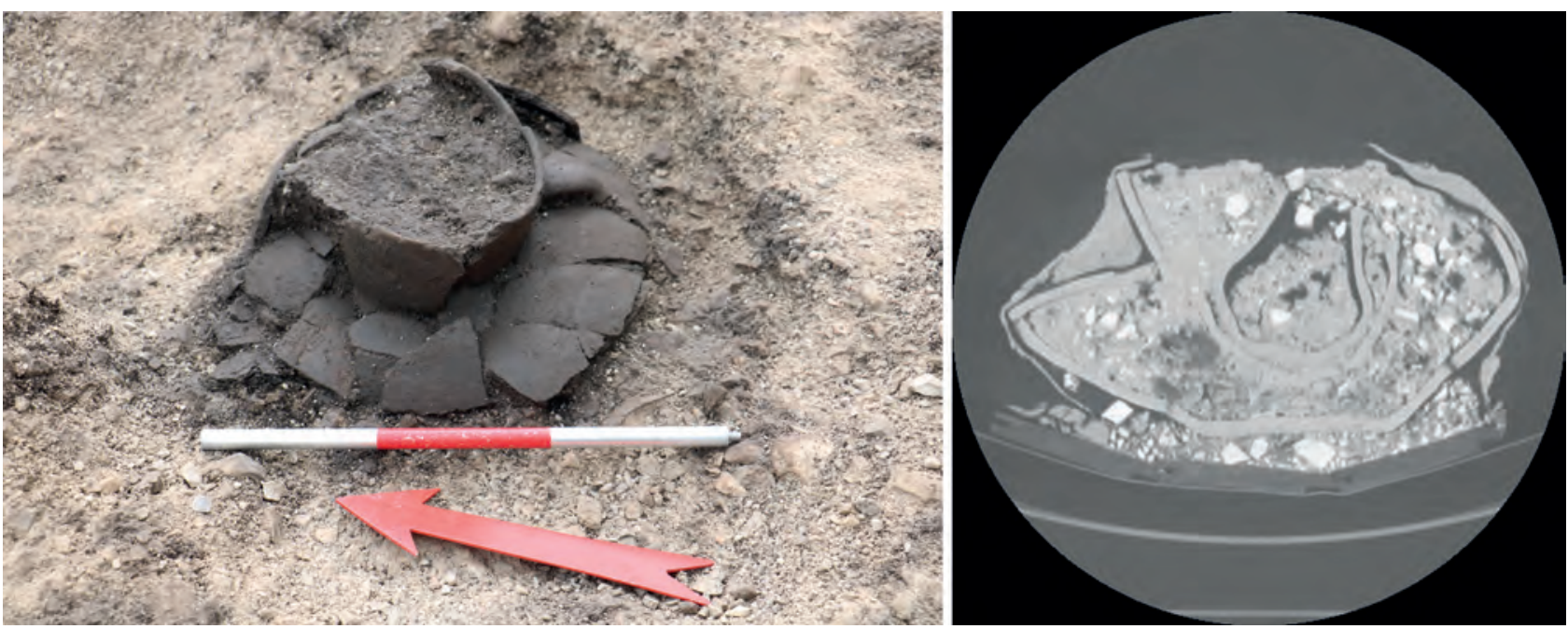

Abb. 18. Kundl, Schottergrube Wimpissinger. - Links: Die Urnenbestattung im eisenzeitlichen Siedlungsareal. - Rechts: Im CT-Bild sind weitere Gefäßbeigaben erkennbar (Foto: TALPA; CT-Bild: Universitätsklinik für Radiologie Innsbruck).

der Schmiedetätigkeiten deutete. ${ }^{46}$ Vor allem die schattige Lage am Nordfuß des Kragenjochs scheint völlig ungeeignet für den Ackerbau. Dennoch ist ein vergleichbarer Befund aus dem inneralpinen Raum bekannt: In der eisenund römerzeitlichen Siedlung von Brig-Glis „Waldmatte“ (Kanton Wallis, Schweiz), die ähnlich Kundl im Schatten des Glishorns auf Schwemmkegeln lag, wurden ebenfalls

46 LANG 1998, 19-20 und Abb. 10. hangparallele Pflugspuren auf vermurtem Gelände dokumentiert. Trotz der widrigen Bedingungen wurde hier mehrfach - sowohl in der Eisenzeit als auch in der Spätantike, nach Auflassung der Siedlungen auch im Mittelalter und in der Neuzeit - der karge Boden unter den Pflug genommen, ohne dass ein ritueller Kontext erkennbar ist. ${ }^{47}$

47 Benkert et al. 2014, z. B. 76 und Abb. 67; 93 und Abb. 92; 105106. - Fries-KNoblach 2020, 76. 

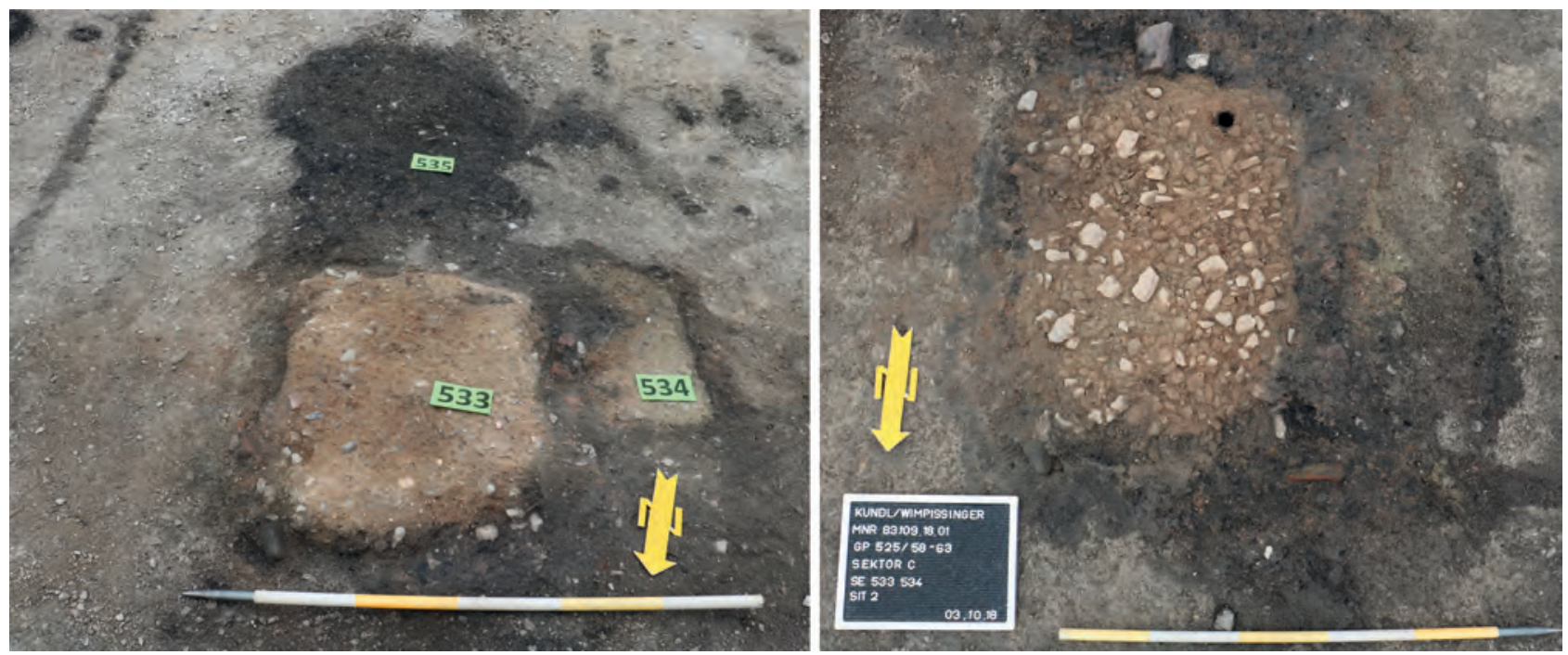

Abb. 19. Kundl, Schottergrube Wimpissinger. - Links: Das Röstbett SE 534 wurde vom jüngeren Röstbett SE 533 geschnitten, im Hintergrund die stark mit Holzkohle und Asche verfüllte Grube. - Rechts: Aus Steinen gesetzter Unterbau von SE 533 (Fotos: TALPA).

\subsection{Eine Siedlungsbestattung}

Eine weitere Besonderheit stellte ein Urnengrab inmitten des eisenzeitlichen Siedlungs- und Werkareals auf dem Kundler Lus dar (Abb. 18). Es handelte sich dabei um eine komplett erhaltene Urne, die mit einem Stein abgedeckt war. Die CT-Aufnahme des im Block geborgenen, aber noch nicht vollständig freigelegten Urnengrabes zeigt im Inneren des großen Gefäßes mehrere ineinander gestapelte Gefäße. In der Nähe lag ein weiteres vollständiges, jedoch fragmentiertes Gefäß. Vom Leichenbrand aus der Urne konnten bisher nur ein Wirbelfragment und ein Dauerzahn anthropologisch untersucht werden. Der Zahn stammt von einem Individuum, das im Alter von mindestens zwölf Jahren verstarb. ${ }^{48}$

Die Lage des Urnengrabes inmitten der Siedlung wirft Fragen auf, da westlich des Siedlungsareals ein separates Gräberfeld existierte, in dem der überwiegende Teil der Bevölkerung von $\mathrm{Ha} \mathrm{D}$ bis in frührömische Zeit bestattet wurde. Üblicherweise wurden nur verstorbene Neugeborene und Säuglinge während der Eisenzeit im häuslichen Kontext und nicht im Gräberfeld beigesetzt. ${ }^{49}$ Bei den relativ seltenen Siedlungsbestattungen dieser Epoche handelt es sich niemals um Brandbestattungen, sondern ausnahmslos um Körperbestattungen. ${ }^{50}$ Möglicherweise zählt das Urnengrab, das außer seiner Lage im Siedlungsbereich

48 Anthropologische Bestimmung: Marlies Wohlschlager.

49 Beilke-Voigt 2008. - Beilke-Voigt 2010. - Trebsche 2013. Trebsche 2016.

50 Müller-Scheessel 2013. - MüLler-Scheessel et al. 2013. keine „irregulären“ Merkmale aufweist, zu den frühesten Bestattungen der Siedlungsgemeinschaft und wurde zu einer Zeit angelegt, als das Gräberareal noch nicht endgültig festgelegt war. Genauere Hinweise werden die mikroarchäologische Freilegung des im Block geborgenen Grabes und seine exakte Datierung bringen.

\subsection{Die metallurgischen Werkstätten}

Der eisenzeitliche Siedlungsbereich auf dem Kundler Lus weist eine starke handwerklich-gewerbliche Prägung durch die Metallverarbeitung auf. In den älteren Grabungen konnte diese Komponente nur kleinflächig erfasst werden, ${ }^{51}$ während die neuen Untersuchungen dank ihrer großen Fläche nun den Umfang und die räumliche Strukturierung der Werkstättenareale sowie die Intensität der handwerklichen Produktion in Kundl deutlich machen. In erster Linie handelt es sich um Einrichtungen zur Kupfer- und Eisenverarbeitung, die sich zum alten Bachlauf hin konzentrieren. Grob gesprochen können drei Gruppen von Befunden unterschieden werden: Röstbetten, Grubenöfen und Lehmwannen.

Die erste Gruppe der Röstbetten (mind. 15 Befunde) weist meist einen ovalen bis rechteckigen Grundriss mit Ausmaßen bis zu 1,00 × 2,00 m auf (Abb. 19). Der Unterbau besteht aus Bruchsteinen, flach gesetztem Steinmaterial oder gepresstem Schotter und ist mit stark brandgerötetem Lehm abgedeckt. Neben diesen Röstbetten befanden sich häufig mit Holzkohle und Asche gefüllte Gruben. Von

51 LANG 1998, 11-19 und Abb. 7-10. 

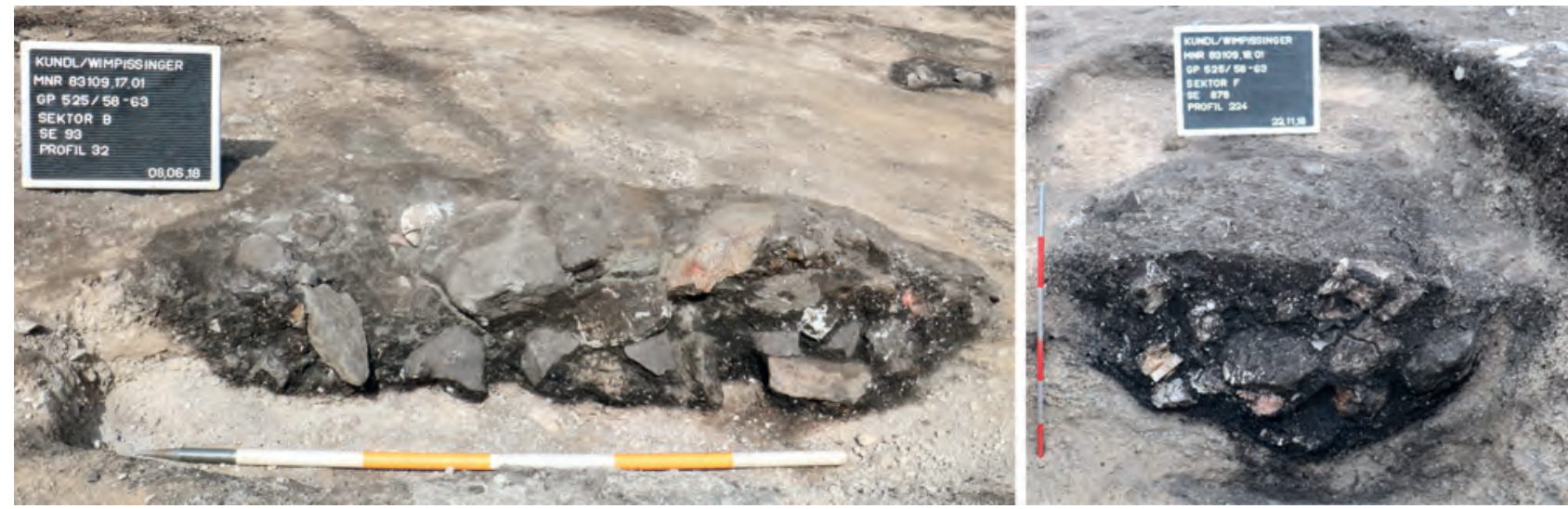

Abb. 20. Kundl, Schottergrube Wimpissinger. - Links: Westprofil der Grube SE 93. - Rechts: Ostprofil der Grube SE 878 (Fotos: TALPA).

gewöhnlichen Herdstellen zum Kochen unterscheiden sich die Befunde aufgrund ihrer Größe und der wesentlich stärkeren Hitzeeinwirkung. Diese Befundgattung trat beiderseits des alten Bachlaufs auf, wobei sich drei Konzentrationen von jeweils drei bis fünf Röstbetten abzeichnen. Drei Röstbetten an der Grenze der Grabungssektoren C und D sind in einer Reihe mit regelmäßigen Abständen von rund $4 \mathrm{~m}$ angelegt; die anderen Röstbetten folgen keiner regelmäßigen Anordnung. Auf ähnliche Befunde stießen auch Lang und Sydow bei ihren Grabungen 1984-1990. Lang sah in den kreisrunden Herden dieser Art Ausheizherde zum Ausschmieden der Roheisenluppen. ${ }^{52}$ Das Ausheizen der Luppen erfolgt im Eisenproduktionsprozess für gewöhnlich unmittelbar nach dem Schmelzen des Eisenerzes in einem Rennofen. Die dafür benötigten Herde ähneln jedoch eher den Schmiedeessen und müssen nicht derart groß dimensioniert sein. ${ }^{53}$ Unseres Erachtens dienten die runden, ovalen und rechteckigen großen Herde eher als Röstbetten zum Rösten von Eisen- oder Kupfererz vor der Verhüttung.

Die zweite Befundgruppe umfasst etwa 20 runde Gruben mit einem Durchmesser bis zu 1,00 m sowie größere ovale Gruben (bis zu 1,30 × 1,50 m), die massiv mit Holzkohle und mit Steinen verfüllt waren (Abb. 20). Die Grubensohlen waren meist durch Hitze rötlich verfärbt und der anstehende Schotter erschien dadurch „verbacken“. Derartige Befunde könnten als Schmiedeessen bzw. als Ausheizherde gedient haben, es wäre aber auch möglich, dass es sich um einfache Grubenöfen zur Eisenverhüttung ${ }^{54}$ oder um Herdgruben zum Schmelzen von Kupfer bzw. Bronze

52 LANG 1998, 12

53 Pleiner 2000.

54 Vgl. Garner 2010, 64-66, 89 und Abb. 91. handelte. Rund 50 sehr ähnliche, allerdings ältere (mittel- bis spätbronzezeitliche) Grubenöfen wurden 1987 in der Hub Obkirchen, Gemeinde St. Johann im Pongau in Salzburg entdeckt; weitere Befunde dieser Art sind auch aus anderen bronzezeitlichen Siedlungen im Pongau sowie aus Wörgl im Unteren Inntal bekannt. ${ }^{55}$ Fritz Moosleitner deutete diese Befunde als Öfen zur Reduktion von Schwarzkupfer, die im Nahbereich oder am Rand der Siedlungen erfolgte. ${ }^{56} \mathrm{Die}$ Grubenöfen wurden in Kundl (mit einer Ausnahme) nur östlich des alten Bachlaufs angelegt; dort häufen sie sich im Süden und Osten von Grabungssektor B und im Osten von Sektor F. Sie scheinen also rund um die Zone mit den Röstbetten angelegt worden zu sein.

Im nordöstlichen Grabungsareal konzentrierte sich die dritte Befundgruppe der Lehmwannen (Abb. 21). Diese waren einander im Aufbau sehr ähnlich: Zuunterst bestanden die wannenartigen Eintiefungen aus verdichtetem, lehmigem bis schottrigem Erdmaterial. Darüber wurde eine Lage aus beigem Lehm eingebracht und stark verdichtet. Die solcherart abgedichteten Wasserwannen könnten zur nassmechanischen Aufbereitung von Erzen und Schlacken oder zum Abschrecken von Schmiedeprodukten im Wasser gedient haben. Aber auch für zahlreiche andere Handwerke war ein Wasservorrat notwendig. Vergleichbare Gruben mit Lehmauskleidung sind aus dem Bereich des Handwerkerareals auf dem Waschenberg bei Bad Wimsbach in Oberösterreich bekannt, wo in der Späthallstattzeit Eisen verhüttet und weiterverarbeitet wurde. ${ }^{57}$ Der Ausgräber Manfred Pertlwieser sah in diesen lehmausgekleideten Gruben aber

55 Zemmer-Plank 1990, 93. - Moosleitner 2004. - Knoche 2016. 56 Moosleitner 2004, 220.

57 Pertlwieser 1970, 44 und Textabb. 3/1 (Herdgrube A); 46-47 und Textabb. 2 (Herdgrube B). 

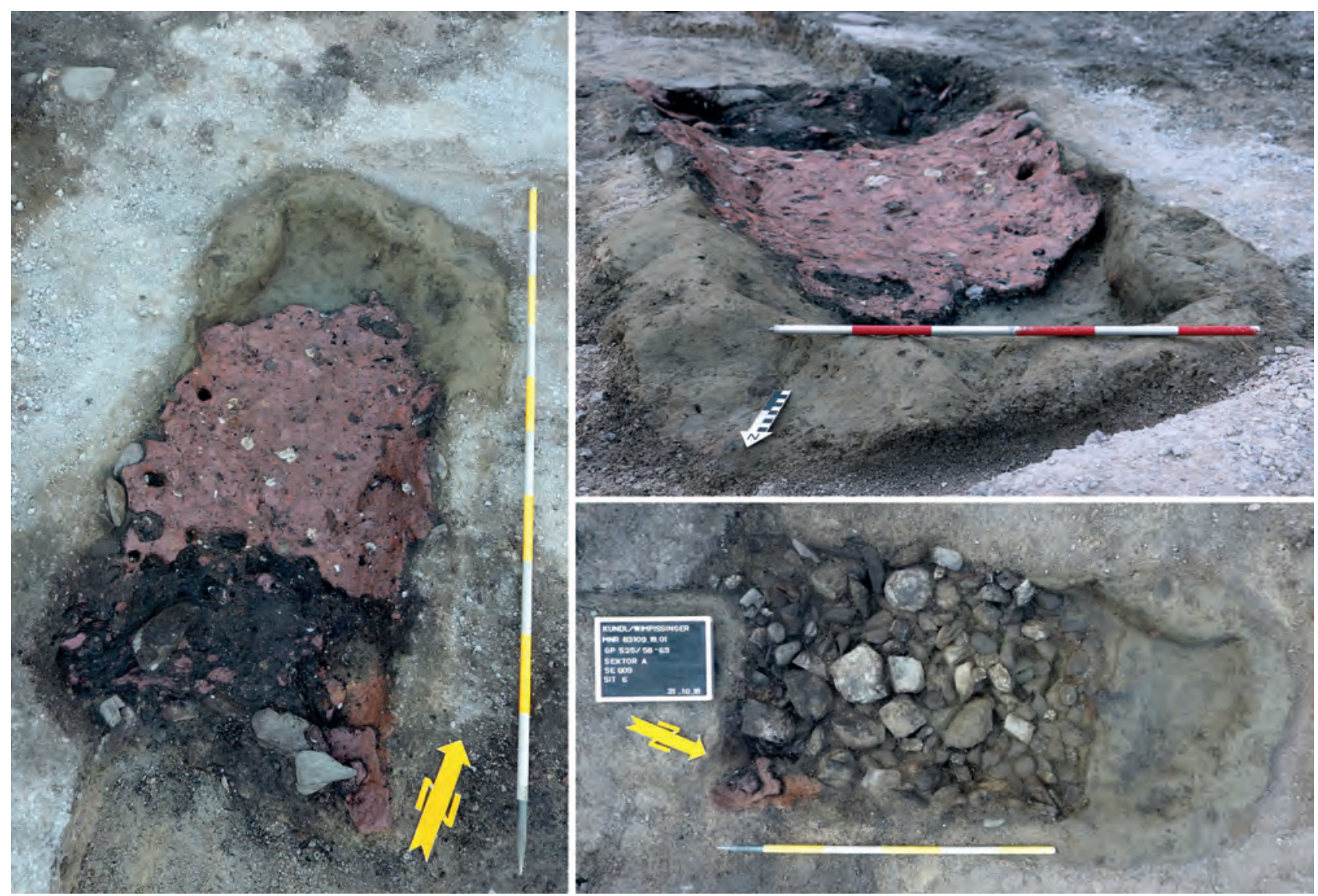

Abb. 21. Kundl, Schottergrube Wimpissinger. - Die wannenförmige Konstruktion aus verziegeltem Lehm (links) und deren steinerner Unterbau (rechts) (Fotos: TALPA).

eher Einrichtungen zum Dörren, Backen oder Räuchern von Lebensmitteln..$^{58}$

Die genaue Funktion der beschriebenen Röstbetten, Grubenöfen/Herdgruben und Lehmwannen kann erst im Zuge der geplanten Befundauswertung geklärt werden. Eine Nutzung dieser Werkstätten zur primären Eisenverhüttung (mit einfachen Grubenöfen, Röstbetten und Ausheizherden) ist nicht auszuschließen, zumal ein lokales Vorkommen von Eisenerz in Kundl beim Schotterabbau im Jahr 1983 beobachtet wurde. ${ }^{59}$ Hinweise auf typische Rennöfen konnten jedoch bislang in Kundl nicht beobachtet werden. Durch Produktionsabfälle ist bislang auch nur die Weiterverarbeitung von Schmiedestahl nachgewiesen, ${ }^{60}$ was zum Beispiel durch die charakteristischen kalottenförmigen Schmiedeschlacken aus den neuen Grabungen bestätig wird (Abb. 22). Die archäometallurgische Untersuchung und

58 Pertl wieser 1970, 50.

59 LANG 1998, 14.

60 Maurer 1993.

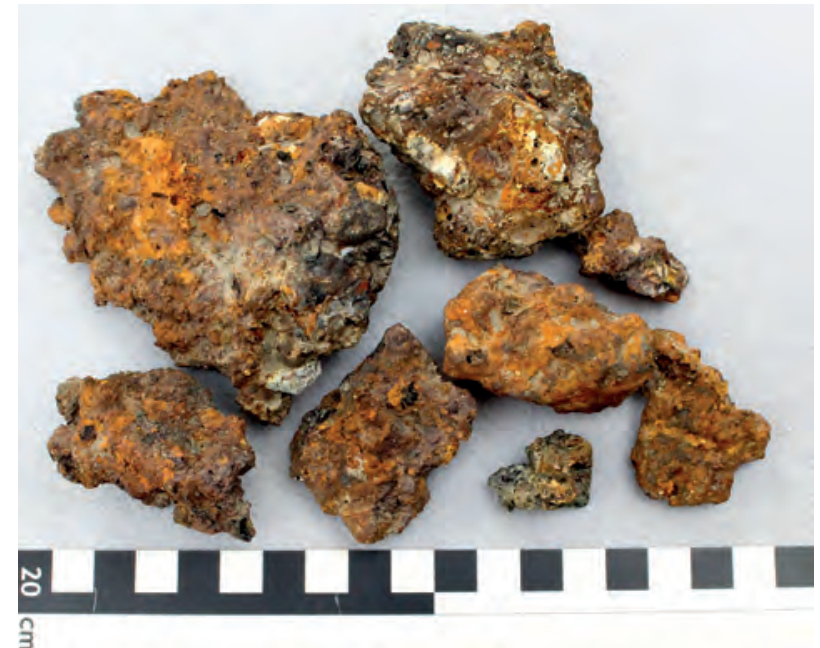

Abb. 22. Kundl, Schottergrube Wimpissinger. - Kalottenförmige Eisenschmiedeschlacken (Foto: TALPA). 

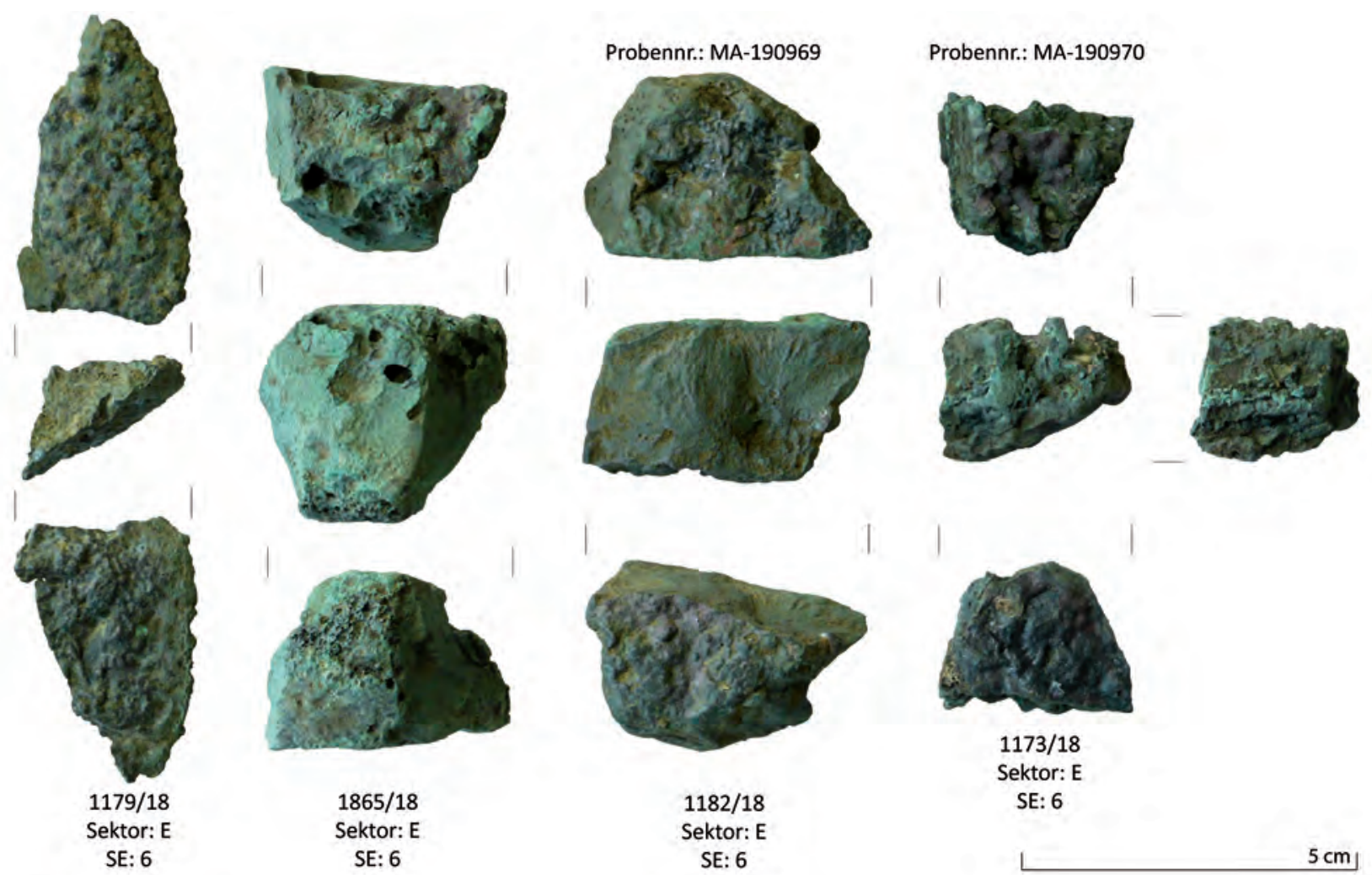

$5 \mathrm{~cm}$

Abb. 23. Kundl, Schottergrube Wimpissinger. - Gusskuchenfragmente aus der eisenzeitlichen Kulturschicht. Bei Fundnr. 1173/18 war bei der Herstellung eine „Sollbruchstelle“ in Form einer Trennungsmarke angebracht worden (Grafik: M. Staudt).

die Verteilungsanalyse der zahlreichen Produktionsabfälle können auf jeden Fall wichtige Beiträge zur Rekonstruktion der metallurgischen Produktionskette und der Funktion der Werkstatteinrichtungen liefern.

Nicht nur die Verarbeitung von Eisen ist in Kundl nachgewiesen, die Grabungen der Jahre 2018/2019 erbrachten auch zahlreiche Funde, die mit der Verarbeitung von Kupfer(legierungen) in der Eisenzeit zusammenhängen. Vier kleine Gusskuchenfragmente wurden entweder direkt auf dem Kundler Lus hergestellt oder gelangten aus den nahe gelegenen Produktionsstätten im Bergbaugebiet Brixlegg-Schwaz dorthin (Abb. 23).

Archäometallurgische Analysen von Joachim Lutz (Curt-Engelhorn-Zentrum für Archäometrie) an zwei der kleinen Gusskuchen belegen, dass beim Lus in der Eisenzeit Schwarzkupfer weiterverarbeitet und sehr wahrscheinlich auch produziert wurde. Aufgrund der hohen Silber-, Antimon-, und Arsenanteile ${ }^{61}$ kann davon ausgegangen werden, dass für die Erzeugung des Schwarzkupfers die nahegelegenen Fahlerzlagerstätten im Unterinntal genützt wurden.

61 MA-190969: Cu 78; Ag 1,04; Sb 13,5; As 6,7 Gew.-\%; MA190970: Cu 82; Ag 0,86; Sb 8,8; As 5,2 Gew.-\%.
Der Fahlerzbergbau und die damit verbundene Kupferproduktion im Unterinntal dauerte, mit Ausnahme der kupfer-bzw. frühbronzezeitlichen Aktivitäten, vom Beginn der späten Bronzezeit (spätestens ab dem 12. Jh. v. Chr.) kontinuierlich über mindestens 500 Jahre wahrscheinlich bis ans Ende der frühen Eisenzeit ( $\left.\mathrm{Ha} \mathrm{D}_{2}{ }^{62}\right)$, wie die montanarchäologischen Untersuchungen und zahlreichen naturwissenschaftlichen Analysen des Forschungszentrums HiMAT (= History of Mining Activities in the Tyrol and Adjacent Areas - Impact on Environment and Human Societies) zeigen konnten. ${ }^{63}$ Für die These einer lokalen Kupferproduktion in Kundl noch während der Eisenzeit sprechen auch ein größeres Plattenschlackenfragment und der hintere Teil eines mutmaßlichen Gebläsetopfes mit Lochung aus den neuen Grabungen. Der Gebläsetopf könnte allerdings auch beim Bronzeschmelzen eingesetzt worden sein. Ein Bodenfragment eines Schmelztiegels und das Halbfabrikat einer

62 Ein schlackengemagertes Keramikgefäß aus der Kundler Nekropole datiert in die Stufe Ha D2 und könnte den bisher jüngsten indirekten Beleg für die Produktion von Fahlerzkupfer darstellen: LANG 1998, 366.

63 Goldenberg et al. 2011. - Goldenberg, Staudt, Grutsch 2019. - STAUdT et al. 2019a. - STAUdT et al. 2019b. 
Fibel weisen jedenfalls auch auf eine sekundäre Metallurgie, d. h. die Verarbeitung von Kupfer bzw. Bronze im eisenzeitlichen Werkstattareal auf dem Kundler Lus hin.

\subsection{Ausgewählte eisenzeitliche Funde}

Neben zahlreichen für Nordtirol typischen Keramikfragmenten der Fritzens-Sanzeno-Kultur, Glasschmuck, eisernen Waffen und Arbeitsgeräten verdient die große Menge an Fibeln besondere Beachtung, welche im gesamten eisenzeitlichen Horizont entdeckt wurde. Nach einer ersten Materialdurchsicht sind 122 Fibeln und Fibelfragmente aus der $10.100 \mathrm{~m}^{2}$ großen Grabungsfläche vorhanden, die durch systematisches Absuchen der Fläche mit der Metallsonde zwischen den einzelnen Abhüben der Kulturschicht durch den Bagger entdeckt wurden. Das Fibelspektrum deckt die gesamte Latènezeit $a b$ und belegt eine ungebrochene Nutzung des Werkareals während dieser Periode (Abb. 24). In die ausgehende Hallstattzeit verweisen nur einzelne Keramikfunde, Kugel- (Abb. 24/2) ${ }^{64}$ und Rollenkopfnadeln (Abb. 24/1), ${ }^{65}$ Dreiecksanhänger bzw. -rähmchen ${ }^{66}$ sowie Stangengliederketten. ${ }^{67}$

Die frühe Latènezeit (Lt A) wird von der Ostalpinen Tierkopffibel (Abb. 24/3-5) (88 $^{6}$ dominiert, welche mit mindestens elf Stück vertreten ist. Die relativ große Anzahl sowie die auffallende Uniformität - gemessen an der generellen Vielfalt dieses Typs - lassen an eine Fibelproduktion vor Ort denken. ${ }^{69}$ Während Lt B kommen nur vereinzelt Duxer (Abb. 24/7) ) $^{70}$ nd Münsinger (Abb. 24/6) ) $^{71}$ Fibeln vor. Bei der mit mindestens 19 Exemplaren häufigsten Form in Kundl handelt es sich um Fibeln vom Mittellatèneschema (Abb. 24/10-13). ${ }^{72}$ Weiters können die vereinzelt

64 Mansfeld 1971, 94-98. - К̌ IHovskÝ 1979, 124-130. - TorbRÜGGE 1979, 74.

65 ŘiHovsKÝ 1979, 136-145. - Fries 2005, 127.

66 ZÜRN 1952, 44. - WARNEKE 1999, 151-155.

67 Schiek 1956, 110. - SchaAfF 1974, 68-73. - Pauli 1978, 180-182. 68 v. Merhart 1927, 102. - Pauli 1978, 106. - Parzinger 1989, 99-100. - ADAM 1996, 87-88.

69 Der genaue Herstellungsprozesses inklusive „Handschriftanalyse“ wird im Rahmen einer Dissertation über die Kleinfunde aus Kundl durch Daniel Lueger untersucht.

70 Filip 1956, 90-96, 523-524. - Pauli 1978, 123-127. - Bujna 1991, 241-244. - AdAM 1996, 121-122. - RAmsL 2002, 68-69. - BujNa 2003, 47-48, 62-64, 83-85, 94-96 und Abb. 7/33. - HүE 2009, 51-52. RAMSL 2011, 140-145.

71 Beltz 1911, 679-680. - Hodson 1968, 16-17 und Taf. 123, Spalte 31. - Pauli 1978, 123-127. - Hye 2009, 51-52.

72 GeHring 1974, 52-55. - STÖCKLI 1974. - FEUGÈre 1985, 80-200. - Gebhard 1991. - Adam 1996, 167-179. - Hye 2009, 57-59. - An eine eingehende Analyse werkstatttypischer Besonderheiten ist hier jedoch nicht zu denken, da die Mehrzahl aus Eisen besteht und dadurch heftiger Korrosion ausgesetzt war. angetroffenen Mandolinenfibeln (Abb. 24/9) ${ }^{73}$ in die Mittellatènezeit datiert werden. In der Spätlatènezeit ist bei den Fibeln ein massiver Rückgang im Fundanfall zu verzeichnen. Lediglich eine Schüsselfibel der spätesten Latènezeit, ${ }^{74}$ eine Fibel vom Typ Cenisola ${ }^{75}$ und wenigstens noch eine weitere Fibel vom Spätlatèneschema scheinen die Stufe Lt D zu repräsentieren.

Zu dem bisher einzigen sicheren Beleg für die Produktion von Fibeln in Kundl, dem Halbfabrikat einer Spätlatènefibel, das bei den Baggerarbeiten der 1970er Jahre ans Licht kam, ${ }^{76}$ kommt durch die jüngsten Grabungen ein zwar unscheinbarer, aber besonders aufschlussreicher Neufund hinzu. Es handelt sich dabei um die abgebrochene Spirale einer Fibel, in deren Zentrum noch der Eisenstift steckt, um den herum die Spirale gewickelt wurde. Die Frage, ob die geringe Zahl spätlatènezeitlicher Fibeln mit einem generellen Rückgang der Werktätigkeit auf dem Lus zusammenhängt, wird sich durch die Bearbeitung der übrigen Kleinfunde in naher Zukunft beantworten lassen.

Als deutlicher Beleg für umfangreiche Kulturkontakte oder Handel ist die latènezeitliche Graphitton- und Kammstrichkeramik ${ }^{77}$ aus Kundl zu werten. Sie ist im eisenzeitlichen Siedlungsareal ebenso wie im Gräberfeld auffallend häufig vertreten. ${ }^{78}$ Im Tiroler Inntal ist zwar eine Reihe von Fundplätzen bekannt, ${ }^{79}$ jedoch liegen jeweils nur sehr wenige Stücke vor. Den mit Abstand reichsten Bestand bildeten bisher 42 Fragmente auf dem sog. „Brandopferplatz“ bei der Siedlung auf dem "Himmelreich“ von Wattens. ${ }^{80}$ Gerade die größte Siedlung der nördlichen Fritzens-Sanzeno-Kultur auf dem Hörtenberg in Pfaffenhofen enthielt auffälligerweise, obwohl großflächig untersucht, nicht ein einziges Stück keltischer Importkeramik. ${ }^{81}$ Es wäre naheliegend, in diesem hochwertigen Kochgeschirr den Gegenwert der möglicherweise in die Latènekultur exportierten Metallprodukte zu vermuten. Erwähnenswert ist in diesem

\footnotetext{
73 АDAm 1996, 164-166. - Hye 2009, 52-56.

74 Gleirscher 1987, 67-88. - AdAm 1996, 221-223.-Meller 2012, 71-95.

75 Gleirscher 1992, 93-107. - AdAm 1996, 217-218. - DemetZ 1999, 63-64. - Meller 2012, 44-52.

76 LANG 1998, 70 und Taf. 7/157.

77 Kappel 1969. - Pauli 1987. - Trebsche 2011. - Zur Datierung anhand der Randbildungen (gattungsübergreifend): GEILENBRÜGGE 1992.

78 LANG 1998, 184-185.

79 Fundliste siehe Gleirscher 1987, 261 und Anm. 501. - Ergänzend: STADLER 1987, 156 und Taf. 2/8 (Münster-Pfarrkirche). - CireSA 2006, 59 und Taf. 64/2 (Fritzens-Pirchboden). - Kirchmayr 2015, 106 (Mieming-Locherboden).

80 Sinnhuber 1949, 62-63, 101 und Taf. 24 oben.

81 Freundlicher Hinweis von Markus Wild.
} 

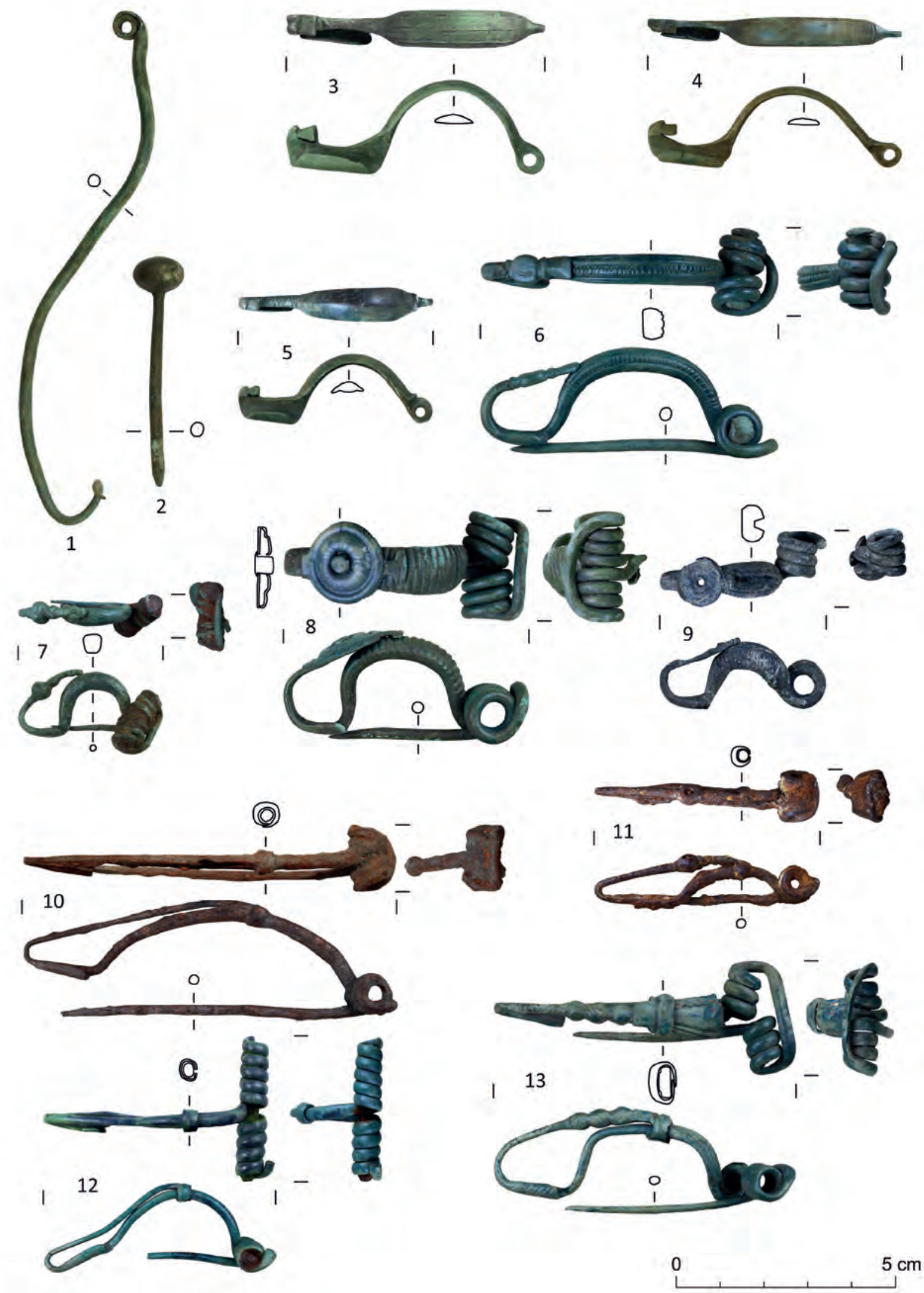

Abb. 24. Kundl, Schottergrube Wimpissinger. - Auswahl an Nadeln und Fibeln aus der eisenzeitlichen Kulturschicht (Grafik: TALPA). 


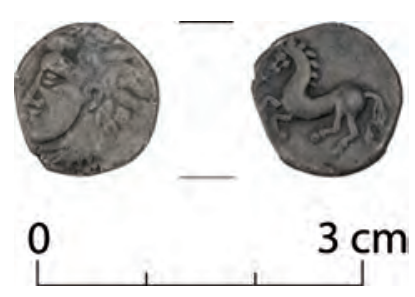

Abb. 25. Kundl, Schottergrube Wimpissinger. - Büschelquinar, Silber (Grafik: TALPA).

Zusammenhang auch ein mittellatènezeitlicher Büschelquinar aus Silber (Abb. 25). Keltische Münzen sind in Tirol zwar bekannt, kommen aber nur sehr vereinzelt vor. Auch das Fragment eines Sapropelitarmringes stellt das bislang einzige bekannte Exemplar in Nordtirol dar. Generell ist die Nähe zum keltischen Kulturkreis im Fundgut sehr präsent. So kommen beispielsweise auch die oben erwähnten und für die ausgehende Hallstattzeit im Alpenvorland typischen Formen wie die Dreiecksanhänger und Stangengliederketten durchaus häufig auch in Kundl vor, während diese Schmuckelemente im Gebiet der FritzensSanzeno-Kultur ansonsten unbekannt sind.

Richtung Süden verweist das Fragment eines Kruges vom Typ Stenico, der nördlich des Alpenhauptkammes nicht bzw. nur als Import vorkommt, in den Südalpen jedoch sehr verbreitet ist. ${ }^{82}$

Auch eine Anzahl von Glasperlen und Glasarmringen gehört zu den Neuentdeckungen auf dem Lus in Kundl (Abb. 26), darunter auch solche aus farblosem Glas mit gelber Innenauflage. Für die auch in Kundl vertretene Variante mit Streifenauflage ${ }^{83}$ wurde aktuell eine inneralpine Produktion postuliert und eine Datierung in die Phase Lt D vorgeschlagen. ${ }^{84}$

\section{Zusammenfassung und Ausblick}

In den Jahren 2018 und 2019 führte die Firma TALPA die mit einer Fläche von ca. $10.600 \mathrm{~m}^{2}$ bislang größte archäologische Grabung zur Urgeschichte Nordtirols in der Schottergrube Wimpissinger in Kundl (Bezirk Kufstein) durch. In dem aufgedeckten Werkstattareal wurde spätestens ab der späten Bronzezeit Kupfer aus den nahegelegenen Fahlerzlagerstätten von Schwaz-Brixlegg verhüttet. In der darauffolgenden Werksiedlung der Eisenzeit wurde Bronze verarbeitet und Eisen möglicherweise verhüttet,

82 Gleirscher, Nothdurfter, Schubert 2002, 115-118.

83 Lang 1998, Katalognr. 1195, 1199. - Zerobin 2017, Taf. 52/8-9; Taf. 53/13, 15; Taf. 54/18-19, 21; Taf. 56/26, 28.

84 Lueger 2020. auf jeden Fall aber in großem Umfang verarbeitet. Die Grabungsbefunde sind nicht nur aufgrund der großflächigen Erforschung besonders aussagekräftig, sondern stechen auch durch den exzellenten Erhaltungszustand hervor. Die urgeschichtlichen Nutzungs- und Bauhorizonte wurden nämlich mehrfach im Zuge von Vermurungen des Stubtalbaches mit dicken Schotterschichten bedeckt und auf diese Art und Weise „versiegelt“.

Dank des Entgegenkommens des Grundbesitzers und der Grabungsfirma konnte unmittelbar im Anschluss an die Rettungsgrabungen mit der wissenschaftlichen Auswertung, ersten archäometrischen Analysen, der mikroarchäologischen Untersuchung der im Block geborgenen Gefäße und der Aufbereitung der zahlreichen Sedimentproben zur Gewinnung von Mikroresten und botanischen Funden begonnen werden. Im Zuge der Auswertungen, die am Institut für Archäologien der Universität Innsbruck stattfinden, wird es möglich sein, wesentliche Fragen zur alpinen Ressourcenwirtschaft zu beantworten.

Dazu gehört erstens die Laufzeit der Kupfergewinnung im Unteren Inntal, die in der Spätbronzezeit eine Hochblütezeit erreichte. Das Abklingen dieser Kupferkonjunktur im Laufe der älteren Eisenzeit lässt sich anhand der Befunde aus Kundl im Detail verfolgen. Erste archäometallurgische Analysen zu eisenzeitlichen Gusskuchen aus Kundl deuten auf die Nutzung der Fahlerzlagerstätten bis in die Hallstattzeit hin. Dies steht im Einklang mit den in den letzten Jahren gewonnenen dendrochronologischen Datierungen mehrerer Grubenbauten (Fälldaten von Feuerholz), die die bislang jüngsten Bergbauaktivitäten in den Teilrevieren Sommerau, Zimmermoos, Thierberg, Großkogel und Burgstall in der 2. Hälfte des 8. Jhs. v. Chr. dokumentieren. ${ }^{85}$

Zweitens wird es anhand der ausgezeichnet erhaltenen pyrotechnischen Befunde in Kundl möglich sein, die Funktion der unterschiedlichen Typen von Grubenöfen, Röstbetten und Lehmwannen im Zuge der metallurgischen Produktionskette zu klären. Dafür sind archäometallurgische Analysen der zahlreichen Produktionsabfälle (Erze, Schlacken, Gusstropfen etc.) geplant, die im Kontext mit den metallurgischen Anlagen durch händische Auslese, aber auch durch systematische Entnahme von Schlämmproben gewonnen werden konnten (Abb. 27).

Drittens ermöglichen die große Untersuchungsfläche von ca. $10.600 \mathrm{~m}^{2}$ und die hohe Dichte der Befunde Einblick in die räumliche Organisation der Werkstätten und Siedlungsgebäude. Auf den ersten Blick zeichnet sich die unterschiedliche räumliche Struktur der bronze- und der eisenzeitlichen Werkareale ab: Während die pyrotechnischen

85 STAUdT et al. 2019a. 

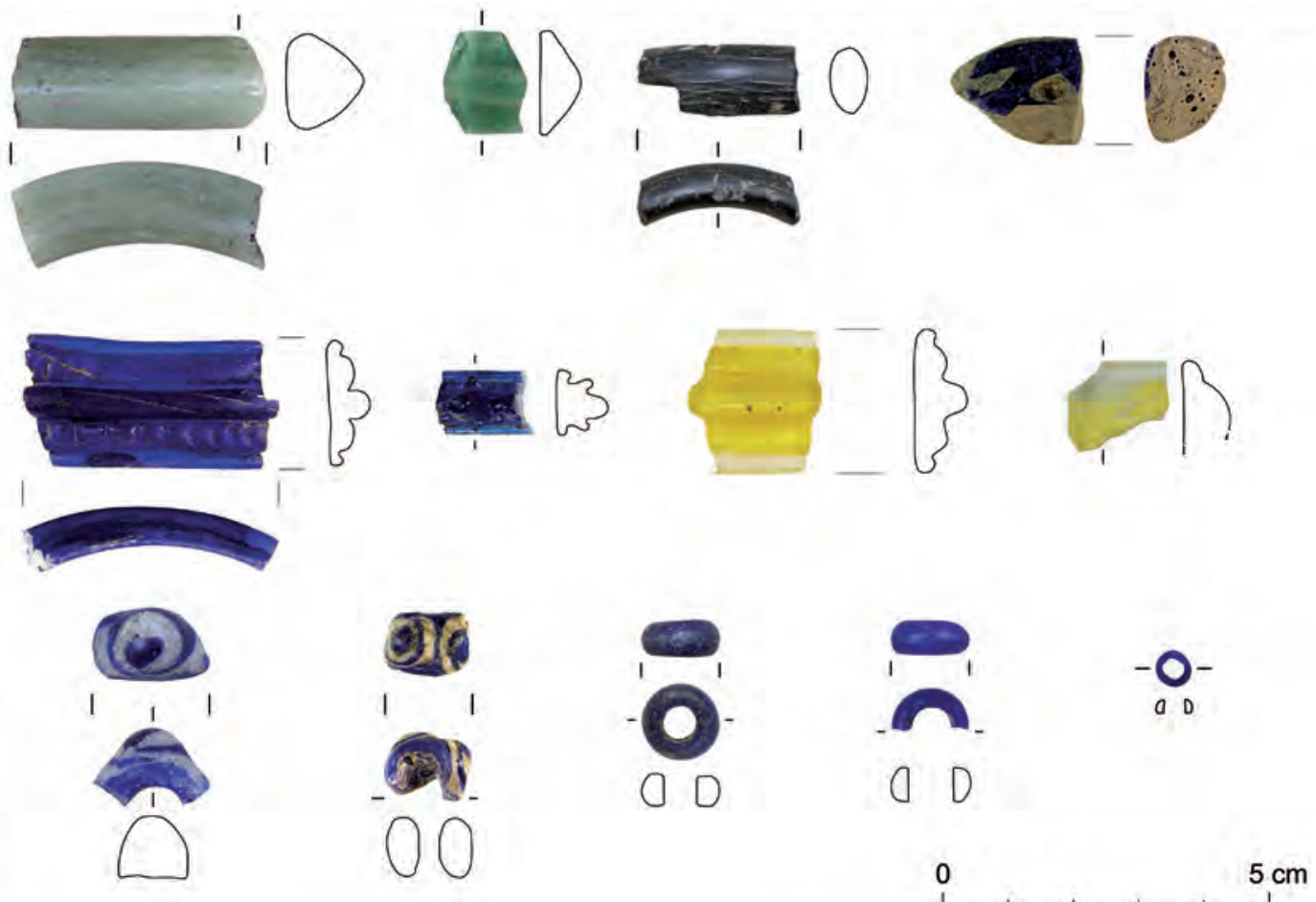

Abb. 26. Kundl, Schottergrube Wimpissinger. - Auswahl an Glasarmreifen und Glasperlen aus der eisenzeitlichen Kulturschicht (Grafik: TALPA).

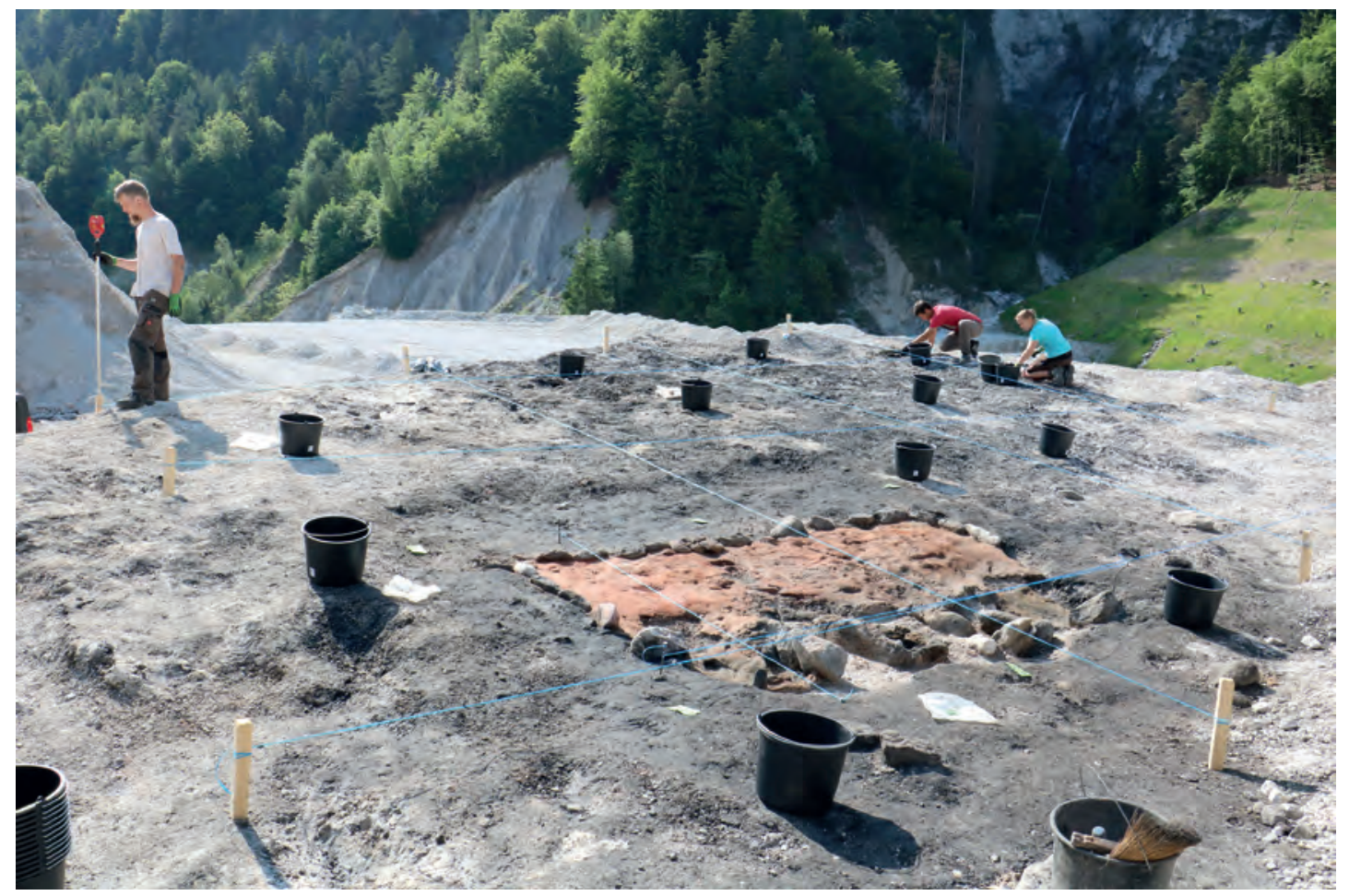

Abb. 27. Kundl, Schottergrube Wimpissinger. - Beprobung der bronzezeitlichen Kulturschicht SE 925 im Raster, im Hintergrund rechts der tiefe Einschnitt des Stubtalbaches (Foto: TALPA). 
Anlagen der Bronzezeit inselartig isoliert in einigen Dutzenden Metern Abstand zueinander auf dem Schwemmfächer angelegt wurden und von den Wohngebäuden offensichtlich getrennt waren, liegen die metallurgischen Werkstätten der Eisenzeit in der Nähe des alten Bachlaufs in direktem Zusammenhang mit Wohngebäuden und anderen handwerklichen Tätigkeiten wie der Textilproduktion. Sogar landwirtschaftliche Produktion ist aus dem Areal der Werksiedlung von Kundl durch Ackerfurchen und Viehzäune belegt. Die große Menge der geborgenen Tierknochen sowie die systematisch durch Flotation gewonnenen verkohlten Pflanzenreste versprechen ein hohes Erkenntnispotential zur Subsistenz und Ernährung der EinwohnerInnen. Die Versorgung und die Organisation der über den lokalen Bedarf hinausgehenden Metallproduktion bzw. -verarbeitung kann so diachron über beide Siedlungsphasen hinweg untersucht werden.

Die einzigartige Kombination von Werkareal und zugehörigem Gräberfeld ${ }^{86}$ ermöglicht für die eisenzeitliche Phase darüber hinaus einen vierten Forschungsansatz: den Vergleich der materiellen Kultur, die im Siedlungsbereich hinterlassen wurde, mit jenen ausgewählten Objekten, die den Verstorbenen ins Grab mitgegeben wurden. Anhand der Häufigkeit bestimmter Fundtypen (vor allem Fibeln, Glas und Keramik) und der „Handschrift“ bestimmter Handwerker lässt sich in Kombination mit archäometrischen Analysen die lokale Produktion der Gemeinschaft in Kundl charakterisieren und der Warenfluss im Austausch mit dem nördlichen Alpenvorland, entlang des Inntals sowie mit den Gebieten südlich des Alpenhauptkammes über kleinere und größere Distanzen verfolgen.

Allen Besucherinnen und Besuchern der Rettungsgrabungen 2018/2019 in der Schottergrube Wimpissinger drängte sich angesichts der meterdicken Murschotter am Ausfluss des Sturzbaches die Frage auf: Warum legten die Menschen der Bronzezeit an dieser durch Naturkatastrophen ständig bedrohten Stelle ihre Werkstätten an? Warum wurde auch nach zahlreichen Überschwemmungen und Vermurungen in der Eisenzeit über Jahrhunderte immer wieder an derselben Stelle gebaut? Welche Vorteile bot das „Lus“auf dem Schwemmfächer in Kundlfür die bronze-und eisenzeitlichen SiedlerInnen, dass sie diesen Naturgewalten die Stirn boten? Die Antworten sollen in den kommenden Jahren durch eine interdisziplinäre Forschungsgruppe gefunden werden, die in dieser Region Nordtirols auf umfangreichen Vorarbeiten zur holozänen Entwicklung des Kundler Schwemmfächers, ${ }^{87}$ zur Vegetationsgeschichte des

86 LANG 1998.

87 Patzelt, Weber 2015.
Inntals ${ }^{88}$ und zur Klimaentwicklung in den Alpen ${ }^{89}$ aufbauen kann.

\section{Danksagung}

Unser herzlicher Dank gilt der Firma Wimpissinger Beton Umweltschutz GmbH u. Co KG für die Finanzierung und tatkräftige Unterstützung der Rettungsgrabungen, der Grabungsfirma TALPA GnbR und allen GrabungsmitarbeiterInnen, Wilfried Allinger-Csollich, Gert Goldenberg, Amei Lang, Gernot Patzelt, dem Tiroler Landesmuseum Ferdinandeum sowie dem Curt-Engelhorn-Zentrum für Archäometrie in Mannheim.

\section{Literatur}

ADAM 1996

A. M. Adam, Le Fibule di Tipo Celtico nel Trentino. Patrimonio Storico e Artistico del Trentino 19, Trento 1996.

BADER 2020

M. BAder, KG Liesfeld, MG Kundl, Fundberichte aus Österreich 57/2018, 2020, 435-436.

BADER 2021

M. BADER, Die eisenzeitliche Großsiedlung und spätbronzezeitliche Siedlungs- und Werkplätze in Kundl/Tirol auf dem Areal der Wimpissinger Beton Umweltschutz GmbH: MaßnahmenNummer 83109.18.01 und 83109.19.01: Grabungsbericht, Fundberichte aus Österreich 58/2019, 2021, D8148-D8258.

BANKus 1995

M. Bankus, Frühe und mittlere Bronzezeit. In: K. H. Rieder, A. Tillmann (Hrsg.), Archäologie um Ingolstadt: Die archäologischen Untersuchungen beim Bau der B 16 und der Bahnverlegung. Kipfenberg 1995, 53-88.

BeILKe-Voigt 2008

I. Beilke-Voigt, Zum rituellen Umgang mit verstorbenen Kleinstkindern im eisenzeitlichen Bestattungsbrauch. In: C. EGGL, P. Trebsche, I. Balzer, J. Fries-Knoblach, J. K. Koch, H. Nortmann, J. Wiethold (Hrsg.), Ritus und Religion in der Eisenzeit. Beiträge zur Sitzung der AG Eisenzeit während der Jahrestagung des Mittel- und Ostdeutschen Verbandes für Altertumsforschung e. V. in Halle an der Saale 2007. Beiträge zur Ur- und Frühgeschichte Mitteleuropas 49, Langenweißbach 2008, 37-47.

Beilke-Voigt 2010

I. Beilke-Voigt, Kaum gelebt und schon begraben: $\mathrm{Zu}$ den Siedlungsbestattungen von Kleinstkindern in vor- und römischer Zeit, Mitteilungen der Anthropologischen Gesellschaft Wien 140, 2010, 101-140.

BELTZ 1911

R. BeLtz, Die Latènefibeln, Zeitschrift für Ethnologie 43, 1911, 664-943.

BENKERT et al. 2014

A. Benkert, C. Epiney-Nicoud, J.-C. Moret, O. Paccolat, L'habitat alpin de Gamsen (Valais, Suisse): 1. Cadre des recherches archéologiques et chronologie des occupations. Cahiers d'Archéologie Romande 153, Lausanne 2014.

Bujna 1991

J. Bujna, Das latènezeitliche Gräberfeld bei Dubnik II: Analyse und Auswertung, Slovenská Archeológia 39, 1991, 221-255.

88 Oeggl 2013. - Oeggh 2019.

89 SPÖTL et al. 2007. 
BuJNA 2003

J. Bujna, Spony z keltských hrobov bez výzbroje z územia Slovenska: Typovo-chronologické triedenie LTB- a C1-spôn, Slovenská Archeológia 51, 2003, 39-108.

CIERNY 2008

J. Cierny, Prähistorische Kupferproduktion in den südlichen Alpen, Region Trentino Orientale. Der Anschnitt, Beiheft 22, Bochum 2008.

Ciresa 2006

M. Ciresa, Die eisenzeitliche Siedlung am Pirchboden oberhalb Fritzens. Unveröffentlichte Dissertation, Universität Innsbruck 2006.

DEMETZ 1999

S. Demetz, Fibeln der Spätlatène- und frühen römischen Kaiserzeit in den Alpenländern. Archeologia delle Alpi 6, Rahden/Westf. 1999.

Eß 2021

L. M. Eß, Die mikroarchäologische Ausgrabung eines spätbronzezeitlichen Keramikgefäßes aus Kundl (Nordtirol): Die Weiterentwicklung feinstratigraphischer Freilegungsmethoden unter Berücksichtigung mikroarchäologischer Techniken. Unveröffentlichte Masterarbeit, Universität Innsbruck 2021.

FEUGÈre 1985

M. Feugìre, Les fibules en Gaule Méridionale de la conquête à la fin du Ve siècle après J.-C. Revue Archéologique de Narbonnaise Suppl. 12, Paris 1985.

FILIP 1956

J. Filip, Keltové v stredni evrope. Prag 1956.

FRIES 2005

J. E. FrIEs, Die Hallstattzeit im Nördlinger Ries. Materialhefte zur Bayerischen Vorgeschichte A88, Kallmünz 2005.

Fries-KNOBLACH 2009

J. Fries-KNoblach, Hüttenlehm als Quelle zu Bauweise und Gestaltung eisenzeitlicher Gebäude. In: P. Trebsche, I. Balzer, C. Eggl, J. Fries-Knoblach, J. K. Koch, J. Wiethold (Hrsg.), Architektur: Interpretation und Rekonstruktion. Beiträge zur Sitzung der AG Eisenzeit während des 6. Deutschen Archäologie-Kongresses in Mannheim 2008. Beiträge zur Ur- und Frühgeschichte Mitteleuropas 55, Langenweißbach 2009, 31-53.

FRIES-KNOBLACH 2020

J. Fries-Knoblach, Eisenzeitlicher Pflugackerbau in West-, Mittel- und Nordeuropa. In: P. Trebsche, H. Wendling, M. Augstein, J. Fries-Knoblach, K. Ludwig, R. Schumann, C. TapPERT, J. WIETHOLD (Hrsg.), LANDwirtschaft - LANDnutzung: Aspekte der Aneignung und Ökonomie ländlicher Ressourcen im eisenzeitlichen Mitteleuropa. Beiträge zur Sitzung der AG Eisenzeit bei der Tagung des Nordwestdeutschen Verbandes für Altertumsforschung in Münster 2016. Beiträge zur Ur- und Frühgeschichte Mitteleuropas 93, Langenweißbach 2020, 61-97.

GARNER 2010

J. GARner, Der latènezeitliche Verhüttungsplatz in Siegen-Niederschelden „Wartestraße“, Metalla 17/1-2, 2010.

GEBHARD 1991

R. Gebhard, Die Fibeln aus dem Oppidum von Manching. Die Ausgrabungen in Manching 14, Stuttgart 1991.

GEHRING 1974

B. GeHring, Die Fibeln von Mechel im Nonsberg. Unveröffentlichte Dissertation, Universität Innsbruck 1974.
GeILENBRÜGge 1992

U. Geilenbrügge, Die Keramik. In: F. Maier, U. Geilenbrügge, E. Hahn, H.-J. KöHler, S. Sievers, Ergebnisse der Ausgrabungen 1984-1987 in Manching. Die Ausgrabungen in Manching 15, Stuttgart 1992, 65-136.

Gleirscher 1987

P. Gleirscher, Tiroler Schüssel- und Palmettenfibeln, Germania 65, 1987, 67-88.

GLEIRSCHER 1992

P. Gleirscher, „Tiroler“ Cenisolafibeln? Eine neue Definition der Variante Vill, Archäologisches Korrespondenzblatt 22, 1992, 93-107.

Gleirscher, Nothdurfter, Schubert 2002

P. Gleirscher, H. Nothdurfter, E. Schubert, Das Rungger Egg: Untersuchungen an einem eisenzeitlichen Brandopferplatz bei Seis am Schlern in Südtirol. Römisch-Germanische Forschungen 61, Mainz am Rhein 2002.

Goldenberg 2004

G. Goldenberg, Ein Verhüttungsplatz der mittleren Bronzezeit bei Jochberg (Nordtirol). In: G. Weisgerber, G. GoldenberG (Hrsg.), Alpenkupfer - Rame delle Alpi. Der Anschnitt, Beiheft 17, Bochum 2004, 165-176.

Goldenberg 2013

G. Goldenberg, Prähistorischer Fahlerzbergbau im Unterinntal Montanarchäologische Befunde. In: K. OEgGL, V. Schaffer, Montanwerke Brixlegg (Hrsg.), Cuprum Tyrolense: 5550 Jahre Bergbau und Kupferverhüttung in Tirol. Reith i. A. 2013, 89-122.

Goldenberg, Staudt, Grutsch 2019

G. Goldenberg, M. Staudt, C. Grutsch, Montanarchäologische Forschungen zur frühen Kupferproduktion in Nordtirol - Forschungsfragen, Forschungskonzepte und Ergebnisse. In: S. HYE, U. Töchterle (Hrsg.), UPIKU:TAUKE. Festschrift für Gerhard Tomedi zum 65. Geburtstag. Universitätsforschungen zur Prähistorischen Archäologie 339, Bonn 2019, 159-178.

Goldenberg et al. 2011

G. Goldenberg, E. Breitenlechner, S. Deschler-Erb, K. Hanke, G. Hiebel, H. Hüster-Plogmann, S. Hye, M. Klaunzer, K. Kovács, M. Krismer, J. Lutz, A. Maass, M. Moser, K. Nicolussi, K. Ofggl, E. Pernicka, T. Pichler, N. Pöllath, J. Schibler, M. Staudt, B. Stopp, A. Thurner, U. Töchterle, G. Tomedi, P. Tropper, F. Vavtar, T. Weinold, Prähistorischer Kupfererzbergbau im Maukental bei Radfeld/Brixlegg. In: G. Goldenberg, U. Töchterle, K. Oeggl, A. Krenn-Leeb (Hrsg.), Forschungsprogramm HiMAT - Neues zur Bergbaugeschichte der Ostalpen. Archäologie Österreichs Spezial 4, Wien 2011, 61-110.

Hanning, Herdits, Silvestri 2015

E. Hanning, H. Herdits, E. Silvestri, Alpine Kupferschmelzen - technologische Aspekte. In: T. Stöllner, K. OEggl (Hrsg.), Bergauf Bergab: 10.000 Jahre Bergbau in den Ostalpen (Ausstellungskatalog, Deutsches Bergbau-Museum Bochum). Veröffentlichungen aus dem Deutschen Bergbau-Museum Bochum 207, Bochum 2015, 225-232.

HERDITS, LÖCKER 2004

H. Herdits, K. Löcker, Eine bronzezeitliche Kupferhütte im Mitterberger Kupferkies-Revier (Salzburg). In: G. WEIsGERBER, G. Goldenberg (Hrsg.), Alpenkupfer - Rame delle Alpi. Der Anschnitt, Beiheft 17, Bochum 2004, 177-188. 
Hodson 1968

I. Hodson, The La Tène cemetery at Münsingen-Rain. Acta Bernensia 5, Bern 1968.

Hye 2009

S. Hye, Studien zum eisenzeitlichen Heiligtum am Demlfeld bei Ampass, Nordtirol. Unveröffentlichte Magisterarbeit, Universität Innsbruck 2009.

KAPPEL 1969

I. KAPPEL, Die Graphittonkeramik von Manching. Die Ausgrabungen in Manching 2, Stuttgart 1969.

KIRCHMAYR 2015

M. Kirchmayr, Ein prähistorisches Wirtschaftsareal beim Locherboden in Mieming. Unveröffentlichte Masterarbeit, Universität Innsbruck 2015.

KLEMM 2015

S. Klemm, Bronzezeitliche Kupfergewinnung in den Eisenerzer Alpen, Steiermark. In: T. Stöllner, K. Oeggl (Hrsg.), Bergauf Bergab: 10.000 Jahre Bergbau in den Ostalpen (Ausstellungskatalog, Deutsches Bergbau-Museum Bochum). Veröffentlichungen aus dem Deutschen Bergbau-Museum Bochum 207, Bochum 2015, 195-200.

KNOCHE 2016

I. KNoche, KG Wörgl-Kufstein, SG Wörgl, Fundberichte aus Österreich 53/2014, 2016, 375-376; D5992-D6074.

Koch Waldner, Klaunzer 2015

T. Koch Waldner, M. Klaunzer, Das prähistorische Bergbaugebiet in der Region Kitzbühel. In: T. Stöllner, K. OEgGL (Hrsg.), Bergauf Bergab: 10.000 Jahre Bergbau in den Ostalpen (Ausstellungskatalog, Deutsches Bergbau-Museum Bochum). Veröffentlichungen aus dem Deutschen Bergbau-Museum Bochum 207, Bochum 2015, 165-173.

Krismer, Tropper 2013

M. Krismer, P. Tropper, Die historischen Fahlerzlagerstätten von Schwaz und Brixlegg: Geologische und mineralogische Aspekte zum Bergbau im Unterinntal. In: K. OEggl, V. Schaffer, MoNTANwerke Brixlegg (Hrsg.), Cuprum Tyrolense: 5550 Jahre Bergbau und Kupferverhüttung in Tirol. Reith i. A. 2013, 11-28. LANG 1986

A. LANG, KG Kundl, OG Kundl, VB Kufstein, Fundberichte aus Österreich 23/1984, 1986, 276.

LANG 1998

A. LAng, Das Gräberfeld von Kundl im Tiroler Inntal: Studien zur vorrömischen Eisenzeit in den zentralen Alpen. Frühgeschichtliche und Provinzialrömische Archäologie, Materialien und Forschungen 2, Rahden/Westf. 1998.

LOBISSER 2005

W. Lobisser, Die eisenzeitlichen Bauhölzer der Gewerbesiedlung im Ramsautal am Dürrnberg bei Hallein. Dürrnberg-Forschungen 4, Rahden/Westf. 2005.

LUEGER 2020

D. Lueger, Die Kleinfunde der eisenzeitlichen Siedlung Stams-Glasbergl. Universitätsforschungen zur Prähistorischen Archäologie 352, Bonn 2020.

LUTZ 2016

J. LuTz, Alpenkupfer - die Ostalpen als Rohstoffquelle in vorgeschichtlicher Zeit. In: M. Bartelheim, B. Horejs, R. Krauss (Hrsg.), Von Baden bis Troia: Ressourcennutzung, Metallurgie und Wissenstransfer. Eine Jubiläumsschrift für Ernst Pernicka. Oriental and European Archaeology 3, Rahden/Westf. 2016, 333-358.
Lutz, Krutter, Pernicka 2019

J. Lutz, S. Krutter, E. Pernicka, Zusammensetzung prähistorischer Rohkupfer-Gusskuchen aus Salzburg, Tirol und Südbayern. In: S. Hye, U. Töchterle (Hrsg.), UPIKU:TAUKE. Festschrift für Gerhard Tomedi zum 65. Geburtstag. Universitätsforschungen zur Prähistorischen Archäologie 339, Bonn 2019, 319-328.

MANSFELD 1971

G. Mansfeld, Späthallstattzeitliche Kleinfunde von Indelhausen (Kr. Münsingen), Fundberichte Schwaben 19, 1971, 89-117.

Maurer 1993

H.-P. Maurer, Archäometallurgische Untersuchungen an Schlacken- und Eisenfunden der latènezeitlichen Schmiedewerkstatt Kundl-Lus und aus dem Oppidum von Manching, Archäologisches Korrespondenzblatt 23/3, 1993, 313-325.

Meller 2012

H. Meller, Die Fibeln aus dem Reitia-Heiligtum von Este (Ausgrabungen 1880-1916): Studien zu den Spätlatèneformen. Studien zu vor- und frühgeschichtlichen Heiligtümern 2/2, Mainz am Rhein 2012.

v. Merhart 1927

G. v. Merhart, Archäologisches zur Frage der Illyrer in Tirol, Wiener prähistorische Zeitschrift 14, 1927, 65-118.

Migliavacca 1996

M. Migliavacca, Lo spazio domestico nell'Età del Ferro: tecnologia edilizia e aree di attività tra VII e I secolo a. C. in una porzione dell'arco alpino orientale, Preistoria Alpina 29/1993, 1996, 5-161.

\section{ModL 2010}

D. ModL, Zur Herstellung und Zerkleinerung von plankonvexen Gusskuchen in der spätbronzezeitlichen Steiermark, Österreich, Experimentelle Archäologie in Europa 9, 2010, 127-152.

ModL 2019

D. ModL, Recording plano-convex ingots (Gusskuchen) from Late Bronze Age Styria and Upper Austria - a short manual for the documentation of morphological and technological features from production and partition. In: R. Turck, T. STÖllner, G. Goldenberg (Hrsg.), Alpine Copper II - Alpenkupfer II - Rame delle Alpi II - Cuivre des Alpes II: New Results and Perspectives on Prehistoric Copper Production. Der Anschnitt, Beiheft 42, Rahden/Westf. 2019, 373-398.

\section{Moosleitner 2004}

F. Moosleitner, Bronzezeitliche Grubenöfen in St. Johann im Pongau (Salzburg). In: G. Weisgerber, G. Goldenberg (Hrsg.), Alpenkupfer - Rame delle Alpi. Der Anschnitt, Beiheft 17, Bochum 2004, 213-221.

Müller-SCheESSEl 2013

N. Müller-Scheessel, Im Tode gleich? Eisenzeitliche Bestattungen von Frauen und Männern in Siedlungskontexten und in ,regulären' Gräbern im Vergleich. In: S. WefErs, J. E. Fries, J. Fries-Knoblach, C. Later, U. Rambuschek, P. Trebsche, J. Wiethold (Hrsg.), Bilder - Räume - Rollen. Beiträge zur gemeinsamen Sitzung der AG Eisenzeit und der AG Geschlechterforschung während des 7. Deutschen Archäologenkongresses in Bremen 2011. Beiträge zur Ur- und Frühgeschichte Mitteleuropas 72, Langenweißbach 2013, 69-80.

MüLleR-SCHEESSEL et al. 2013

N. Müller-Scheessel, C. Berszin, G. Grupe, A. Schwentke, A. Staskiewicz, J. Wahl, Ältereisenzeitliche Siedlungsbestattungen in Baden-Württemberg und Bayern. In: N. MüLLER-SCHEEssel (Hrsg.), ,Irreguläre` Bestattungen in der 
Urgeschichte: Norm, Ritual, Strafe ...? Akten der Internationalen Tagung in Frankfurt a. M. vom 3. bis 5. Februar 2012. Kolloquien zur Vor- und Frühgeschichte 19, Bonn 2013, 409-424.

Nothdurfter, Hauser 1986

H. Nothdurfter, L. Hauser, Bronzezeitliche Kupferschmelzöfen aus Fennhals, Denkmalpflege in Südtirol - Tutela di beni Culturali in Alto Adige, 1986, 177-190.

Oeggl 2013

K. Oeggl, Die Vegetations- und Siedlungsgeschichte im mittleren Unterinntal seit dem Neolithikum. In: K. Oeggl, V. Schaffer, Montanwerke Brixlegg (Hrsg.), Cuprum Tyrolense: 5550 Jahre Bergbau und Kupferverhüttung in Tirol. Reith i. A. 2013, 29-54.

Oeggl 2019

K. OegGL, Vegetation und Landnutzungsänderungen im mittleren Alpenraum während der Eisen- und Römerzeit. In: W. Zanier (Hrsg.), Kulturwandel um Christi Geburt: Spätlatène- und frühe römische Kaiserzeit in den mittleren Alpen zwischen Südbayern und Gardasee, Band 2. Akten des Kolloquiums in Innsbruck am 18. und 19. Oktober 2017. Münchner Beiträge zur Vor- und Frühgeschichte 67, München 2019, 531-544.

PARZINGer 1989

H. Parzinger, Chronologie der Späthallstatt- und Frühlatènezeit. Quellen und Forschungen zur prähistorischen und provinzialrömischen Archäologie 4, Weinheim 1989.

Patzelt, Weber 2015

G. Patzelt, A. Weber, Die nacheiszeitliche Entwicklung des Schwemmfächers von Kundl und des Talraumes im Inntal (Tirol), Jahrbuch der Geologischen Bundesanstalt 155/1-4, 2015, 11-31.

Pauli 1978

L. Pauli, Der Dürrnberg bei Hallein III: Auswertung der Grabfunde. Münchner Beiträge zur Vor- und Frühgeschichte 18, München 1978

Pauli 1987

L. Pauli, Gewässerfunde aus Nersingen und Burlafingen. In: M. Mackensen (Hrsg.), Frühkaiserzeitliche Kleinkastelle bei Nersingen und Burlafingen an der Oberen Donau. Münchner Beiträge zur Vor- und Frühgeschichte 41, München 1987, 281-312.

Pertllwieser 1970

M. Pertl wieser, Die hallstattzeitliche Höhensiedlung auf dem Waschenberg bei Bad Wimsbach/Neydharting, politischer Bezirk Wels, Oberösterreich, II. Teil: Die Objekte, Jahrbuch des Oberösterreichischen Musealvereins 115, 1970, 37-70.

Pleiner 2000

R. Pleiner, Iron in Archaeology: The European Bloomery Smelters. Prag 2000.

Prader 2013

K. Prader, Spätbronzezeitliche und latènezeitliche Kulturschichten in der Schottergrube Wimpissinger (Kundl): Mineralogische und petrologische Charakterisierung der metallurgischen Reste und Keramiken. Unveröffentlichte Bachelorarbeit, Universität Innsbruck 2013.

RAMSL 2002

P. Ramsl, Das eisenzeitliche Gräberfeld von Pottenbrunn: Forschungsansätze zu wirtschaftlichen Grundlagen und sozialen Strukturen der latènezeitlichen Bevölkerung des Traisentales, Niederösterreich. Fundberichte aus Österreich, Materialhefte A11, Wien 2002.
Ramsl 2011

P. RamsL, Das latènezeitliche Gräberfeld von Mannersdorf am Leithagebirge, Flur Reinthal Süd, Niederösterreich: Studien zu Phänomenen der latènezeitlichen Kulturausprägungen. Mitteilungen der Prähistorischen Kommission 74, Wien 2011.

Reitmaier-Naef 2019

L. Reitmaier-Naef, Copper smelting slag from the Oberhalbstein (Canton of Grisons, Swizerland): methodological considerations on typology and morphology. In: R. TuRCK, T. STÖLLner, G. Goldenberg (Hrsg.), Alpine Copper II - Alpenkupfer II - Rame delle Alpi II - Cuivre des Alpes II: New Results and Perspectives on Prehistoric Copper Production. Der Anschnitt, Beiheft 42, Rahden/Westf. 2019, 229-244.

Ř IHOVsKÝ 1979

J. Ǩ̃нovsкÝ, Die Nadeln in Mähren und im Ostalpengebiet. Prähistorische Bronzefunde XIII/5, München 1979.

SCHAAFF 1974

U. SchaAfF, Ein keltisches Fürstengrab von Worms-Herrnsheim, Jahrbuch des Römisch-Germanischen Zentralmuseums Mainz 18/1971, 1974, 51-117.

SсHіек 1956

S. SCHIEK, Fürstengräber der jüngeren Hallstattkultur in Südwestdeutschland. Dissertation, Eberhart Karls Universität Tübingen 1956.

SENFTER 2011

T. SEnfter, KG Thaur I, OG Thaur, PB Innsbruck-Land, Fundberichte aus Österreich 49/2010, 2011, 433-434.

Silvestri, Bellintani, Hauptmann 2019

E. Silvestri, P. Bellintani, A. Hauptmann, Bronze Age copper ore mining and smelting in Trentino (Italy). In: R. TURCK, T. Stöllner, G. Goldennerg (Hrsg.), Alpine Copper II - Alpenkupfer II - Rame delle Alpi II - Cuivre des Alpes II: New Results and Perspectives on Prehistoric Copper Production. Der Anschnitt, Beiheft 42, Rahden/Westf. 2019, 261-278.

SinNHUBER 1949

K. Sinnhuber, Die Altertümer vom „Himmelreich“ bei Wattens: Ein Beitrag zur Vorgeschichte des tirolischen Unterinntals. Schlern-Schriften 60, Innsbruck 1949.

SÖLDER 1994

W. SöLDER, „Casa retica“ - das „rätische“ Haus. Unveröffentlichte Diplomarbeit, Universität Innsbruck 1994.

SPÖTL et al. 2007

C. Spötl, K.-H. Offenbecher, R. Boch, M. Meyer, A. Mangini, J. Kramers, R. Pavuza, Tropfstein-Forschung in österreichischen Höhlen - ein Überblick, Jahrbuch der Geologischen Bundesanstalt 147/1-2, 2007, 117-167.

STADLER 1987

H. Stadler, Die Kleinfunde aus der Kirchengrabung Münster, Fundberichte aus Österreich 24-25/1985-1986, 1987, 153-158.

StAudt 2016

M. STAUdT, Die spätbronzezeitliche Siedlung beim Weiler Mairhof im Kaunertal (OG Kaunerberg), Tirol, Fundberichte aus Österreich 53/2014, 2016, 41-82.

STAUDT in Vorb.

M. STAUDT, Untersuchungen zum prähistorischen Fahlerzbergbau im Montanrevier Schwaz-Brixlegg. Dissertation, Universität Innsbruck, in Vorbereitung.

Staudt, Tomedi 2015

M. Staudt, G. Tomedi, Zur Besiedlungsgeschichte der Ostalpen in der Mittel- bis Spätbronzezeit: Bestand, Kolonisation und 
wirtschaftlicher Neuanfang in der mittleren und späten Bronzezeit in Nordtirol. In: T. Stöllner, K. OegGl (Hrsg.), Bergauf Bergab: 10.000 Jahre Bergbau in den Ostalpen (Ausstellungskatalog, Deutsches Bergbau-Museum Bochum). Veröffentlichungen aus dem Deutschen Bergbau-Museum Bochum 207, Bochum 2015, 135-143.

STAUDT et al. 2019a

M. Staudt, G. Goldenberg, M. Scherer-W Indisch, K. NicolusSI, T. Pichler, Late Bronze Age/Early Iron Age fahlore mining in the Lower Inn Valley (North Tyrol, Austria). In: R. Turck, T. Stöllner, G. Goldennerg (Hrsg.), Alpine Copper II - Alpenkupfer II - Rame delle Alpi II - Cuivre des Alpes II: New Results and Perspectives on Prehistoric Copper Production. Der Anschnitt, Beiheft 42, Rahden/Westf. 2019, 115-142.

STAUDT et al. 2019b

M. Staudt, G. Goldenberg, M. Scherer-Windisch, C. Grutsch, R. Lamprecht, B. Zerobin, The Late Bronze Age smelting site Rotholz in the Lower Inn Valley (North Tyrol, Austria). In: R. Turck, T. Stöllner, G. Goldenberg (Hrsg.), Alpine Copper II - Alpenkupfer II - Rame delle Alpi II - Cuivre des Alpes II: New Results and Perspectives on Prehistoric Copper Production. Der Anschnitt, Beiheft 42, Rahden/Westf. 2019, 279-298.

STÖCKLI 1974

W. STÖCKLI, Bemerkungen zur räumlichen und zeitlichen Gruppierung der Funde im Oppidum von Manching, Germania 52, 1974, 368-377.

STÖLLNER 1999

T. STÖLLner, Bemerkungen zu den archäologischen Ergebnissen der Untersuchungen im Ramsautal 1988 bis 1989. In: E. PucheR (Hrsg.), Archäozoologische Untersuchungen am Tierknochenmaterial der keltischen Gewerbesiedlung im Ramsautal auf dem Dürrnberg (Salzburg). Dürrnberg-Forschungen 2, Rahden/ Westf. 1999, 1-15.

SYDOw 1988

W. SyDow, KG Liesfeld, OG Kundl, VB Kufstein, Fundberichte aus Österreich 26/1987, 1988, 227.

SYDOw 1990

W. Sydow, KG Liesfeld, MG Kundl, VB Kufstein, Fundberichte aus Österreich 28/1989, 1990, 202.

SYDOw 1991

W. SyDow, KG Liesfeld, MG Kundl, VB Kufstein, Fundberichte aus Österreich 29/1990, 1991, 219-220.

TöChTERLE et al. 2013

U. Töchterle, G. Goldenberg, P. Schneider, P. Tropper, Spätbronzezeitliche Verhüttungsdüsen aus dem Bergbaurevier Mauken im Unterinntal, Nordtirol: Typologie, mineralogischpetrographische Zusammensetzung und experimentelle Rekonstruktionsversuche, Der Anschnitt 65/1-2, 2013, 2-19.

Tomedi, Staudt, Töchterle 2013

G. Tomedi, M. Staudt, U. Töchterle, Zur Bedeutung des prähistorischen Bergbaus auf Kupfererze im Raum Schwaz-Brixlegg. In: K. Oeggl, V. Schaffer, Montanwerke Brixlegg (Hrsg.), Cuprum Tyrolense: 5550 Jahre Bergbau und Kupferverhüttung in Tirol, Reith i. A. 2013, 55-70.

Torbrügge 1979

W. TorbrüGge, Die Hallstattzeit in der Oberpfalz 1. Materialhefte zur bayerischen Vorgeschichte A 39, Kallmünz 1979.

Trebsche 2009

P. TREBSChe, Does form follow function? Towards a methodical interpretation of archaeological building features, World Archaeology 41/3, 2009, 504-518.
Trebsche 2011

P. Trebsche, Eisenzeitliche Graphittonkeramik im mittleren Donauraum. In: K. Sснмотz (Hrsg.), Vorträge des 29. Niederbayerischen Archäologentages. Rahden/Westf. 2011, 449-481.

Trebsche 2013

P. Trebsche, Die Regelhaftigkeit der ,irregulären' Bestattungen im österreichischen Donauraum während der Latènezeit. In: N. Müller-Scheessel (Hrsg.), ,Irreguläre` Bestattungen in der Urgeschichte: Norm, Ritual, Strafe ...? Akten der Internationalen Tagung in Frankfurt a. M. vom 3. bis 5. Februar 2012. Kolloquien zur Vor- und Frühgeschichte 19, Bonn 2013, 387-408.

Trebsche 2016

P. Trebsche, Latènezeitliche Leichen im Keller? Überlegungen zur Deutung von Siedlungsbestattungen im österreichischen Donauraum. In: L. Hustr, K. Sснмотz (Hrsg.), Vorträge des 34. Niederbayerischen Archäologentages. Rahden/Westf. 2016, 79-117.

Tropper et al. 2019

P. Tropper, G. Goldenberg, M. Krismer, D. Bechter, M. SteiNer, H.-P. Viertler, F. Vavtar, Mineral-chemical characterisation of chalcopyrites and fahlore-group minerals from selected $\mathrm{Cu}$-ore deposits in the Eastern Alps. In: R. Turck, T. STÖllner, G. Goldenberg (Hrsg.), Alpine Copper II - Alpenkupfer II - Rame delle Alpi II - Cuivre des Alpes II: New Results and Perspectives on Prehistoric Copper Production. Der Anschnitt, Beiheft 42, Rahden/Westf. 2019, 143-164.

Tropper et al. 2019

P. Tropper, M. Staudt, U. Töchterle, M. Krismer, G. GoldenBERG, Encapsulated industrial processes: slag-tempered ceramics and its implications for prehistoric metallurgy in the Lower Inn Valley (North Tyrol, Austria). In: R. TURCK, T. STÖlLner, G. Goldenberg (Hrsg.), Alpine Copper II - Alpenkupfer II - Rame delle Alpi II - Cuivre des Alpes II: New Results and Perspectives on Prehistoric Copper Production. Der Anschnitt, Beiheft 42, Rahden/Westf. 2019, 299-310.

TURCK 2019

R. TURCK, Organising smelting places: a keynote on Iron Age copper smelting in the Oberhalbstein (Canton of Grisons, Swizerland). In: R. Turck, T. Stöllner, G. Goldenberg (Hrsg.), Alpine Copper II - Alpenkupfer II - Rame delle Alpi II - Cuivre des Alpes II: New Results and Perspectives on Prehistoric Copper Production. Der Anschnitt, Beiheft 42, Rahden/Westf. 2019, 209-228.

VOLMer, Zimmermann 2012

L. Volmer, W. H. Zimmermann (Hrsg.), Glossar zum prähistorischen und historischen Holzbau: Französisch, Englisch, Niederländisch, Deutsch, Dänisch, Norwegisch, Schwedisch, Polnisch und Tschechisch. Studien zur Landschafts- und Siedlungsgeschichte im südlichen Nordseegebiet 3, Rahden/Westf. 2012.

WALLNER 2019

J. WALLNER, Ein eisenzeitliches Siedlungsareal in Fließ (Nordtirol). Universitätsforschungen zur Prähistorischen Archäologie 330, Bonn 2019.

WARNEKE 1999

T. WARNEKE, Hallstatt- und latènezeitlicher Anhängerschmuck: Studien zu Metallanhängern des 8.-5. Jahrhunderts v. Chr. zwischen Main und Po. Internationale Archäologie 50, Rahden/Westf. 1999.

Zemmer-Plank 1990

L. Zemmer-Plank, Urzeitlicher Bergbau in Tirol. In: G. Ammann (Hrsg.), Silber, Erz und weißes Gold (Ausstellungskatalog, Tiroler Landesausstellung, Schwaz 1990). Innsbruck 1990, 74-97. 
Zerobin 2017

B. Zerobin, Die latènezeitlichen Glasarmringe aus Nordtirol. Unveröffentlichte Masterarbeit, Universität Innsbruck 2017.

Zuber 2011

J. Zuber, Nicht nur Rauch und Feuer - Neues zur Urnenfelderzeit in Ostbayern, Fines Transire 20, 2011, 267-313.

ZÜRN 1952

H. Zürn, Zum Übergang von Späthallstatt zu Latène im südwestdeutschen Raum, Germania 30, 1952, 38-45.

Markus Staudt Institut für Archäologien Universität Innsbruck Langer Weg 11 6020 Innsbruck

Österreich markus.standt@uibk.ac.at

Maria Bader

TALPA GnbR - Büro für archäologische Dienstleistungen Sr. Bibiane-Blaickner-Straße 4 6300 Wörgl

Österreich

TALPA.GnbR@gmx.at

Lisa Maria E $\beta$ Institut für Archäologien Universität Innsbruck Langer Weg 11 6020 Innsbruck Österreich lisa.m.ess@student.uibk.ac.at

Daniel Lueger Institut für Archäologien Universität Innsbruck

Langer Weg 11 6020 Innsbruck

Österreich daniel.lueger@student.uibk.ac.at

Lena Sigrid Oettel Institut für Mineralogie und Petrographie Universität Innsbruck

Innrain 52

6020 Innsbruck

Österreich

lena.oettel@student.uibk.ac.at
Peter Tropper Institut für Mineralogie und Petrographie Universität Innsbruck

Innrain 52 6020 Innsbruck

Österreich

peter.tropper@uibk.ac.at

Peter Trebsche Institut für Archäologien Universität Innsbruck Langer Weg 11 6020 Innsbruck

Österreich peter.trebsche@uibk.ac.at orcid.org/0000-0001-5258-0615 